Universidade de São Paulo

Instituto de Física

\title{
Relações entre topologia e dinâmica em processos de crescimento e contágio em redes complexas
}

\author{
Alexandre Hannud Abdo
}

Orientador: Prof. Dr. Alessandro Paulo Sérvio de Moura

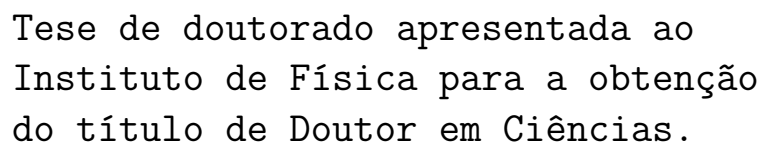

\section{Banca Examinadora}

Prof. Dr. Alessandro Paulo Sérvio de Moura (University of Aberdeen)

Prof. Dr. Nestor Felipe Caticha Alfonso (IF-USP)

Prof. Dr. Osame Kinouchi Filho (FFCLRP-USP)

Prof. Dr. Renato Vicente (EACH-USP)

Profa. Dra. Tânia Tomé Martins de Castro (IF-USP) 


\section{FICHA CATALOGRÁFICA}

Preparada pelo Serviço de Biblioteca e Informação do Instituto de Física da Universidade de São Paulo

Abdo, Alexandre Hannud

Relações entre topologia e dinâmica em processos de crescimento ou contágio em redes complexas - São Paulo, 2009.

Tese (Doutorado) - Universidade de São Paulo. Instituto de Física. Departamento de Física Geral

Orientador: Prof. Dr. Alessandro Paulo Sérvio de Moura

Área de Concentração: Física

Unitermos: 1. Redes Complexas; 2. Sociologia Econômica; 3. Modelos Epidemiológicos; 5. Difusão da Informação; 4. Grafos Aleatórios.

USP/IF/SBI-078/2009 


\section{Copyleft (0) 2009 by Alexandre Hannud Abdo \\ Alguns Direitos Reservados}

Esta obra é licenciada sob os termos da Licença Creative Commons Atribuição Compartilhamento pela mesma Licença Brasil 2.5. A licença está disponível em http: //creativecommons .org/licenses/by-sa/2.5/br/.

\section{(1)(อ}

Atribuição - Compartilhamento pela mesma Licença

\section{Você pode:}

Compartilhar - copiar, distribuir, exibir e executar a obra

Modificar - criar obras derivadas

\section{Sob as seguintes condições:}

(i)

Atribuição - Você deve dar crédito ao autor original, da forma especificada pelo autor ou licenciante (mas sem sugerir que eles aprovam você ou seu uso da obra).

Compartilhamento pela mesma Licença - Se você alterar, transformar, ou criar outra obra com base nesta, você somente poderá distribuir a obra resultante sob uma Licença idêntica.

\section{Compreendendo que:}

Renúncia - Qualquer uma destas condições podem ser renunciadas, desde que você obtenha permissão do detentor dos direitos autorais.

Uso Legítimo - A licença não interfere nas limitações do direito de autor, tais como para a reflexão acadêmica e exercício da liberdade de expressão.

Direitos Morais - De nenhuma forma a licença afeta os direitos morais do autor.

Notificação - Para cada novo uso ou distribuição, você deve deixar claro para outros os termos da licença desta obra. A melhor maneira de fazê-lo é com um apontador para a página http://creativecommons .org/licenses/by-sa/2.5/br/. 
Chi ha dato ha dato, chi ha avuto ha avuto.

- Teofilatto dei Leonzi 
Dedico esta tese à Mentira com suas pernas curtas; e ao Diabo que lhe emprestou pernas de pau. 


\section{Reconhecimentos}

Se um manuscrito pode representar parte do meu aprendizado nesses anos de estudo, ele deixa de fora uma outra muito maior. Por esta agradeço aos professores Manuel, Sônia, Barone, Imre, Gilson e aos colegas Ricardo, Luise, Seong, Mauricio, Neide, João e Lilian.

Deste trabalho tenho pela confiança, conhecimento e amizade, gratidão especial ao meu orientador Alessandro. E pelo incentivo dele conto também a oportunidade de trabalhar com meu co-orientador Duncan e conviver com os brilhantes colegas Matt, Dunia, Gueorgi, Rob, John, Roby e Wilson em Nova York.

Reconheço pela extensão da minha vida, mas destacadamente nesse período, a influência espiritual do meu avô Elias, o aprendizado do crescer ao lado de minha irmã Tatiana e os exemplos de meus pais, Emilio e Anete, que juntos ensinaram-me a voar com os pés no chão.

À minha fada-madrinha Verusca e meu tio Eduardo, meus padrinhos, por sempre entregarem-se de alma a cultivar o melhor de mim, sem esperar nada em retorno.

Uma salva de Ni!s à Turma 9 e aos demais integrantes da comunidade orbitando o Curso Experimental de Ciências Moleculares. Que nossa amizade e trabalho sirva de luz para uma universidade onde o centro esteja em todo lugar.

Uma boa cachaça mineira aos colegas do Departamento de Física Geral, singrando os mares de entropia em bordo à nau do Capitão S. Fabio, Henrique, Eduardo, Masayuki. E um brinde aos não tão aventureiros colegas de outras embarcações do Instituto. Everton, Carlos, Washington, Chico.

Aquele abraço para os amigos do Movimento Nossa São Paulo, do CORO Coletivo e da Wikimedia Brasil, que tomaram tempo precioso deste trabalho, mas renderam frutos muito maiores. Em especial à Mila, Caci, Xixo, Ariel, Flávia, Euler, George, Thomas, Raul, Névio e Rodrigo.

E enfim, os últimos que são os primeiros...

Pela companhia e pelo amor fraterno, meus irmãos Thiago, Grilli, Kenji, Ivo, Kike, AnaFê\&Rê, Eric, Paula, Glauco, Luis e toda a turma da época de Dante, assim como nossas famílias, em particular as queridas tias Vera e Maria.

Por permitir-me preservar minha insanidade, a grandessíssima comunidade tecnoanarquista da casa do Kuko, seguidores do astrofungo, vulga Federação Zumbaê.

Ao amigo Tiago. Ao Laerte, à Camile, à Ksenia. Não há reverência que faça juz ao meu débito com vocês, mas prometo muitos Ni!s e Babushka!s até que os demônios assombrosos me arrastem deste pálido ponto azul.

Aos funcionários das instituições e lares que me abrigaram durante esses anos. Aonde encontrei um ambiente limpo, uma burocracia funcional, um serviço bem provido, um alimento saudável, deixo minha profunda admiração e agradecimento.

E para não esquecer dos amigos Nelson e Vinicius, às mulheres. Todas Anas, Marias, Evelyns, Camiles e à miríade de combinações inimagináveis das suas belezas.

Agosto de 2009

Alexandre Hannud Abdo 


\section{Resumo}

Esta tese apresenta um estudo de modelos de crescimento e contágio em redes, relacionando propriedades topológicas das redes com propriedades dinâmicas da evolução. Dos modelos de crescimento, desenvolve-se uma extensão do conceito de coeficiente de aglomeração para melhor determinar a validade desses modelos, demonstrando-se a utilidade de tal extensão em informar o papel não trivial da topologia dos ciclos entre modelos e redes reais. Dos modelos de contágio, utiliza-se uma modificação do modelo generalizado de Dodds e Watts para investigar o problema prático de planejar estratégias para difusão proposital de uma epidemia, em que se busca contaminar uma fração significativa de uma população a partir da inseminação de um grupo menor de indivíduos. Mostra-se que a modificação introduzida, a variabilidade da razão entre o tempo investido por influenciante e influenciável, determina o sentido e intensidade da relação entre o grau das sementes e o sucesso das estratégias. Esse problema também pode ser interpretado como um estudo de estabilidade com respeito a condições iniciais em que a variável em questão, o conjunto infectado, assume valores nos subconjuntos dos vértices do grafo. 


\begin{abstract}
This thesis presents a study of models of network contagion and network growth, relating topological properties of the network with dynamical properties of the evolution. Of network growth models, an extension to the concept of clustering coefficient was applied to better determine the validity of some models, demonstrating the practical use of this extension and revealing the non-trivial role of the cycle topology between real-world networks and models. Of the network contagion models, an extension of Dodds-Watts' generalized model of contagion was used to approach the practical problem of planning seeding strategies for large-scale interventions, where one wishes to infect some population through diffusion from a smaller initially infected group. It is shown that the extension introduced, which parametrizes the ratio between the time invested by the influential and the influenced, determines the direction and intensity of the relationship between the degree of the seeds and the success of strategies. This second problem can also be interpreted as a study of the stability with respect to initial conditions, where the relevant variable, the infected set, takes values on the subsets of the graph's vertices.
\end{abstract}




\section{Sumário}

1 Introdução 3

1.1 Alguns conceitos básicos sobre redes . . . . . . . . . . . 4

2 Medindo ciclos locais na evolução de redes $\quad 7$

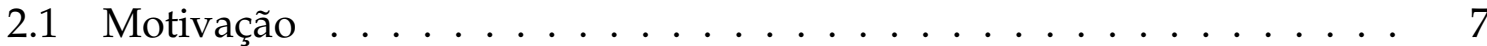

2.2 Histórico de trabalhos relacionados . . . . . . . . . . . . . . . . 8

2.3 Definição de um coeficiente de aglomeração estendido . . . . . . . . . 8

2.4 Medidas e natureza . . . . . . . . . . . . . . . . . . . . . . . . 10

2.5 Perfil de aglomeração . . . . . . . . . . . . . . . . . . . . . . . 11

2.6 Aglomeração a partir de dados de redes . . . . . . . . . . . . . . . 12

2.7 Aglomeração a partir da correlação de graus . . . . . . . . . . . . . 12

2.7.1 Tratamento semi-analítico . . . . . . . . . . . . . . . . . . . 13

2.7.2 Tratamento computacional . . . . . . . . . . . . . . 15

2.8 Aplicação ao interactoma da Saccharomyces . . . . . . . . . . . . . 16

2.9 O coeficiente estendido não é inversível . . . . . . . . . . . . . . . 21

3 Dinâmica e topologia local num modelo generalizado de contágio 24

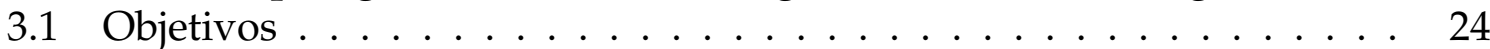

3.2 Teorias de influência social e modelos . . . . . . . . . . . . . . 24

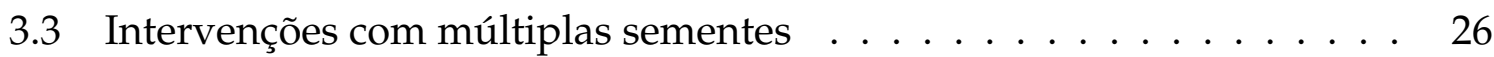

3.4 O modelo generalizado de contágio $\ldots \ldots \ldots \ldots \ldots$

3.4 .1 Parâmetros do modelo . . . . . . . . . . . . . . . . . . . . . 28

3.4 .2 Interpretação dos parâmetros . . . . . . . . . . . . . . . 30

3.4.3 Memória, limiares e epidemias . . . . . . . . . . . . . . . . . 31

3.4.4 Descrição algorítmica e implementação . . . . . . . . . . . . 32

3.5 A rede de mensagens . . . . . . . . . . . . . . . . . . . 34

3.5 .1 Características . . . . . . . . . . . . . . . . . . 35

3.5.2 A rede embaralhada . . . . . . . . . . . . . . . . . . 38

3.6 Estratégias de semeadura . . . . . . . . . . . . . . . . . . . . . . 39

3.6 .1 Amostragens . . . . . . . . . . . . . . . . . . . . . 39

3.6 .2 Propriedades . . . . . . . . . . . . . . . . . . 40

3.6 .3 Definição das estratégias . . . . . . . . . . . . . . . . . 40

3.6.4 Características . . . . . . . . . . . . . . . . . . . . . 41

3.7 Resultados . . . . . . . . . . . . . . . . . . . . . . . 46

3.8 Discussão . . . . . . . . . . . . . . . . . . . . . . 48

3.8.1 Desimportância da topologia quando $D^{*}=1$ e $r=0$ para qualquer $T \ldots \ldots \ldots \ldots \ldots \ldots \ldots$ 
3.8.2 Dominância do grau sob balanço de tempo $\tau$ desequilibrado . . 48

3.8.3 Reforço, reciprocidade e aglomeração . . . . . . . . . . . . . 50

3.8.4 Mensagens recebidas ou vizinhos? . . . . . . . . . . . . . . . 53

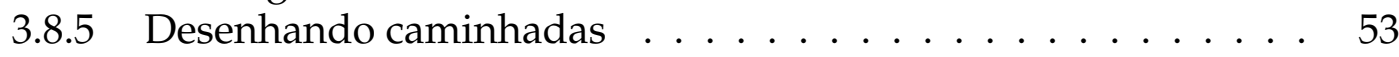

3.9 Crítica e dificuldades deste estudo . . . . . . . . . . . . . . 54

4 Conclusões $\quad 56$

Do primeiro capítulo . . . . . . . . . . . . . . . . . 56

Do segundo capítulo . . . . . . . . . . . . . 57

A Gráficos das propriedades topológicas das estratégias de semeadura 59

B Tabelas dos resultados das simulações $\quad 76$

B.1 Rede de mensagens . . . . . . . . . . . . . . . . . . . . 76

B.2 Rede embaralhada . . . . . . . . . . . . . . . . . 86

C Atividades de extensão universitária $\quad 96$

Referências Bibliográficas $\quad 96$ 


\section{Capítulo 1}

\section{Introdução}

Redes complexas é uma área de pesquisa recente. Surgiu como resposta ao avanço e barateamento do poder computacional, que permitiu colher e processar uma massa de dados relacionais difícil de imaginar.

Em poucos anos foram mapeadas interações entre moléculas, genes, proteínas, células, órgãos, organismos, espécies, ecosistemas, sociedades. A internet, mediando cada vez uma parcela maior das relações humanas, acrescenta a essa massa uma fonte auto-alimentada, contínua e acelerada de registro do nosso comportamento social, econômico e cognitivo.

A favor dessa correnteza, desenvolve-se uma ciência tramitando entre a carência de uma definição e a inadequação de todas elas. Um termo composto no cruzamento de dois caminhos sinuosos:

Redes fazem parte da teoria matemática dos grafos, uma área reconhecida pela dificuldade de entender-se dela algo além de uma coletânea de técnicas para problemas específicos, sem uma hierarquia teórica que a estruture.

Complexidade, por sua vez, é uma palavra com tantos significados quanto aplicações diferentes. Associa-se a outros conceitos como emergência, auto-organização, caos, coletividade, heterogeneidade, imprevisibilidade, evolução.

Assim, talvez o melhor seja entender o estudo de redes complexas pela sua prática, sem definí-lo a priori.

Este trabalho tem dois capítulos que lidam com problemas bastante distintos, ainda que dentro desta mesma área.

O primeiro capítulo busca refinar a avaliação de algoritmos que descrevem o crescimento de redes, ao tornar mais detalhada e robusta uma medida amplamente utilizada, o coeficiente de aglomeração. Este coeficiente é uma medida da estrutura local de redes em termos de seus ciclos.

As demais medidas topológicas para avaliação desses modelos ou tem caráter global, como a ciclicidade, ou não cíclico, como distâncias, graus e correlações de grau - conceitos que explicaremos adiante. Ou então são ad hoc como os motifs, estruturas pequenas e arbitrárias de frequência característica a uma rede ou função particular.

Ver-se-á que o coeficiente de aglomeração pode ser definido de várias maneiras equivalentes, havendo uma que ressalta seu caráter cíclico e pode ser utilizada para extendê-lo de forma simples.

Medidas relacionadas a ciclos, especialmente ciclos locais, costumam ser pouco e 
irregularmente investigadas ao caracterizar-se uma rede ou compará-la a modelos de crescimento.

O objetivo deste capítulo será indicar uma medida que permita de forma sistemática e abrangente observar a importância desses ciclos.

Os modelos escolhidos serão de redes biológicas, pela disponibilidade de dados e pela simplicidade possível a estes. Mais especificamente, redes que descrevem relações no metabolismo de bactérias e interações entre proteínas. Contudo, os métodos apresentados aplicam-se a qualquer sistema descrito por uma rede.

O segundo capítulo lida com o problema menos abstrato, originalmente estudado pela sociologia, de difusão ou contágio em sociedade.

Através de um modelo computacional de agentes em rede, simulou-se a troca de influências numa sociedade artificial, estruturada segundo dados obtidos de interações humanas mediadas pela internet.

O objetivo é explorar relações entre parâmetros do modelo de contágio e a topologia da rede, em particular o envolvimento diferencial do propagador e receptor no ato de contágio e os efeitos da ciclicidade conforme estudada no primeiro capítulo.

Dentro dessa finalidade, deve ser lembrado que a sociologia e a física não são disciplinas irmãs e, apesar disso não ter impedido a mútua fertilização no passado, não devem ser levainamente consideradas amigas.

É tentador, do ponto de vista físico, simplificar a natureza das interações humanas a agentes numa rede evoluindo por regras simples. Em redes regulares, isso permite até o tratamento de problemas por métodos conhecidos da mecânica estatística.

Contudo, o ser humano tem várias características que tornam essa proposta irreconciliável com a realidade, como a capacidade de introspecção, isto é, de agir segundo seu próprio modelo mental do coletivo que participa e constantemente reinterpretálo, ou mesmo o simples impulso de agir criativamente.

Deve-se entender, portanto, que o uso desses modelos de agente, como feito aqui, tem como objetivo orientar - e não descrever - a evolução de grupos humanos. Seu valor está na possibilidade de informar quais razões físicas relacionar a certas tendências e quais não, sob uma variedade de condições e controle inacessíveis na prática. Seu valor não é o de afirmar a inevitabilidade, ou mesmo a probabilidade, de tais tendências; pois além da imprecisão intrínsica a qualquer descrição da sociedade, seus agentes a todo momento são capazes de introduzir novos parâmetros não previstos num modelo.

O trabalho aqui apresentado, por exemplo, ainda que busque um tom negativo e desmistificante, pode ser facilmente confundido como um manual de marketing boca-a-boca. Espera-se que não cometam este erro.

\subsection{Alguns conceitos básicos sobre redes}

Antes de iniciar os temas centrais, segue-se uma curta apresentação de vocabulário.

Uma rede é a representação de relações através de um objeto matemático chamado grafo, denotado $G$.

Pictoricamente, pode-se pensar num grafo como pontos de algum espaço onde segmentos os conectam com ou sem uma direção preferencial.

Formalmente, um grafo é uma sequência de dois elementos $G=(V, E)$, ambos 
conjuntos, onde os membros do primeiro conjunto $V$ chamam-se vértices e os membros do segundo conjunto $E$, chamados arestas, são pares de membros do primeiro.

Uma aresta, por sua vez, pode ser um conjunto $\{v, w\}$ ou uma sequência $(v, w)$ de dois vértices distintos $v, w \in V$, chamando-se aresta dirigida no segundo caso. Dizse que um grafo é dirigido se todas as suas arestas o são, e não dirigido se nenhuma o é. Se for uma sequência de dois vértices iguais $(v, v)$, a aresta chama-se laço e não é considerada dirigida, nem conta para determinar se o grafo o é.

Quando necessário representar arestas diferentes mas paralelas, isto é, conectando os mesmos vértices e no mesmo sentido se aplicável, as arestas terão um índice inteiro positivo associado a elas. Um grafo sem arestas paralelas é chamado simples. Um grafo com arestas paralelas, também ditas múltiplas, é chamado multigrafo.

De cada aresta $e \in E$, chama-se pontas ou extremidades o par de vértices que a formam. Num grafo dirigido as pontas chamam-se, na sequência, origem e destino, denotados $s(e)$ e $t(e)$.

Os vizinhos $N(v)$ de um vértice são o conjunto dos vértices que fazem par com ele em arestas não dirigidas. Os vizinhos de saída $N_{\text {out }}(v)$ são o conjunto dos destinos das arestas das quais ele é origem, e os vizinhos de entrada $N_{i n}(v)$ são as origens das arestas das quais ele é destino.

O grau $\delta(v)$ de um vértice é o número de arestas não dirigidas de que participa. $\mathrm{O}$ grau de saída $\delta_{\text {out }}(v)$ é o número de arestas dirigidas de que participa como origem. O grau de entrada $\delta_{i n}(v)$ é o número de arestas dirigidas de que participa como destino.

Um caminho $v \ldots . . w$ é um grafo cujos vértices admitem uma permutação onde cada vértice é vizinho ou vizinho de saída do seu predecessor.

Um ciclo ou circuito $v \ldots w v v$ é um caminho onde, adicionalmente, o primeiro vértice é vizinho ou vizinho de saída do último.

O comprimento de um caminho $l(v \ldots w)$ ou de um ciclo $l(v \ldots w v)$ é seu número de arestas. Um ciclo tem comprimento igual ao número de seus vértices, um caminho tem comprimento igual ao número de seus vértices menos um.

Um subgrafo do grafo $G$ é todo grafo $H=(W, F)$ onde $W$ é subconjunto de $V$ e $F$ é subconjunto de $E$.

A distância $d(v, w)$ entre dois vértices de um grafo é o comprimento do menor subgrafo caminho com início no primeiro e fim no segundo. Note que a distância em grafos com arestas dirigidas pode não ser simétrica, isto é, a distância entre o primeiro e o segundo vértice pode ser diferente da distância entre o segundo e o primeiro.

A ciclicidade de um grafo é a medida do número de seus subgrafos ciclo com um determinado comprimento.

O subgrafo induzido $G[W]$, do grafo $G$ por um subconjunto $W$ de $V$, é o subgrafo $H=(W, F)$ tal que $F$ são as arestas em $E$ cujas pontas sejam ambas elementos de $W$.

As correlações de grau são quantidades que relacionam os diferentes graus, seja de um mesmo vértice ou das pontas de uma aresta. Por exemplo, podem medir a frequencia com que um vértice de dado de grau de entrada tem um certo grau de saída, ou a frequencia com que uma aresta tem certos valores de grau em cada ponta.

Um grafo é dito assortativo se as correlações de grau entre vértices vizinhos favorecem conexões entre graus semelhantes, dissortativo se elas favorecem conexões entre graus polarizados e neutro se não há favorecimento. 
Demais conceitos serão apresentados à medida da necessidade. Para uma abordagem abrangente dos métodos e aplicações de redes complexas, em inglês, veja [Newman, 2003b, Boccaletti et al., 2006]. Para uma introdução a aspectos combinatórios da teoria dos grafos em português, recomenda-se [Feofiloff et al., 2004]. Para um tratamento mais profundo dessa teoria, em inglês, recomenda-se [Diestel, 1997]. Todos disponíveis gratuitamente em versão eletrônica. 


\section{Capítulo 2}

\section{Medindo ciclos locais na evolução de redes}

\subsection{Motivação}

Em 1998, Watts e Strogatz [Watts and Strogatz, 1998] publicam um estudo que inicia a onda de interesse de físicos em problemas que vieram a ser categorizados pelo nome redes complexas [Newman, 2003b]. Já nesse trabalho, o coeficiente de aglomeração, ou clustering coefficient, surge como medida central. Seu argumento é que, ao introduzir-se conexões aleatóreas numa rede, a distância média diminui rapidamente enquanto o coeficiente de aglomeração permanece relativamente estável.

Ali, o coeficiente de aglomeração é definido, num grafo não dirigido, como a média em todos os vértices da fração de seus vizinhos conectados entre si. A distância média é simplesmente a média da distância entre todos os pares de vértices do grafo.

Isso explicaria o conflito entre a percepção ingênua de um mundo de comunidades fechadas e as experiências demonstrando a proximidade entre todos os seus habitantes, como realizadas inicialmente por Milgram [Travers and Milgram., 1969] e, mais recentemente, pelo próprio Watts et al [Dodds et al., 2003]. Ou explicaria, numa interpretação mais preocupante, por que doenças contagiosas espalham-se rapidamente por grupos que se consideram isolados ou seguros, como no caso da AIDS.

Após esse trabalho, ainda descobriu-se que uma alta aglomeração era característica de várias redes presentes na natureza, mas marcadamente nas sociais, sendo a principal medida a distinguí-las de redes biológicas e tecnológicas [Newman and Park, 2003, Jin et al., 2001].

A relevância e ampla aplicação do conceito de aglomeração sugere que este seja bastante geral e robusto.

Contudo, classes úteis de redes, como as redes bipartidas, tem coeficiente de aglomeração sempre zero. Nessas redes, por definição, há dois grupos de vértices onde cada vértice só se conecta com o grupo oposto, impedindo os vizinhos de um vértice de conectarem-se.

Redes bipartidas surgem naturalmente nos contextos mais diversos, para representar relações sexuais entre grupos heterossexuais, participação de moléculas em reações químicas, relações comerciais entre produtores e consumidores ou conflitos entre aldeias de tribos distintas. 
Essa limitação do coeficiente de aglomeração acaba por forçar a adaptação de redes empíricas para poder-se aplicar o conceito, causando perda de informação, como numa transformação utilizada e bastante difundida para estudar redes metabólicas [Ravasz et al., 2002].

Além dessa, outras famílias de redes muito úteis tem coeficiente de aglomeração trivial, como os mais diferentes reticulados, regulares ou irregulares, determinísticos ou aleatórios, desde que não permitam triângulos em sua estrutura.

Agrava o problema que os demais conceitos comumente empregados para descrever redes sejam como a ciclicidade, estritamente globais, ou como grau, distância, correlações de grau e motifs [Milo et al., 2002], que não medem de forma genérica a presença de ciclos no grafo.

Outra limitação do coeficiente, a ambiguidade na determinação do sentido das arestas, também acaba por forçar a adaptação de grafos, em geral removendo-lhes a direção [Ravasz et al., 2002] para permitir seu cálculo.

\subsection{Histórico de trabalhos relacionados}

Trabalhos anteriores já abordaram o problema das limitações da aglomeração, apresentando perspectivas outras ou parciais.

Em 2002, Guido Caldarelli et al. [Caldarelli et al., 2004] desenvolveu uma versão particular do coeficiente de aglomeração para medir ciclos de comprimento quatro, sem considerar uma extensão ou levantar a questão de minimalidade que será vista adiante. Essa idéia reaparece em 2005 em Pedro G. Lind et al. [Lind et al., 2005].

Em 2002, Agata Fronczak et al. [Fronczak et al., 2002] aplicaram a definição do coeficiente estendido derivada adiante, mas para grafos não dirigidos e sem considerá-lo em função do grau, no contexto específico de estudar a evolução desses coeficientes durante o crescimento do modelo de BA.

A partir de 2003, Ginestra Bianconi et al. [Bianconi and Capocci, 2003, Bianconi and Marsili, 2005] exploraram a medida global de ciclicidade ou loopiness.

E a partir de 2004, Luciano da F. Costa et al. [Costa and da Rocha, 2006, Costa and Silva, 2006] investigam uma abordagem diferente para generalizar medidas como a aglomeração, baseada em mudar o domínio de medição ao invés da medida.

Merece menção também o trabalho sobre aglomeração de M. Ángeles Serrano et al. [Serrano and Boguñá, 2006a,Serrano and Boguñá, 2006b] em 2006, onde resultados relacionandos a uma dinâmica são obtidos mudando-se o foco da medida de vértices para arestas.

\subsection{Definição de um coeficiente de aglomeração esten- dido}

Assim, voltando à aglomeração usual, o problema pode ser melhor entendido reescrevendose a definição do coeficiente em função de distâncias ou ciclos.

Para grafos não dirigidos, as definições abaixo para o coeficiente de aglomeração de um vértice são equivalentes: 
1. A fração de seus pares de vizinhos conectados entre si.

2. A fração de seus pares de vizinhos contidos num caminho de comprimento 1 .

3. A fração de seus pares de vizinhos que, juntos consigo, estão contidos num ciclo de comprimento 3 .

4. A fração de seus pares de vizinhos à distância 1 .

5. A fração de seus pares de vizinhos que, juntos consigo, estão contidos num ciclo mínimo de comprimento 3.

As definições 3 e 5 mostram o caminho para estender naturalmente o coeficiente para caminhos, distâncias, ciclos ou ciclos mínimos de comprimento variável: basta parametrizar o comprimento do ciclo por um valor inteiro maior ou igual ao original.

As definições 2 e 4 não podem ser simplesmente parametrizadas, pois entre dois vizinhos de um vértice há sempre o caminho de comprimento 2 que os liga através dele. Mas podem ser adaptadas para tal, impondo-se descartar o próprio vértice no cálculo das distâncias.

Contudo, essa adaptação de 2 e 4 é apenas uma forma indireta de falar em ciclos, correspondendo-as às definições 3 e 5 respectivamente; com isso, de agora em diante considerar-se-á apenas estas últimas.

As extensões das definições 3 e 5, porém, não são equivalentes. A introdução da exigência de minimalidade confere algumas propriedades interessantes.

A principal diferença a privilegiar a definição em termos de ciclos mínimos é a possibilidade de averiguar quanto dos vizinhos encontram-se acessíveis entre si, que é a proposta original do coeficiente.

Sem minimalidade, não há como diferenciar um vértice com o qual todos os pares de vizinhos partilham ciclos, de um outro com o qual apenas uma parte partilha, mas cada par dessa parte partilha vários ciclos de comprimentos diferentes.

Na definição minimal, por outro lado, a fração dos pares de vizinhos que partilham com o vértice algum ciclo de comprimento menor que $n$ é simplesmente a soma dos valores do coeficiente para valores do parâmetro menores que $n$.

Assim, tal definição constrange mais eficientemente a topologia da rede considerada ao redor do vértice. E ainda que restrinja também o espaço levado em consideração, tal restrição pode ser entendida como uma menor redundância com medidas globais como a ciclicidade.

Resta, enfim, a questão de estender o coeficiente para grafos dirigidos ou que contenham arestas dirigidas.

Para isso, nesta interpretação do coeficiente em termos de ciclos, basta considerar o sentido dos próprios. Dessa forma, as combinações de vizinhos na definição não dirigida traduzem-se em arranjos de vizinhos tal que, quando dirigidos, sejam primeiros se de entrada e segundos se de saída.

E a definição completa para a extensão, parametrizada pelo comprimento $d$, do coeficiente de aglomeração de um vértice será:

A fração dos possíveis arranjos de um vizinho ou vizinho de entrada com um vizinho ou vizinho de saída do vértice para os quais o menor ciclo a conter os três tem comprimento

$$
d+2 \text {. }
$$


Lembrando que o sentido das arestas dirigidas num ciclo deve ser coerente. Somase 2 ao índice para que o coeficiente em 1 seja o usual e represente o menor ciclo. Circuitos de comprimento 2 são tratados à parte, numa medida chamada reciprocidade, por envolverem um único vizinho e só fazerem sentido para arestas dirigidas.

As Figuras 2.3.1 e 2.3.2 fornecem exemplos da aplicação dessa definição para, respectivamente, um vértice em um grafo não dirigido e em um dirigido.

\subsection{Medidas e natureza}

Deve-se observar, contudo, que todas as medidas genéricas de redes são intrinsicamente artificiais.

Tais objetos são abstrações aplicáveis às naturezas mais diversas e o papel de suas projeções não pode ser previsto a priori como o de um atributo físico.

Ainda que a estatística de algumas dinâmicas em rede admita captar-se por medidas topológicas, como a medida do grau para os passeios aleatórios em grafos não dirigidos [Noh and Rieger, 2004], estas são relações específicas de dada combinação entre medida e processo, e não quantidades universais cuja relevância independa da dinâmica em ação [Borgatti, 2005].

As medidas investigativas, ditas básicas, são escolhidas na base do artifício e devem ser entendidas como ferramentas úteis para uma primeira triagem das qualidades do sistema estudado.

Isto é, valem-se da simplicidade de medí-las, da complementariedade de suas

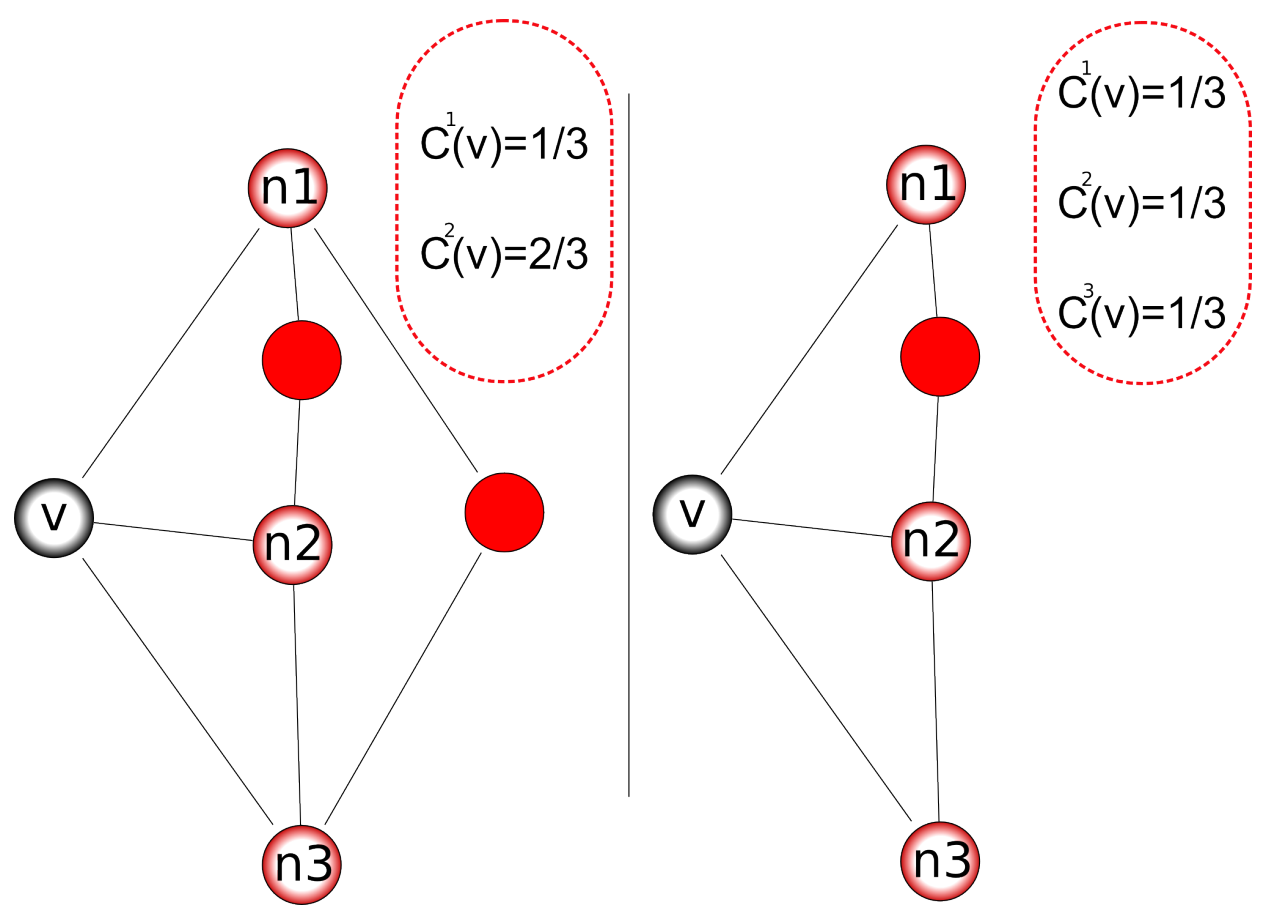

Figura 2.3.1: Dois exemplos de aplicação do coeficiente estendido em grafos não dirigidos. No exemplo da direita o ciclo mínimo por $n 1$ e $n 3$, de comprimento 5, acaba também cruzando $n 2$. 


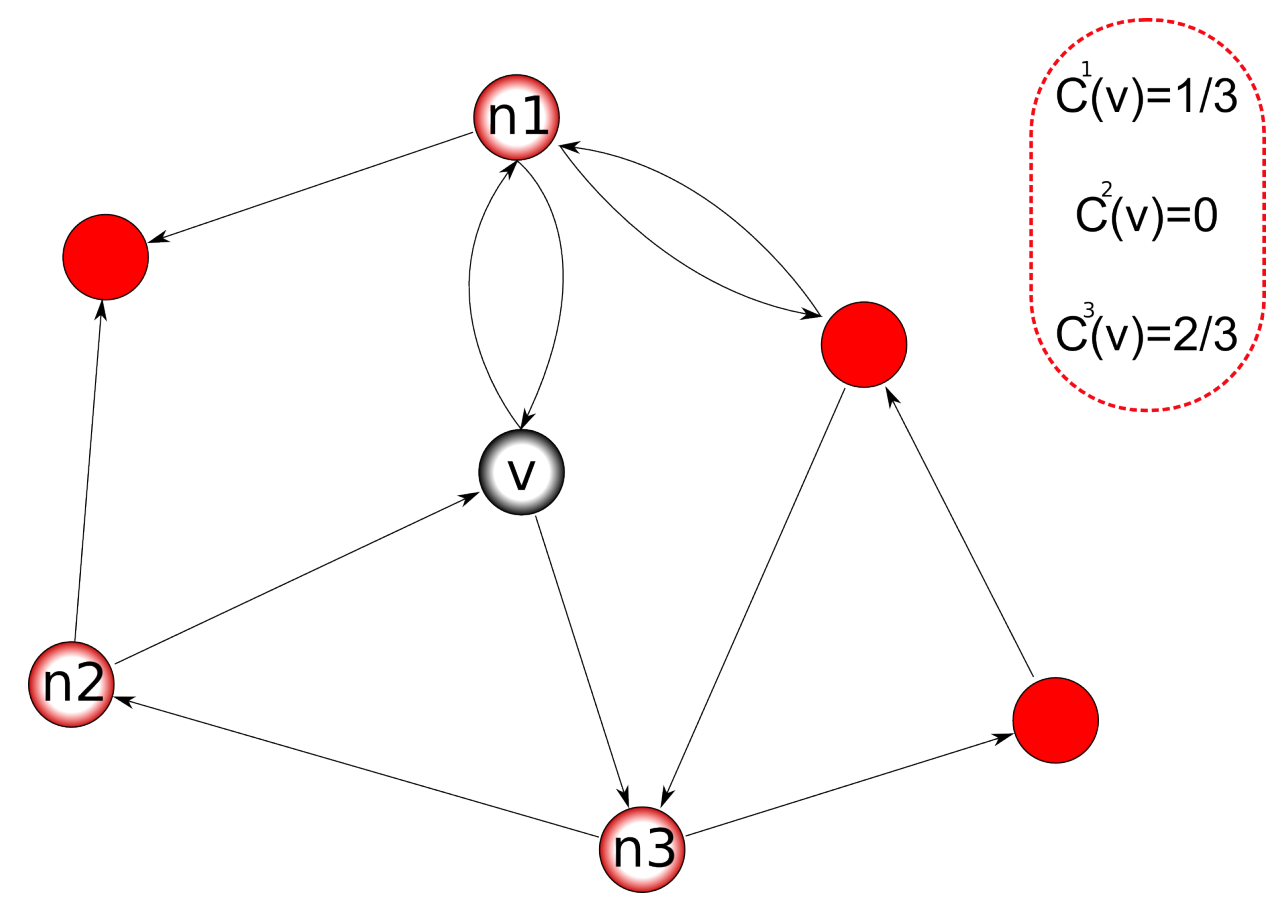

Figura 2.3.2: $\mathrm{O}$ caso mais complicado de um grafo dirigido. Por não formar um par de vizinhos, o par de arestas entre $v$ e $n 1$ não é contado. Os pares de vizinhos e o comprimento dos seus cíclos mínimos são: $(n 2, n 1)$ com 5 , $(n 2, n 3)$ com 3 e $(n 1, n 3)$ com 5.

perspectivas, da sua relevância para dinâmicas empíricas frequentemente estudadas.

Com base nas duas primeiras dessas características tentou-se superar as limitações do coeficiente de aglomeração e propôr uma medida da topologia de ciclos locais.

O restante deste capítulo dedica-se a apontar sua relevância, desenvolvendo ferramentas para aplicá-la.

\subsection{Perfil de aglomeração}

Para um grafo $G=(V, E)$, seja $l_{\min }\left(v_{1}, v_{2}, v_{3}\right)$ o comprimento do menor ciclo contendo esses três vértices de sentido $v_{1} \rightarrow v_{2} \rightarrow v_{3}$, com arestas não dirigidas podendo ser consideradas a favor de ambos os sentidos.

Seja $K(v)=\left\{\left(v_{i}, v_{0}\right) \in\left(N(v) \cup N_{\text {in }}(v)\right) \times\left(N(v) \cup N_{\text {out }}(v)\right) \mid v_{i} \neq v_{0}\right\}$ as combinações de um vizinho ou vizinho de entrada com um vizinho ou vizinho de saída do vértice.

Então o coeficiente de aglomeração estendido de um vértice $v$ pode ser escrito como:

$$
C^{d}(v)=\frac{\left|\left\{(u, w) \in K(v) \mid l_{\min }(u, v, w)=d+2\right\}\right|}{|K(v)|},
$$


Com que tem-se a propriedade de

$$
\sum_{d \geq 1} C^{d}(v) \leq 1
$$

E pode-se definir sua média no grafo como

$$
C^{d}=\frac{\sum_{v \in V} C^{d}(v)}{|V|}
$$

Contudo, mais que a média do coeficiente em todo o grafo, estudar a média entre vértices de mesmo grau revela relações entre essas duas medidas que traduzem melhor os detalhes de sua topologia [Ravasz and Barabási, 2003].

Assim, definimos o perfil de aglomeração em função do grau $k$ como:

$$
C_{k}^{d}=\frac{\sum_{\{v \in V \mid \delta(v)=k\}} C^{d}(v)}{|v \in V| \delta(v)=k \mid}
$$

\subsection{Aglomeração a partir de dados de redes}

Dada a descrição completa de um grafo em termos de seus vértices e arestas, é preciso um algoritmo para calcular o coeficiente para um vértice.

Uma maneira de calculá-lo é executar uma busca em lagura a partir de cada vizinho e vizinho de saída do vértice, identificando o primeiro encontro com cada outro vizinho ou vizinho de entrada e retornando os comprimentos dos ciclos assim identificados. Pode-se também limitar o comprimento calculado, interrompendo a busca numa largura máxima.

Para obter o coeficiente para um comprimento desejado basta então somar a quantidade de ciclos daquele comprimento e dividí-la pelo denominador correspondente em 2.5.1, que só depende dos graus do vértice.

Denotando por $\left\langle k^{+}\right\rangle$a média, em todos os vértices do grafo, da soma do grau com o grau de saída; e denotando por $d^{*}$ o comprimento máximo buscado, o procedimento tem eficiência $O\left(|V|\left\langle k^{+}\right\rangle^{2+d^{*}}\right)$ no pior caso.

Esse algoritmo, utilizado nas aplicações adiante, foi implementado como parte deste estudo e disponibilizado na biblioteca graph-tool [Peixoto, 2006] para manipulação e estatística de grafos, desenvolvida em python e C++ e distribuída como software livre.

\subsection{Aglomeração a partir da correlação de graus}

No estudo de redes, frequentemente utilizam-se modelos configuracionais, que geram grafos amostrados aleatoriamente de um espaço de configurações definido por vínculos sobre algumas propriedades.

Esses modelos servem como modelos nulos, ou null models, para determinar se o valor de demais propriedades da rede pode ser explicado como consequência dessas, ou se há outras forças em ação. 
Há uma variedade de métodos para trabalhar com tais modelos [Newman et al., 2001, Newman, 2002, Newman, 2003a], seja analiticamente aplicando funções geratrizes ou gerando grafos com algoritmos inspirados em monte carlo.

Em geral os vínculos considerados são a distribuição de graus ou correlações simples em grafos não-dirigidos.

A importância da relação entre correlações de grau e aglomeração é conhecida [Soffer and Vázquez, 2005], podendo ser entendida pela tendência em grafos assortativos de conectar-se vértices semelhantes, favorecendo a aglomeração, e nos dissortativos de conectar-se vértices opostos, dificultando-a, ao menos no caso da aglomeração usual.

Devido às complicações de cálculo introduzidas pelos ciclos do coeficiente de aglomeração estendido e ao interesse em trabalhar com vínculos de correlações de grau mais completas, utilizou-se primariamente métodos computacionais na análise de modelos configuracionais.

O primeiro método é uma aproximação semi-analítica do perfil de aglomeração a partir de correlações de grau entre vizinhos.

O segundo método é um algoritmo de embaralhamento das arestas de um grafo que, mantendo as correlações presentes nele, gera uma amostra no espaço de configurações restrito por elas.

A correlação de graus estudada será a probabilidade $q\left(k, k^{\prime}\right)$ de uma aresta de origem com grau $k$ ter destino com grau $k^{\prime}$.

Essa função não precisa ser simétrica, mas nem toda função é uma correlação válida, pois ela não apenas precisa obedecer à condição de normalização $\sum_{k^{\prime}} q\left(k, k^{\prime}\right)=$ 1, como deve admitir uma distribuição de graus válida, ou seja, o sistema linear $\left\{k p(k)=\sum_{k^{\prime}} k^{\prime} p\left(k^{\prime}\right) q\left(k^{\prime}, k\right) \mid k \in \mathbb{Z}_{>0}\right\}$, onde as variáveis são os valores da distribuição de graus $p(k)$, deve admitir uma solução positiva onde $\sum_{k} p(k)=1$.

Observe-se que a distribuição de graus $p(k)$ é completamente determinada pela solução desse sistema, ou seja, $p(k)$ é uma função da correlação de graus $q\left(k, k^{\prime}\right)$ e portanto não há a necessidade de especificá-la adicionalmente.

\subsubsection{Tratamento semi-analítico}

Pretende-se calcular, a partir de $q\left(k, k^{\prime}\right)$ e do tamanho $N=|V|$ de um grafo não dirigido, seu coeficiente de aglomeração estendido.

Supõe-se que o grafo seja esparso, isto é, que $|E| \ll N^{2}$.

Para calcular o coeficiente usual a partir de $q\left(k, k^{\prime}\right)$, uma aproximação pode ser obtida por uma expressão descomplicada, como o complementar da probabilidade de dois vizinhos não estarem conectados:

$$
C_{k}^{1}=1-\sum_{k^{\prime}, k^{\prime \prime}} q\left(k, k^{\prime}\right) q\left(k, k^{\prime \prime}\right)\left[1-\frac{q\left(k^{\prime}, k^{\prime \prime}\right)}{N p\left(k^{\prime \prime}\right)}\right]^{k^{\prime}-1}
$$

Os primeiros dois termos no produto representam a escolha de um par de vizinhos ponderada pela correlação, e o terceiro a probabilidade deles não se conectarem dados os seus graus selecionados na ponderação.

Aplicando o mesmo princípio para comprimentos maiores do coeficiente, substituise a probabilidade do par de vizihos não se conectar pela probabilidade deles não 
compartilharem ciclos daquele comprimento ou compartilharem de comprimento menor, lembrando que um par de vizinhos contribui apenas para o termo do coeficiente estendido correspondente ao menor ciclo que compartilham com o vértice.

Porém, ao realizar este cálculo em maiores profundidades do coeficiente $(d>1)$, precisa-se lidar com uma rede crescente de possibilidades, incluindo o aparecimento de ciclos e os desvios nas correlações pela finitude do sistema à medida que o cálculo se propaga.

Para isso, formula-se o cálculo através de propagadores de probabilidades que iteram as possibilidades da rede a partir do vértice, dadas as correlações de grau, ao mesmo tempo que, em cada possibilidade, verificam o surgimento de ciclos com a rede até então propagada.

Para um vértice $v$ de grau $k$, sejam 1 e $f$ respectivamente os vértices de grau $k_{1}$ e $k_{f}$, vizinhos a $v$, onde inicia-se a busca por ciclos e onde ela termina. Esses correspondem aos vértices de grau $k^{\prime}$ e $k^{\prime \prime}$ na Equação 2.7.1. A partir de então, cada passo da propagação determinará o vértice $j$ de grau $k_{j}$ para $1<j<d-1$, lembrando que o coeficiente $C^{d}$ considera ciclos de comprimento $d+2$.

Representando a operação de propagação por $F$, cada aplicação sua contempla duas possibilidades: a probabilidade de naquele passo formar-se um circuito com o caminho já propagado e a probabilidade de não se formar. Por $d-1$ passos, segundo a proposta do cálculo, a primeira contribui diretamente, formando um circuito de comprimento menor que $d$, enquanto a segunda, não formando, pondera a propagação seguinte. O passo final será considerado separadamente. Assim, como cada passo de propagação tem como alternativas as $k_{j}-1$ arestas excedentes de $j$ e toda a probabilidade a partir delas deve ser ponderada pelas corelações de grau entre $k_{j} \mathrm{e}$ $k_{j+1}$, a forma de $F$ será:

$$
F\left(q, p, N, k, k_{1} . . k_{j}, k_{f}\right) \phi=\left[\sum_{k_{j+1}} q\left(k_{j}, k_{j+1}\right)((1-h)+h \phi)\right]^{\left(k_{j}-1\right)}
$$

Na fórmula acima, a potência reflete o número de arestas pelas quais o caminho pode seguir e $h$ é uma função que avalia a probabilidade do caminho propagado não formar circuito.

A probabilidade de formar-se circuito com a adição de um novo vértice ao caminho corresponde ao complementar da chance de estar-se escolhendo um dos vértices pertencentes ao caminho já propagado $f \rightarrow v \rightarrow 1 \rightarrow \ldots \rightarrow j$. Tem-se então a função $h, \operatorname{com} \delta_{x y}$ sendo o delta de Kronecker:

$$
h\left(p, N, k, k_{1} . . k_{j+1}, k_{f}\right)=1-\frac{\delta_{k_{f} k_{j+1}}+\delta_{k k_{j+1}}+\sum_{m=1}^{j} \delta_{k_{m} k_{j+1}}}{N p\left(k_{j+1}\right)}
$$

O numerador é o número de vértices com aquele grau no caminho e o denominador o número no grafo todo.

Enfim, considera-se o último passo da propagação de forma diferente de $F$, pois interessa apenas a probabilidade do vértice escolhido não ser o vértice $f$. Para isso escreve-se a função finalizadora $g$, como $F$, mas substituindo-se a soma das possibilidades pelo inverso do número de vértices de grau $k_{f}$ : 


$$
g\left(q, p, N, k, k_{1} . . k_{d}, k_{f}\right)=\left[1-\frac{q\left(k_{d}, k_{f}\right)}{N p\left(k_{f}\right)}\right]^{\left(k_{d}-1\right)}
$$

O coeficiente fica, assim, expresso pela seguinte fórmula:

$$
C_{k}^{d}=1-\sum_{k_{1}, k_{f}} q\left(k, k_{1}\right) q\left(k, k_{f}\right)\left(\prod_{k_{j}=k_{1}}^{k_{d-1}} F\right)(g)
$$

Onde $k_{1}$ e $k_{f}$ são respectivamente os graus do vizinho de partida e chegada pelos quais busca-se um ciclo mínimo, $\Pi$ representa uma produtória de operadores, $F\left(q, p, N, k, k_{1} . . k_{j}, k_{f}\right)$ é um operador que propaga em distância a probabilidade de caminhos no grafo formarem circuitos e $g\left(q, p, N, k, k_{1} . . k_{d}, k_{f}\right)$ é a probabilidade de um passo não atingir o vizinho de chegada.

Ou seja, a idéia por trás do cálculo é obter o coeficiente, no comprimento $d$, como o complementar da probabilidade dos caminhos a partir do vizinho de partida formarem algum circuito em menos de $d$ passos ou, não formando, ao completar os passos não atingirem o vizinho de chegada para formar um ciclo mínimo.

Implementações do cálculo podem incluir modificações para refletir melhor os efeitos da finitude do grafo ou, ainda, conhecimento a priori deste, por exemplo, ser simples, como será o grafo da aplicação adiante.

Note-se que com $d=1$ recupera-se a fórmula obtida para o coeficiente usual.

\subsubsection{Tratamento computacional}

Além da derivação semi-analítica, para corroborá-la e também como uma outra ferramenta útil para o estudo de modelos configuracionais, desenvolveu-se um algoritmo para rearranjar aleatoriamente os vértices de um grafo, dirigido ou não, de maneira a preservar suas correlações de grau.

Resultados do coeficiente para esse grafo embaralhado podem, assim, ser utilizados como modelo nulo para das correlações de grau e como referência para avaliar as distorções do tamanho finito da rede sobre o cálculo semi-analítico.

$\mathrm{O}$ algoritmo, iterando sobre as arestas do grafo, sorteia a cada passo duas outras arestas, uma para cada ponta daquela, tal que uma de suas pontas tenha os mesmos graus da ponta correspondente na aresta original. Se o grafo for dirigido, comparamse apenas as pontas do mesmo tipo. A seguir, substitiu-se essas três arestas pelo cruzamento das pontas respectivas.

Esse reembaralhamento torna-se problemático apenas quando deseja-se evitar a formação de arestas paralelas ou laços. Porém é possível construir rotinas de verificação permitindo que o algoritmo também satisfaça essas condições quando requisitadas.

O desenvolvimento deste foi uma colaboração com Tiago P. Peixoto [Peixoto and Drossel, 2009] e encontra-se implementado na biblioteca graph-tool [Peixoto, 2006]. 


\subsection{Aplicação ao interactoma da Saccharomyces}

Como aplicação dessas ferramentas, optou-se por investigar uma rede não dirigida, a rede de interações de proteínas da bactéria Saccharomyces cerevisiae [Deane et al., 2002], mais conhecida como o fermento de pão.

Redes de interação de proteínas, também chamadas de interactoma, tem essas moléculas como vértices e arestas entre aquelas que participam juntas em alguma reação química. Elas descrevem, assim, relações de dependência funcional, que restringem a evolução dessas redes.

Dois fatos tornam esse exemplo interessante. Primeiro, a existência de um modelo com bases biológicas para seu crescimento [Vázquez et al., 2003]. Segundo, que há uma disputa [Bertin et al., 2007, Batada et al., 2007], com consequências biológicas relevantes, sobre como compilar os dados dos experimentos onde as interações entre proteínas são medidas, dada a confiabilidade variável destes.

Outro ponto positivo é que, à medida em que o interactoma de novos organismos for mapeado, surgirá a possibilidade de testar o comportamento de modelos de crescimento contra organismos com diferentes números de proteínas. Dependendo de como esses organismos estiverem relacionados, isso permitirá contornar a impossibilidade de testar os modelos contra dados da evolução histórica desses organismos.

O modelo de crescimento investigado chama-se duplicação-divergência [Vázquez et al., 2003], pois sua evolução ocorre por esses dois passos. No primeiro passo, um vértice é duplicado, isto é, cria-se um outro vértice com as mesmas conexões que aquele e, com uma probabilidade $a$, conectam-se os dois vértices gêmeos. No segundo passo, sorteia-se uma de cada par de arestas irmãs geradas na duplicação, e com uma probabilidade $r$ esta aresta é removida. O mecanismo está ilustrado na Figura 2.8.1.

A inspiração por trás desse modelo é que novas proteínas surgem em organismos através de mutações genéticas, e que grande parte dessas mutações são de fato duplicações de um gene, seguidas de divergências que preservem o conjunto das funções da proteína original. Ou seja, as duas proteínas irmãs inicialmente são idênticas e participam das mesmas reações, mas como cada uma está amparada pela presença da outra, elas podem sofrer modificações que as retirem de uma reação, desde que sua irmã preserve aquela função.

Quanto à Saccharomyces, utilizar-se-á dados de duas fontes: um já estabelecido subconjunto CORE do repositório Database of Interacting Proteins (DIP) [Salwinski et al., 2004] e uma compilação de diversas fontes feita pelos autores de [Batada et al., 2007], batizada de High Confidence (HC) por exigir maior certeza das interações. Especificamente neste segundo trabalho, os dados HC são utilizados para contestar uma conjectura, até então bem aceita, de que as proteínas de grau mais elevado, chamadas hubs, concentrariam-se entre aquelas que compartilham muitas interações com poucas proteínas parceiras, e as que compartilham poucas interações com muitas.

O conjunto CORE-DIP tem 2808 vértices e 6212 arestas, enquanto o conjunto HC tem 4011 vértices e 9857 arestas. Os resultados apresentados para o modelo de duplicação-divergência serão parametrizado pela fonte HC. Para esse fim, a diferença entre as fontes é o número de vértices, pois a densidade e a distribuição de 


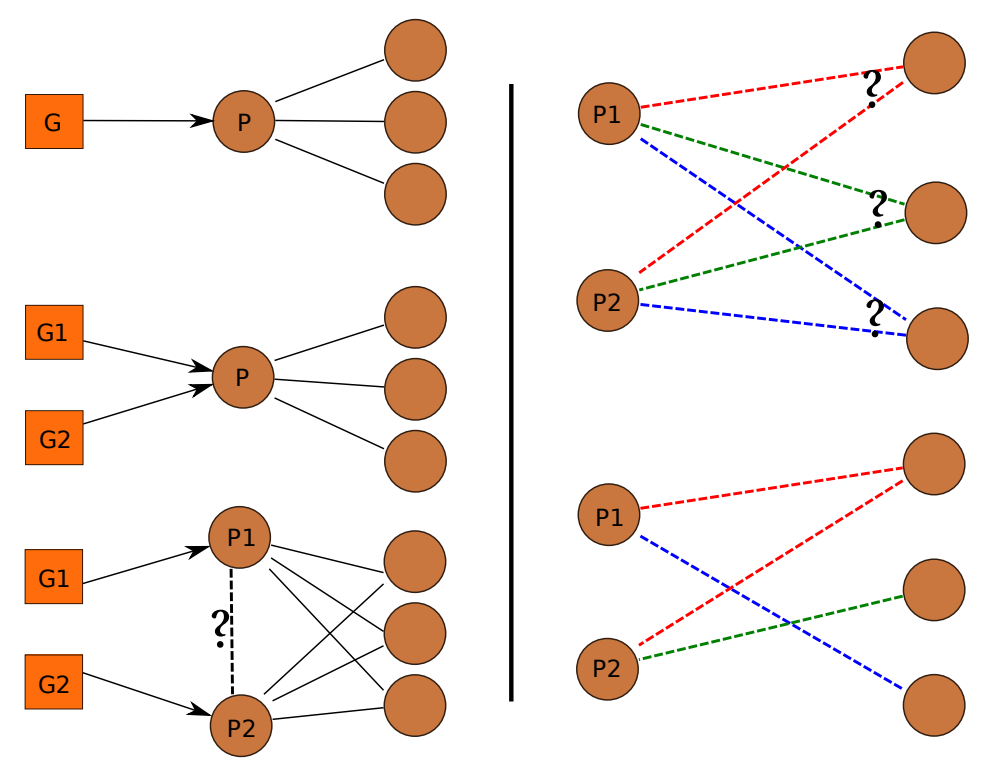

Figura 2.8.1: À esquerda o passo de duplicação: os genes duplicados dão origem à novas proteínas, a princípio idênticas em suas conexões, podendo estabelecer-se uma auto-interação com probabilidade $a$. À direita o passo de divergência: as conexões com outras proteínas são eliminadas com probabilidade $r$, desde que permaneça intacta a conexão de cada outra proteína com pelo menos uma da dupla.

graus, mostrada na Fig.2.8.2, são muito próximas. Como o espaço de parâmetros do modelo é pequeno, pode-se escolher manualmente aqueles que melhor reproduzem o tamanho e distribuição de graus. Neste caso, $a=0.1$ e $r=0.52$ em 6400 iterações.

Parametrizar o modelo pelo conjunto DIP apresenta poucas diferenças, exceto para o coeficiente usual como discutido adiante.

A Fig.2.8.3 apresenta o grau médio dos vizinhos dos vértices em função do grau, que reflete diretamente as correlações de grau nessas redes. Apesar de DupDiv ter sido parametrizada com HC, é esta última que se destaca das demais, ainda que mantendo um aspecto semelhante.

Nos gráficos dos coeficientes de aglomeração, Figs.2.8.4, 2.8.5 e 2.8.6, o conjunto Corr(HC) são valores obtidos através da Expressão (2.7.5) partindo-se das correlações de grau de HC e Rewire(HC) é a rede obtida embaralhando-se as arestas de HC conforme descrito na Seção 2.7.2. Esses valores são assim uma demonstração dos cálculos semi-analíticos e do algoritmo de embaralhamento, provendo o contraste necessário para considerar o efeito da correlação de grau sobre a aglomeração das redes estudadas.

Analisando-se os dados obtidos, na Fig.2.8.4, onde vê-se o coeficiente $C_{k}^{1}$, destacamse três comportamentos. Os modelos configuracionais, $\operatorname{Corr}(\mathrm{HC})$ e Rewire(HC), como esperado tem aglomeração usual quase nula. A rede DIP, assim como o modelo de duplicação-divergência ajustado à rede $\mathrm{HC}$, decrescem monotonicamente mas com valores distintos. Por último, HC destaca-se dos demais pelo comportamento não monótono em $k$. 


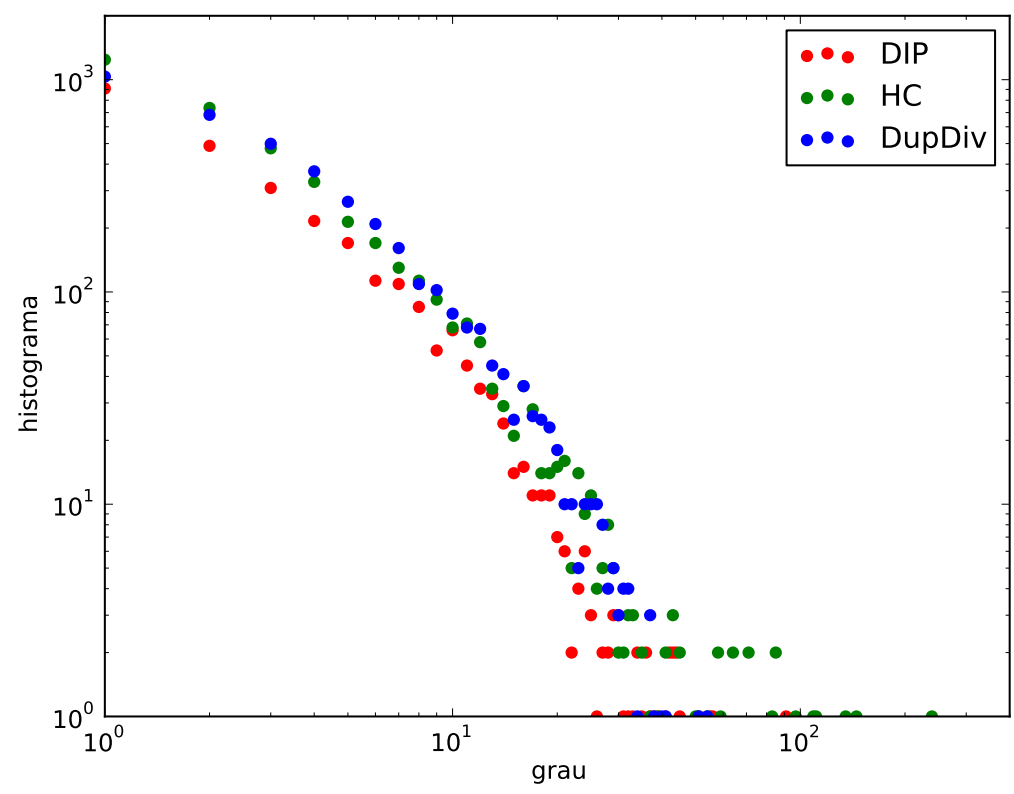

Figura 2.8.2: Histograma de distribuição de graus

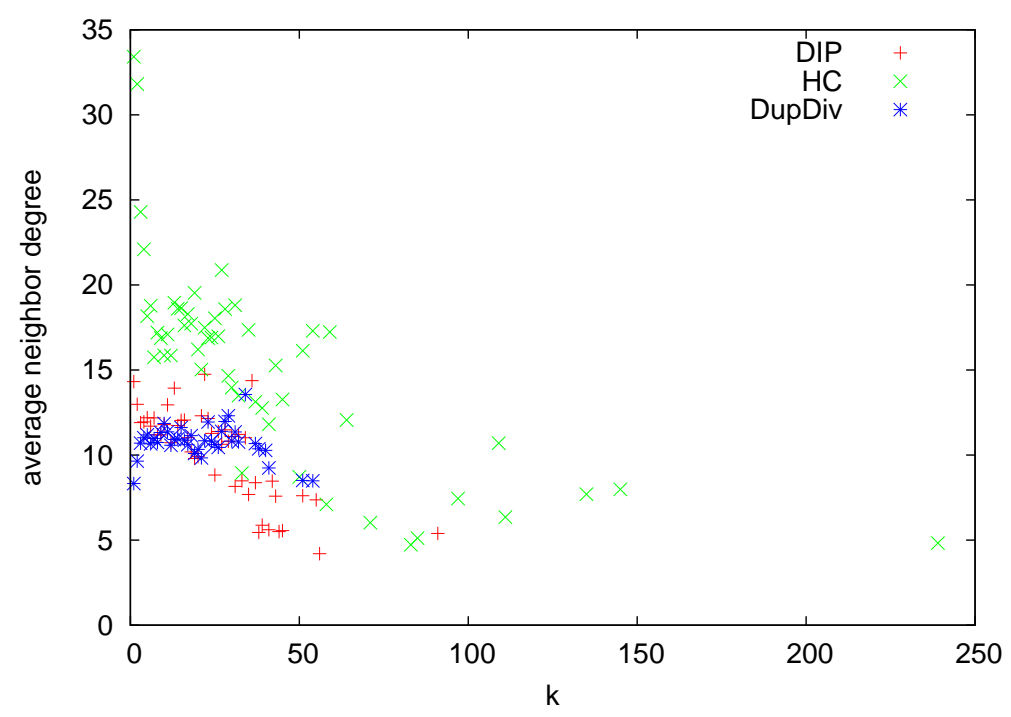

Figura 2.8.3: Grau médio dos vizinhos de vértices de grau $k$ 
Essa divergência precoce da rede HC justifica apresentar o modelo ajustado a ela, para ficar visível não tratar-se de incompatibilidade nos parâmetros. Verificou-se ainda que, se ajustado por DIP, não só a tendência como os valores do coeficiente tornam-se compatíveis entre a rede DIP e o modelo.

Contudo, na Fig.2.8.5 para a segunda ordem de aglomeração, vê-se o modelo de duplicação-divergência partir radicalmente tanto de DIP quanto de HC. Por outro lado, HC e DIP são mais coerentes aqui, e é possível notar a influência da correlação de graus em suas distribuições pelo comportamento dos modelos configuracionais. Quanto a isso, verifica-se ali também a concordância entre os cálculos semi-analíticos e o algoritmo de embaralhamento para o modelo configuracional correlacionado.

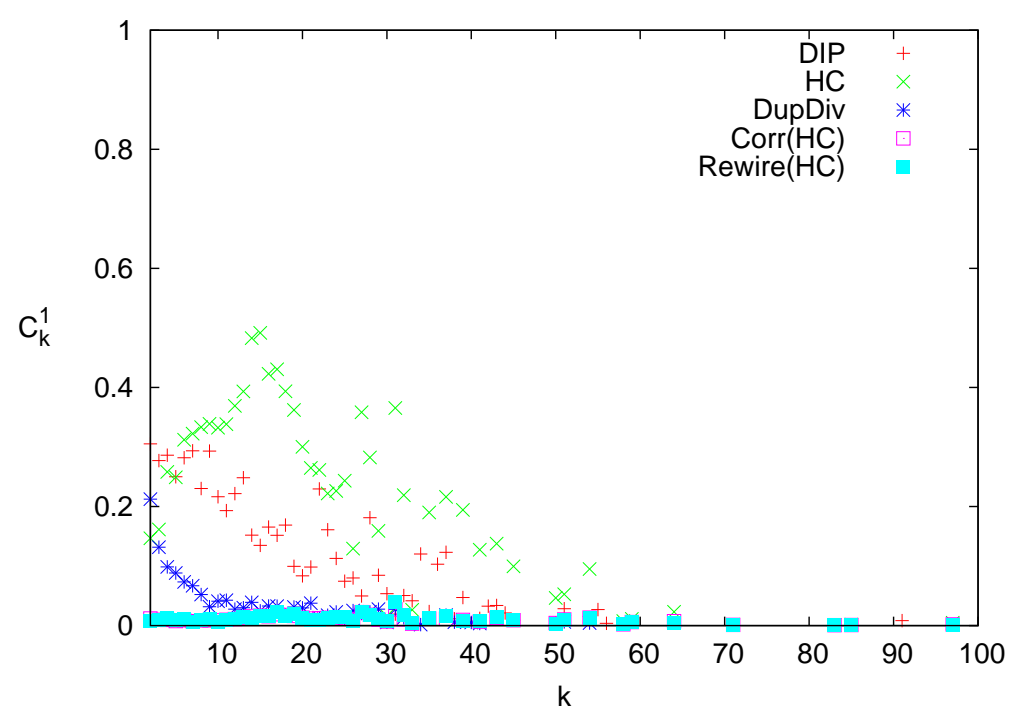

Figura 2.8.4: Aglomeração usual em função do grau $C_{k}^{1}$

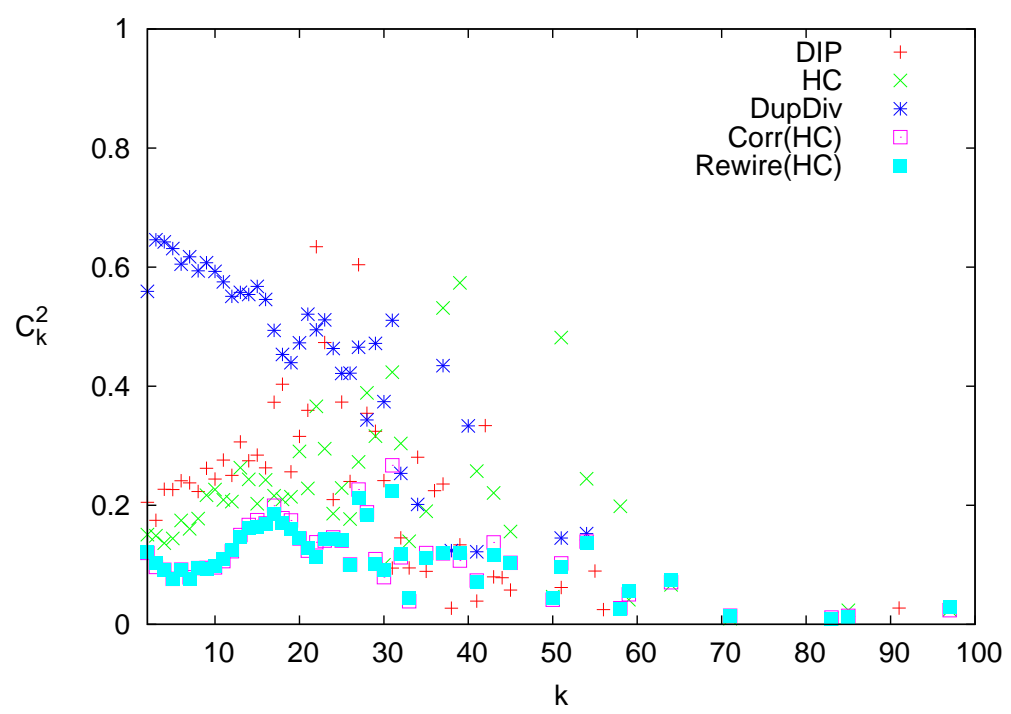

Figura 2.8.5: Aglomeração estendida em função do grau $C_{k}^{2}$ 
A terceira ordem de aglomeração, em Fig.2.8.6, mostra os modelos configuracionais com valores levemente transladados, apesar das curvas alinhadas, consequência do tamanho finito da rede sobre as aproximações do cálculo. Já as redes de interactoma e o modelo de duplicação-divergência exibem pouca aglomeração nesta ordem. Para graus pequenos isso reflete a equação 2.5.2, que limita a soma dos coeficientes pelos muitos ciclos mínimos já encontrados em comprimentos menores. Essa limitação também aparece no valor ligeiramente maior de HC para graus muito pequenos. Para graus grandes $(k>60)$, a pequena aglomeração acumulada implica que os hubs dessas redes fazem parte de muitos poucos ciclos mínimos de comprimento menor que 6.

Assim, conclui-se, por contraste com os modelos configuracionais, que tanto os conjuntos de dados quanto o modelo de duplicação-divergência apresentam uma estrutura de ciclos locais consideravelmente independente da sua distribuição e correlação de graus. Ademais, dentre eles, o conjunto HC apresenta a topologia menos trivial, no sentido de divergir mais dos modelos nulos.

Também observa-se que o modelo de duplicação divergência, apesar de adequarse a várias medidas e apresentar uma topologia de ciclos locais não trivial, mostrase incapaz de reproduzir a estrutura dessa topologia como encontrada na natureza. Esse fato era incerto por medidas do coeficiente usual, pois o modelo é suficiente para reproduzí-lo qualitativamente no caso do conjunto DIP, mas fica claro ao considerarse o primeiro comprimento estendido $C_{k}^{2}$, verificando-se tais diferenças em dois conjuntos de interações, DIP e HC, compilados com métodos bastante distintos.

Quanto à querela entre DIP e HC, as diferenças nos valores e tendências de seus coeficientes, assim como as similaridades do modelo de duplicação-divergência com DIP mesmo quando parametrizado por HC, permitem conjecturar que, para HC estar correto, modelos mais completos para o crescimento dessas redes devem incluir efeitos maiores sobre a aglomeração usual $C^{1}$. Ao mesmo tempo, as diferenças ainda mais marcantes nos comprimentos superiores de aglomeração indica a necessidade

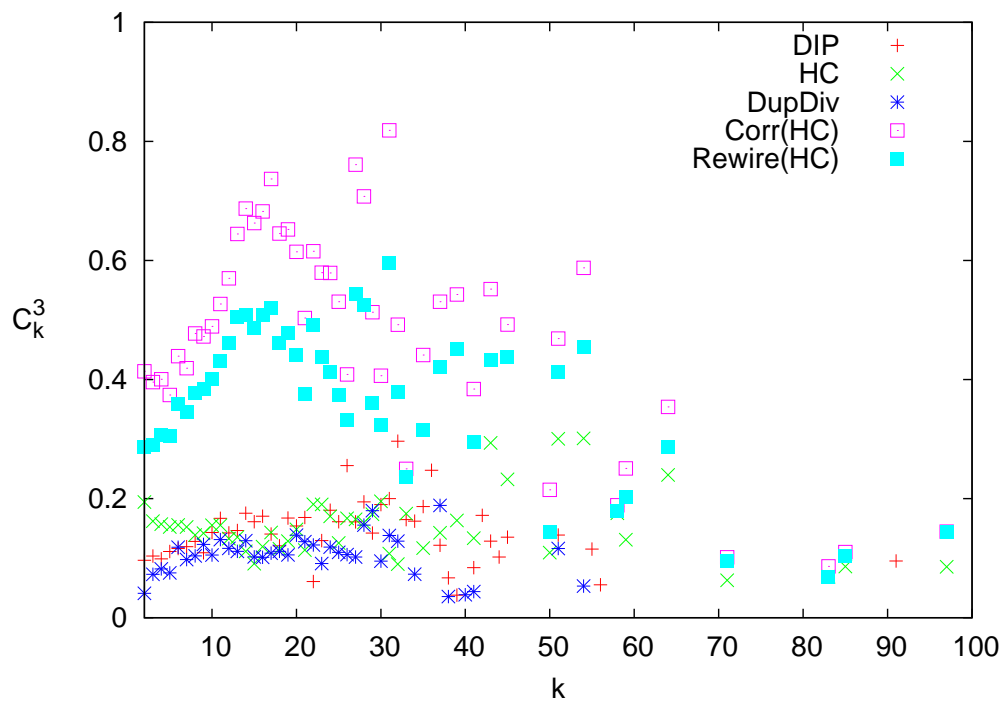

Figura 2.8.6: Aglomeração estendida em função do grau $C_{k}^{3}$ 
desses modelos considerarem processos biológicos que afetem a topologia de ciclos mínimos de forma mais geral.

Assim, ainda que neste momento o coeficiente estendido não seja necessário para diferenciar os modelos e compilações propostas - ainda que já esclareça algumas comparações - ele permite quantificar diferenças mais sutis que podem vir a confirmar ou refutar futuras propostas, muitas vezes não realizadas por falta de uma métrica consistente e detalhada com que compará-las, gerando também uma falsa impressão de satisfação das propostas atuais.

Por fim, o caráter local do coeficiente oferece uma perspectiva alternativa para solucionar a dúvida entre DIP e HC. Dadas as diferenças de aglomeração entre esses conjuntos, ao invés de buscar justificativas globais para suas compilações, poderiase realizar em laboratório um mapeamento com experimentos confiáveis dos ciclos mínimos de algumas proteínas sorteadas. Compararia-se assim esses coeficientes de alta qualidade obtidos com os valores calculados da rede produzida por cada método de compilação, sem depender de um mapeamento global.

\subsection{O coeficiente estendido não é inversível}

O coeficiente de aglomeração estendido informa com maior especificidade a topologia local de um vértice, restringindo as admissíveis variações topológicas ao seu redor. Essa limitação pode ser tal que, em casos extremos, é fácil demonstrar que há uma única topologia local correspondente aos valores do coeficiente:

- Se $C^{1}(v)=1$, portanto $C^{d}(v)=0$ para $d>1$, o subgrafo induzido por $v$ e seus vizinhos é o grafo totalmente conectado de $\delta(v)+1$ vértices, mais comumente conhecido por $K_{\delta(v)+1}$.

- Se $C^{d}(v)=0$ para $d<\alpha$, o subgrafo induzido pelos vértices a distâncias de $v$ menores que $\frac{\alpha+2}{2}$ é necessariamente uma árvore, isto é, não contém ciclos.

Diante disso, parece cabível investigar o que se passa entre os extremos, na transição de clique para árvore à medida que a distribuição do coeficiente desloca-se para termos posteriores da sequência.

Fixado o grau de um vértice, será que a cada sequência de valores do coeficiente corresponde localmente um grafo característico daquela sequência?

As Figuras 2.9.1, 2.9.2 e 2.9.3 apresentam alguns contra-exemplos para essa conjectura. O coeficiente de um único vértice não carrega informação suficiente para definir unicamente a topologia ao redor dele. Mesmo para definições bem restritas de localidade como, por exemplo, o menor subgrafo que contém $v$, seus vizinhos, e ao menos um caminho mínimo entre cada par de vértices, são possíveis múltiplas realizações desse subgrafo, como mostram as figuras.

Tais contra-exemplos revelam o que se pode esperar de quantidades escalares sobre redes em geral. Grafos são objetos discretos multi-dimensionais onde a noção de localidade é muito frágil, não havendo vínculos que permitam uma lente incompleta restringir a diversidade de sua estrutura.

Alinha-se assim esse resultado à observação [Borgatti, 2005] de que a eficácia de métricas em prever a evolução de processos dinâmicos em redes é essencialmente 

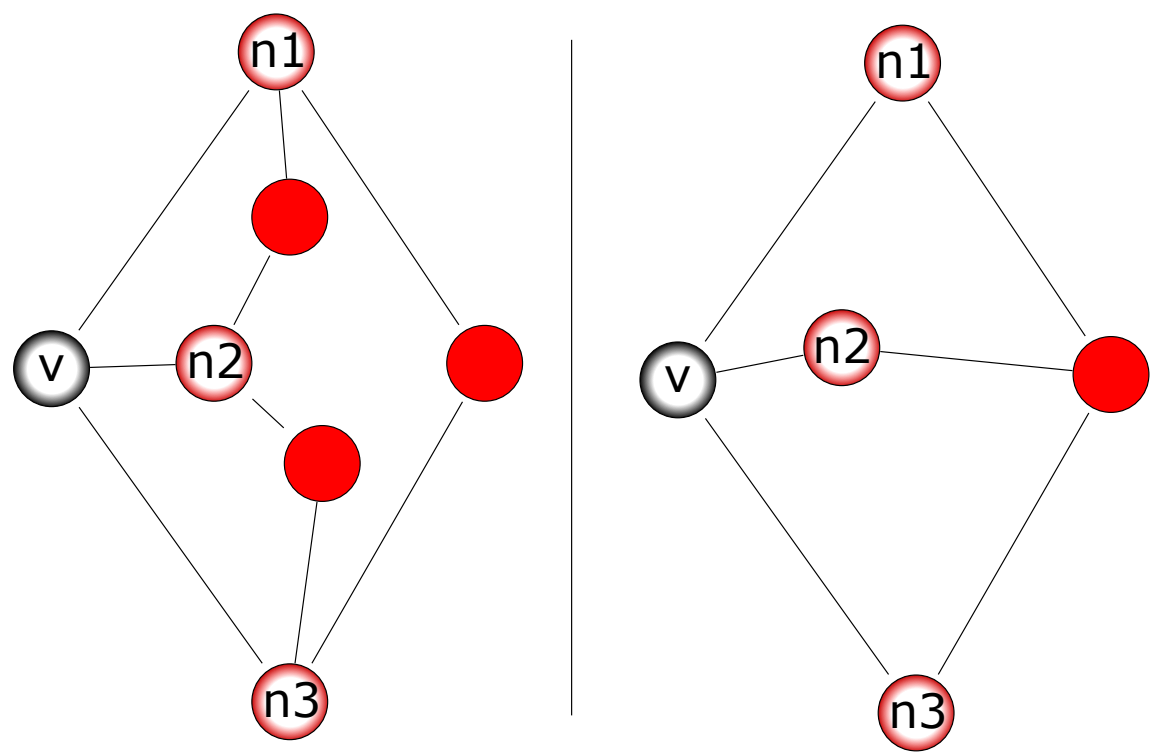

Figura 2.9.1: Mesmo com $\delta(v)=3$ e $C^{d}(v)=0$ para $d>2$, encontra-se exemplos de estruturas locais diferentes que contudo tem o mesmo valor para todos os $C^{d}(v)$.
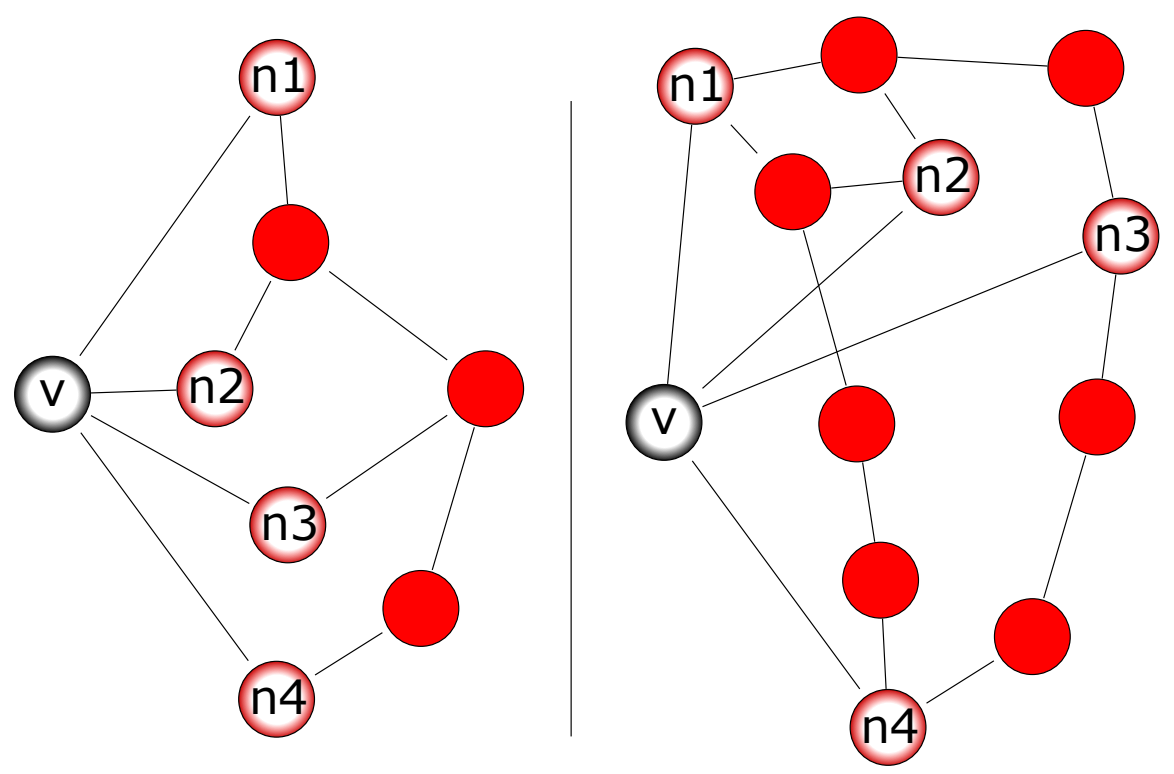

Figura 2.9.2: Ambos os casos têm os mesmos coeficientes, contudo a variabilidade é tamanha que, removendo-se $v$, o grafo à esquerda torna-se uma árvore enquanto o da direita contém mais de um ciclo. 


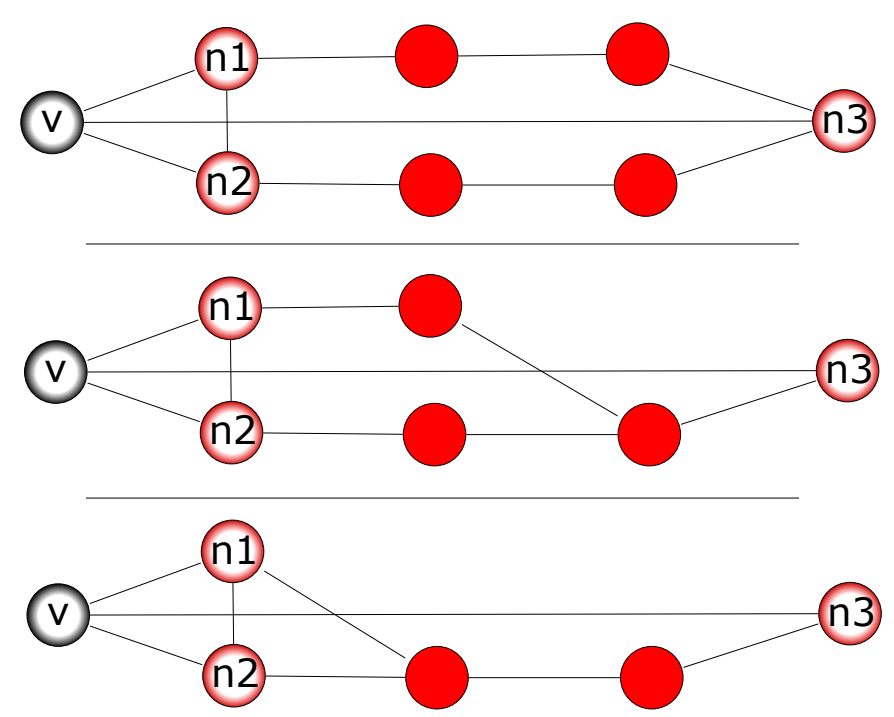

Figura 2.9.3: Uma sequência de exemplos onde todos os $v$ tem os mesmos grau e coeficiente de aglomeração estendido. Essa forma de constuir 3 variantes do subrgafo local pode ser generalizada introduzindo-se, simultaneamente para $n 1$ e $n 2$, vértices intermediários entre estes e seus vizinhos vermelhos. Obtém-se assim exemplos com $d^{\prime}$ variantes e $C^{d^{\prime}}(v)>0$.

específica. Pode a um dado processo corresponder uma métrica adequada, mas uma função de aplicação universal seria indistinta de uma descrição total.

Um enfoque positivo diante disso é que, não podendo ser reduzido a equivalências com estruturas locais, reforça-se a complementaridade entre aglomeração e medidas da frequência de motifs. 


\section{Capítulo 3}

\section{Dinâmica e topologia local num modelo generalizado de contágio}

\subsection{Objetivos}

A finalidade deste trabalho é desenvolver uma metodologia para estudar, através de simulações, processos de contágio social estrategicamente provocados com múltiplas sementes.

O foco será no sucesso de diferentes estratégias de semeadura definidas em termos de propriedades topológicas locais, relativo ao número de sementes necessário para atingir uma adesão significativa e estável ao contágio.

O modelo de contágio será suficientemente genérico para observar tendências e possibilidades a respeito dos diferentes tipos de ambiente e mensagem refletidos em seus parâmetros.

Como pretende-se destacar a metodologia e como são escassos dados com as propriedades desejadas, concentrar-se-á a análise sobre um único exemplo de rede de influências sociais.

O interesse desta linha de pesquisa, além de avançar a compreensão do fenômeno de difusão social em geral, é a médio prazo auxiliar no planejamento de intervenções tanto de interesse público, na difusão de comportamentos e informações para prevenção de doenças, preservação do meio ambiente ou recuperação de catástrofes, como de interesse privado, na veiculação de campanhas publicitárias que prevejam mecanismos de divulgação boca-a-boca.

\subsection{Teorias de influência social e modelos}

A idéia de que nossas escolhas individuais devem-se em parte à influência exercida através de laços sociais remonta aos fundamentos da sociologia, destacadamente à obra de Durkheim [Durkheim, 1895] na passagem do século XIX ao XX. As bases para uma modelagem matemática dessa influência estabeleceram-se meio século depois, partindo dos trabalhos de Paul Lazarsfeld e Solomon Asch.

Matemático por formação, Lazarsfeld contribuiu decisivamente para a metodologia da sociologia, disseminando o uso da estatística e introduzindo a aplicação sis- 
temática de pesquisas amostrais, em particular no estudo da influência interpessoal e dos meios de comunicação [Lazarsfeld et al., 1944]. Realizando a partir da década de 1940 um extenso mapeamento de redes de influência, formulou o modelo do fluxo em duas etapas da comunicação. Segundo este, idéias e opiniões não fluem diretamente da mídia para o cidadão, mas apenas para um grupo mais educado e interessado que, por sua vez, transmite-as para a população geral através de contatos pessoais. A esses grupos, no plural pois a cada campo de influência correspondem grupos diferentes, Lazarsfeld chamou líderes de opinião, e destilou suas qualidades e relações com demais atores [Katz and Lazarsfeld, 1955].

Na mesma década, estudos sobre a resistência de agricultores em adotar novas biotecnologias revelaram que fatores sociais prevaleciam sobre questões econômicas [Ryan and Gross, 1943]. A partir de então, emprendeu-se pesquisas similares em áreas diversas, provocando na década de 1950 outro sociólogo, Everett Rogers, a compilar e analisar conjuntamente casos de difusão de inovações, tecnológicas, agronômicas, médicas e sociais [Rogers, 1962].

Rogers destacou suas similaridades, entre elas a taxa de adesão ao longo do tempo tipicamente gaussiana, ou seja, com poucas adesões no início e um crescimento muito rápido no meio período, que desascelerava apenas com os últimos a aderirem à novidade. Para fins de análise, dividiu essa curva em grupos delimitados pela média e desvio padrão. Por exemplo, aos indivíduos inclusos no primeiro grupo, que aderiram em tempo menor que a média menos o desvio padrão, chamou de adeptos pioneiros. Com divisões como essa, Rogers construiu uma teoria detalhada e, referindose a Lazarsfeld, pôde verificar nesse grupo de adeptos pioneiros a condição de líderes de opinião com relação à inovação respectiva.

Apesar do trabalho de Rogers analisar a difusão somente após completado o ciclo de inovação, limitando-se a uma análise retrospectiva de inovações bem sucedidas, e valer-se apenas de dados da evolução coletiva, ele ainda sugeriu, amparado no formato da curva de adesão e em análises qualitativas, que o mecanismo individual de influência deveria produzir um fenômeno de massa crítica onde, superado um certo número de indivíduos carregando a influência, ela passa a espalhar-se rapidamente.

Já as bases psicológicas para o modelo que irá reproduzir essas qualidades coletivas surge mais cedo nos anos 1950, em uma série de experimentos conduzidos pelo psicólogo Solomon Asch [Asch, 1956]. No mais icônico deles, um grupo de oito alunos é interrogado sobre qual de três linhas tem o mesmo comprimento de uma quarta. A resposta é óbvia, contudo sete deles foram instruídos a darem a mesma resposta errada, e verificou-se que o oitavo escolhia seguir o grupo 35\% das vezes. Asch também observou, ao diminuir a fração dos colegas dando a resposta errada, que o efeito enfraquecia rapidamente, mas não mudava se o número de colegas era alterado mantendo a fração constante.

Um aluno de Asch, Stanley Milgram, deu uma contribuição diversa ao tema na década de 1960. Seus famoso experimento dos seis graus de separação [Travers and Milgram., 1969] oferece sustentação experimental à alegação de que um processo de contágio interpessoal pode atingir uma escala global sem a participação da mídia de massa.

Mas apesar de bem definidas as bases no início dos anos sessenta, essas idéias só seriam sintetizadas em modelos matemáticos, chamados modelos limiares, nos anos 
1970, com a maior facilidade de cientistas sociais e economistas acessarem computadores.

Modelos limiares para difusão social, seguindo os experimentos de Asch, definem a influência que um indivíduo sofre para adotar um comportamento como a fração dos seus contatos sociais que já o adotam. Também determinam para cada indivíduo um limiar, tal que, se a influência sofrida o ultrapassa, ele passa a também adotar o comportamento. O resultado desses modelos, de acordo com o estipulado por Rogers, é uma situação de massa crítica onde, se os limiares distribuírem-se normalmente, conduz a uma taxa de adesão também gaussiana ao longo do tempo [Granovetter, 1978].

Mark Granovetter, reconhecido por estabelecer a moderna sociologia econômica, foi um grande proponente desses modelos, utilizando-os para melhor entender revoltas, segregação urbana e a formação da opinião pública [Granovetter, 1978, Granovetter and Soong, 1988].

Além dos modelos limiares, há uma outra família de modelos de contágio, até mais tradicional, que busca descrevem epidemias biológicas. São os modelos SIR, SIS e variações [Bailey, 1975]. Apesar de ambos serem utilizados para estudar dinâmicas na sociedade, são os modelos limiares que explicitam a divergência mais comum entre epidemias biológicas e sociais, pois enquanto naquelas cada exposição a um indivíduo infectado age isoladamente, nestas é o acúmulo de várias interações que determina a probabilidade de um indivíduo infectar-se. O modelo generalizado utilizado neste trabalho, descrito adiante, tem características que permitem interpolar esses dois mecanismos, descrevendo assim uma variedade maior de processos sociais.

\subsection{Intervenções com múltiplas sementes}

Este estudo dá sequência a um trabalho anterior de Watts e Dodds [Watts and Dodds, 2007], que estudaram epidemias espontâneas, deflagradas por um único indivíduo, com um modelo de contágio muito simples em redes simuladas. Seu objeto são contágios provocados estrategicamente através da inseminação de vários indivíduos, com um modelo de contágio generalizado proposto também por Dodds e Watts [Dodds and Watts, 2004], em uma rede extraída de interações reais entre seres humanos.

A intenção é aproximar as simulações da realidade ao ponto de permitir investigar afirmações simples em uma multiplicidade de contextos. Considera-se o preparo e análise de intervenções empíricas pois, além dos benefícios de sua aplicação, tais intervenções tem grande interesse científico. Dada a natureza errática e multiplexada da comunicação humana, há quem defenda que tais intervenções são a única arena onde pode-se esperar o controle experimental necessário para estabelecer conexões sólidas entre o micro e o macro dos processos de contágio social. [Valente, 2005]

Apesar da importância, poucos estudos de simulações caminharam nesta direção de intervenções com múltiplas sementes e apenas com modelos muito simples. Tão simples que lhes permitem formular soluções heurísticas para o melhor conjunto a ser escolhido, com certas garantias de otimalidade [Kempe et al., 2003, Kempe et al., 2005], ainda que baseadas em algoritmos gulosos que requerem conhecimento completo da rede. Essa vantagem será aqui descartada, em favor de desenvolver uma 
metodologia para modelos mais complexos e estratégias de semeadura aplicáveis em condições experimentais com conhecimento limitado.

Formalmente, o estudo das estratégias de semeadura corresponde ao estudo da estabilidade de uma dinâmica com relação às condições espaciais iniciais. Nos trabalhos anteriores sobre o modelo generalizado não se o considera em uma rede, mas num contínuo de ocupação da população. Nessas condições, deriva-se uma descrição dos pontos críticos do sistema e suas bifurcações, demonstrando a existência de algumas classes universais com respeito à sua massa crítica. [Dodds and Watts, 2004, Dodds and Watts, 2005]

Transpor esse problema para redes complexas, um espaço discreto, heterogêneo e multidimensional, e ainda para redes sociais, onde a estrutura de ciclos é preponderante [Newman and Park, 2003], torna os conceitos de ocupação e massa crítica tão menos úteis quanto são múltiplas as possíveis escolhas de um número de vértices e conexões do grafo, equivalentes nesses termos mas estrutural e dinamicamente distintas. Assim, considerado isso diante de sua vocação eminentemente aplicada, este trabalho toma um caminho um tanto prosaico, abrindo mão de derivações analíticas em favor da experimentação computacional. 


\subsection{O modelo generalizado de contágio}

Em 2004, Dodds e Watts [Dodds and Watts, 2004] introduziram um novo modelo de contágio, com parâmetros adicionais que permitem interpolar os modelos epidemiológicos e limiares. A principal motivação para essa generalização foi o reconhecimento de que seres humanos não avaliam o total da sua rede de contatos instantaneamente, nem consideram cada informação captada indefinidamente. Para refletir isso, introduz-se nos agentes a avaliação da prevalência de contágio nos contatos através da acumulação limitada de amostragens aleatórias individuais. como será detalhado adiante.

O modelo utilizado aqui admitirá ainda uma generalização adicional, a fim de contemplar diferenças no envolvimento dos papéis de influenciante e influenciável. No modelo de Dodds, e de fato na grande maioria dos modelos de difusão que se estuda, a capacidade de influência de um indivíduo é ilimitada, podendo influenciar, a cada unidade de tempo, tantos outros quantas oportunidades tiver. Isso claramente não condiz com a realidade de contágios que requeiram alguma transferência de conhecimento, debate ou convencimento, como geralmente é o caso das aplicações de interesse público. Para refletir esse fato, introduz-se nos agentes um limite de atenção disponível, podendo estar este balanceado a favor de influenciar ou ser influenciado.

Os indivíduos neste modelo podem estar em duas condições: Susceptível (S) ou Infectado $(I)$. Um terceira condição, Removido $(R)$, pode ser incluído, mas este trabalho ocupar-se-á apenas do ciclo SIS. Portanto um indivíduo infectado, ao recuperarse, torna imediatamente a estar susceptível ao contágio. Além desta, algumas outras simplificações do modelo serão adotadas, conforme descrito adiante, para dar foco àqueles parâmetros ou combinações que entende-se mais relevantes.

Ao longo do texto, chamará turno a atualização de um único indivíduo e iteração o passo referente à unidade de tempo, que compreende a atualização de todos.

A idéia básica do modelo é que, a cada turno, um indivíduo Alice busca interagir com alguém que pode influenciá-lo. Alice escolhe aleatoriamente entre seus contatos, correspondendo no grafo aos seus vizinhos de saída, até encontrar um vizinho, Beto, que tenha disponibilidade. Encontrando-o, se Beto estiver Infectado há uma probabilidade de exposição de Alice contrair uma dose de infecção. Se o volume das doses acumuladas por Alice superar seu limiar de dose, ela torna-se Infectada; mas se estiver abaixo e Alice já estiver Infectada, há uma probabilidade de recuperação para Alice recuperar-se tornando Susceptível. Ao final, a disponibilidade de Beto é reduzida em um. E ao início de cada turno, remove-se de cada indivíduo as doses adquiridas há mais tempo que sua memória. Ao final da iteração, recupera-se a disponibilidade de todos de acordo com o balanço de tempo.

Ao longo do texto, ao referir-se aos acontecimentos de um turno, chamará influenciável o indivíduo no papel de Alice e influenciante aquele no papel de Beto.

\subsubsection{Parâmetros do modelo}

Os parâmetros do modelo, como destacados acima, são os seguintes: 


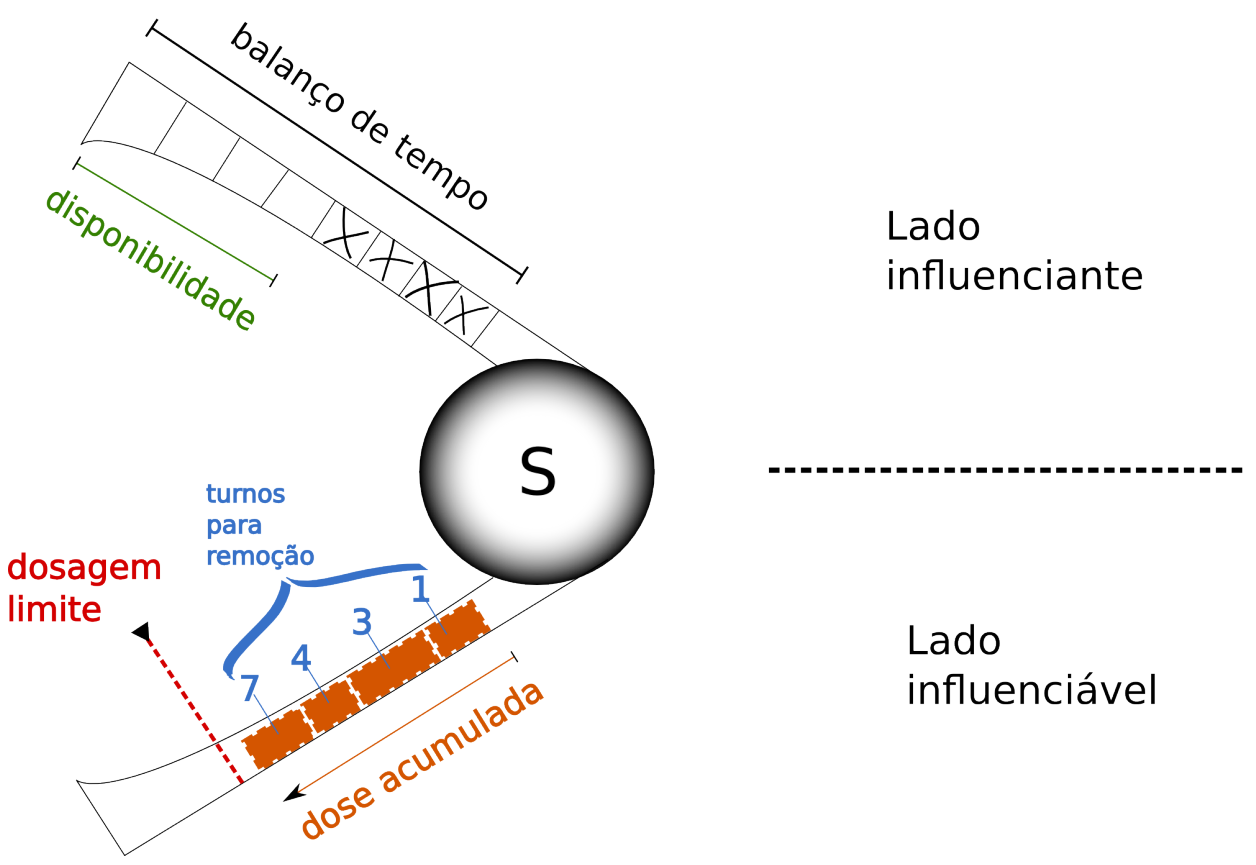

Figura 3.4.1

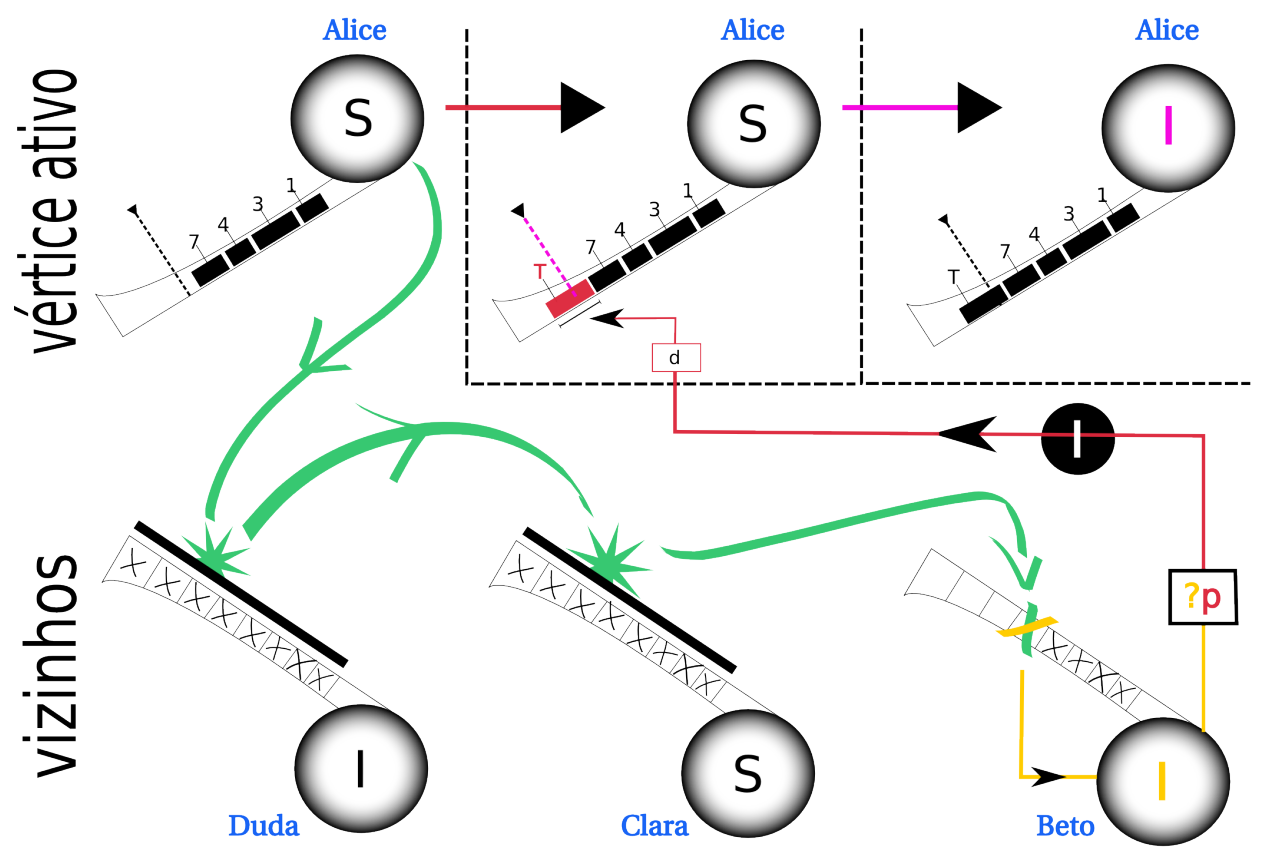

Figura 3.4.2 
d dose de infecção, o volume de influência transmitido em uma interação.

$p$ probabilidade de exposição, a chance de um indivíduo contrair uma dose ao contactar um indivíduo Infectado.

$T$ memória, o número de turnos que uma dose adquirida permanece acumulada.

$D^{*}$ limiar de dose, o valor a partir do qual o volume das doses acumuladas torna um indivíduo Infectado.

$r$ probabilidade de recuperação, a chance de um indivíduo Infectado com volume de doses acumuladas menor que seu limiar de dose recuperar-se ao final do seu turno.

$\tau$ balanço de tempo, se positivo, corresponde à disponibilidade do indivíduo, recuperada a cada iteração; se negativo, o indivíduo tem disponibilidade 1, recuperada a cada $\tau$ iterações.

Outras definições relevantes são:

$v_{i}$ indivíduos, indexados por um índice inteiro não negativo $i$.

$D\left(v_{i}\right)$ volume das doses acumuladas, a soma das doses contraídas por um indivíduo nas últimas $T$ iterações.

$s\left(v_{i}\right)$ condição de um indivíduo: Susceptível $(S)$ ou Infectado $(I)$.

$d_{t}\left(v_{i}\right)$ dose no tempo $\mathbf{t}$, o valor de dose que um indivíduo recebeu na unidade de tempo $t$, correspondendo à $t$-ésima iteração.

$\alpha\left(v_{i}\right)$ disponibilidade, o número de vezes que um indivíduo pode interagir como influenciante a cada iteração.

$\beta\left(v_{i}, v_{i^{\prime}}\right)$ influência sobre $v_{i}$ de $v_{i^{\prime}}$, a probabilidade de $v_{i}$, como influenciável, escolher interagir $\operatorname{com} v_{i^{\prime}}$.

\subsubsection{Interpretação dos parâmetros}

O significado desses parâmetros variará dependendo da aplicação e de como dela deriva-se um limiar, contudo é útil apresentar uma ilustração tentativamente inespecífica antes de formalizá-lo. Assim, dos parâmetros, o valor de $d$ corresponde à eficiência da persuasão do influenciante; $p$ representa a chance do encontro expôr o meio de contágio, seja abordar um tema numa conversa ou permitir observar um produto em uso; $r$ é a facilidade de alguém que perdeu o interesse deixar de difundir o contágio, indo do simples descartar de um item de vestuário, à dificuldade em desvencilhar-se de um padrão de comunicação proprietário, à impossibilidade de ocultar ou reverter algumas formas de arte corporal. 
$T$ e $D^{*}$ precisam ser interpretados em conjunto e relativos ao valor típico da dose, $\langle d\rangle$. Indivíduos podem ser resistentes ou conservadores a uma determinada influência. Um indivíduo muito resistente terá $\frac{D^{*}}{T\langle d\rangle} \approx 1$, ou seja, precisa receber doses constantes para manter-se acima do limiar, independente da sua memória. Já um indivíduo conservador não precisa ser resistente, basta que $T \gg 1$, ou seja, que leve em consideração um período grande de observação do ambiente. $\mathrm{O}$ indivíduo de curta memória, mesmo se resistente, reage rapidamente se o ambiente passa a favorecer o cotágio, enquanto um conservador, mesmo se pouco resistente, levará algum tempo para reagir à mudanças no ambiente.

Por fim, $\tau$, o parâmetro introduzido neste trabalho, determina quem entre o influenciante e o influenciável deve investir mais tempo para que se transmita o contágio. Assim, no caso da difusão de uma moda de indumentária onde basta a simples observação de um pelo outro, $\tau \gg 1$ pois um influenciante pode, numa mesma unidade de tempo, contagiar vários influenciáveis. Por outro lado, em qualquer caso que necessite transferência de conhecimento, como ao difundir o uso de uma ferramenta, $\tau$ tenderá a 1 , podendo até ser menor em casos onde o contágio dependa de algum recurso escasso, por exemplo na difusão de uma nova técnica cirúrgica.

Relevante para essa questão do balanço de tempo é o trabalho de David R. Gibson [Gibson, 2005], em que considerações a respeito de conflitos entre agendamentos de encontros levam a um modelo com restrições semelhantes ao caso $\tau=1$, mas estudando contágios espontâneos. Por outro lado, o modelo de Watts e Dodds, sem restrições de atenção, corresponde a $\tau=\infty$. Portanto o papel formal desse parâmetro é de interpolar as dinâmicas desses dois modelos.

\subsubsection{Memória, limiares e epidemias}

Como observado anteriormente, a principal contribuição do modelo de Dodds e Watts [Dodds and Watts, 2004] foi apresentar os casos clássicos de modelos de contágio, epidemiológico e limiar, como pontos extremos de um modelo mais geral, conec-
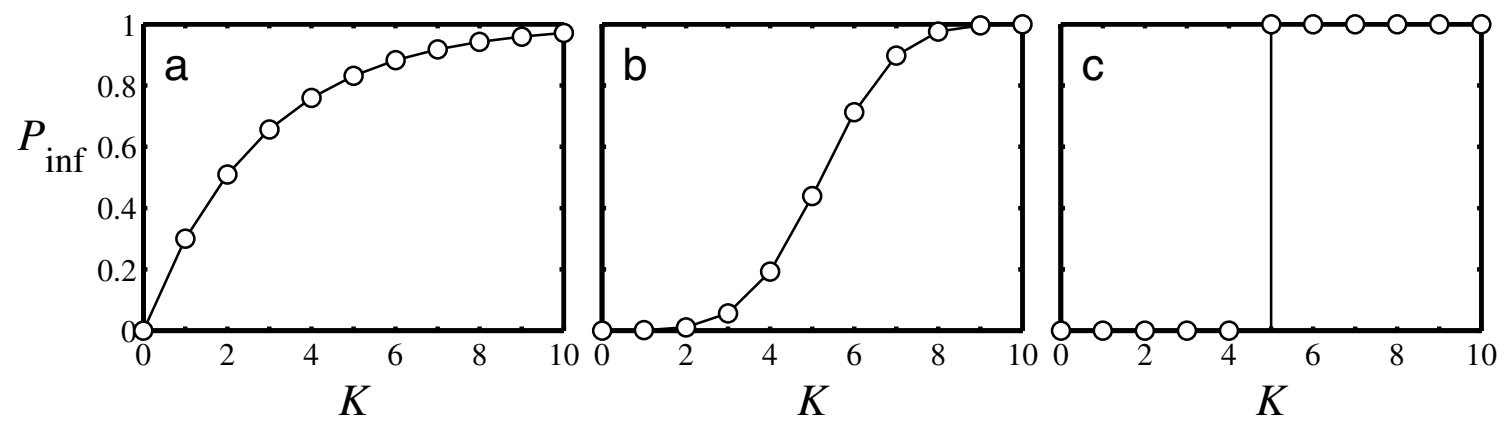

Figura 3.4.3: Probabilidade de infectar-se após $T$ interações, sendo $K$ delas com indivíduos infectados, para $T=10$. (a) Modelo epidemiológico, $d=$ $D^{*}=1$ e $p=0.3$. (b) Um modelo intermediário, $D *=5, p=1$ e as doses $d$ extraídas de uma distribuição lognormal com média 1 e variância 0.4333 . (c) Modelo limiar, com $d=1, D^{*}=5$ e $p=1$. (Fonte: [Dodds and Watts, 2004]) 
tados pelo parâmetro de memória $T$.

Os modelos epidemiológicos correspondem ao caso onde uma única dose basta para o indivíduo infectar-se, ou seja $d=D^{*}=1$. Nesses casos, $T$ determina apenas a permanência mínima na condição Infectado e $p$ é reinterpretado como a probabilidade de transmissão da epidemia numa única interação, não havendo o passo de exposição. Essa probabilidade compõe-se, após um sequência de interações, como vários eventos isolados de infecção e, portanto, de forma estritamente crescente com o número de interações com infectados.

Os modelos limiares correspondem ao caso onde cada interação gera uma exposição, portanto $p=1$, porém o contágio ocorre apenas após um certo número de exposições, ou seja $d=1,1<D^{*} \leq T$. Com isso, a probabilidade de infecção após uma sequência de interações cresce como um degrau com o número de interações com infectados, sendo 0 enquanto $D<D^{*}$ e 1 após a dose acumulada cruzar o limiar.

Note-se que os parâmetros $T$ e $D^{*}$ ficam indefinidos. Isso ocorre pois, nos modelos limiares tradicionais, a cada turno a presença do contágio é avaliada simultaneamente em todos os contatos de um indivíduo. Já no modelo de Dodds, seguindo a tradição epidemiológica, essa avaliação é um processo dinâmico envolvendo uma sequência de interações entre pares. Deve-se, portanto, entender a correspondência proposta em termos do comportamento desses modelos e não de sua dinâmica específica.

A Figura 3.4.3, extraída de [Dodds and Watts, 2004], apresenta a evolução da probabilidade de contágio após seguidas interações com contatos infectados, para parâmetros do modelo generalizado correspondendo aos dois modelos tradicionais e um caso intermediário.

\subsubsection{Descrição algorítmica e implementação}

O modelo será descrito aqui com as características exatas que serão utilizadas nas simulações. Por clareza, esta descrição busca apenas ser precisa e objetiva, sem preocupar-se em refletir as estruturas e detalhes de implementação do algoritmo. $\mathrm{O}$ código efetivamente utilizado foi desenvolvido como parte deste trabalho e pode ser obtido com um módulo para a biblioteca graph-tool [Peixoto, 2006].

Para o grafo $G=(V, E)$, em que os vértices $V=v_{i}$ representam os indivíduos numa sociedade e $E$ contém arestas dirigidas representando as relações de influência entre eles, define-se o processo abaixo.

Nele, os parâmetros $d, m, p, T, r$ e $\tau$ são constantes, $D^{*}$ é uma função dos vértices e $\beta$ uma função das arestas, conforme definidos na Seção 3.4.1. $N_{\text {out }}(v)$ são os vizinhos de saída de $v$. Às condições $S$ e $I$ são atribuídos valores numéricos para facilitar a descrição.

\section{Inicialização}

1. $t=0$

2. $S=0, I=1$ 
3. Para cada $v_{i} \in V$ faça:

(a) $d_{u}\left(v_{i}\right)=0$ para todo $u \in Z$

(b) $D\left(v_{i}\right)=0$

(c) $s\left(v_{i}\right)=S$

(d) $\alpha\left(v_{i}\right)=\tau$ se $\tau>0$, senão $\alpha\left(v_{i}\right)=1$

4. Para cada $v_{i}$ escolhido pela estratégia de semeadura, faça:

(a) $d_{u}\left(v_{i}\right)=d$ para $-T<u \leq 0$

(b) $D\left(v_{i}\right)=\sum_{-T<u \leq 0} d_{u}\left(v_{i}\right)$

(c) $s\left(v_{i}\right)=I$

\section{Iteração}

5. $t=t+1$

6. Para cada $v_{i} \in V$, escolhidos em ordem aleatória, faça:

\section{Turno}

(a) Se $|W|>0$ para $W=\left\{w \in N_{\text {out }}\left(v_{i}\right) \mid \alpha(w)>0\right\}$ :

i. Sorteia-se $w \in W$ com probabilidade proporcional a $\beta\left(v_{i}, w\right)$

ii. Faça $\alpha(w)=\alpha(w)-1$

iii. Faça $d_{t}\left(v_{i}\right)=s(w) d$ com probabilidade $p$

(b) $D\left(v_{i}\right)=\sum_{t-T<u \leq t} d_{u}\left(v_{i}\right)$

7. Para cada $v_{i} \in V$ :

(a) Se $D\left(v_{i}\right)<D^{*}\left(v_{i}\right)$, faça $s\left(v_{i}\right)=S$ com probabilidade $r$

(b) Se $D\left(v_{i}\right) \geq D^{*}\left(v_{i}\right)$, faça $s\left(v_{i}\right)=S$

(c) Se $\tau>0$, faça $\alpha\left(v_{i}\right)=\tau$

(d) Se $\tau \leq 0$ e $(t \equiv 0 \bmod |\tau|)$, faça $\alpha\left(v_{i}\right)=1$

\section{Finalização}

8. Se $t$ atingir um tempo máximo pré-definido $t_{\text {max }}$ ou o número total de infectados $\sum_{v_{i} \in V} s\left(v_{i}\right)$ não se alterar por uma quantidade de turnos pré-definida, interrompe-se o processo. De outra forma, repete-se a Iteração. 


\subsection{A rede de mensagens}

Dados para estudar interações informais na sociedade, como sugerido pela própria informalidade, são de difícil obtenção. Antes da Internet, os conjuntos mais estudados, o mais conhecido deles um registro de recomendações entre médicos, além de pequenos continham fortes componentes instrumentais [Valente, 2005]. Eram, assim, pouco adequados à aplicação no estudo de contágio social.

Contudo, mesmo nos registros digitais não é fácil rastrear ações não instrumentais. A maioria dos serviços oferecidos na Internet dedicam-se a atividades comerciais ou nichos de interesse. Nesse contexo, os sítios de relacionamento, como Orkut e Facebook, destacam-se como fontse privilegiadas de relações neutras. Infelizmente, esses são também os espaços onde há maior quantidade de ruído, como identidades múltiplas ou forjadas e propaganda.

Para realizar este estudo, obteve-se uma rede particularmente apropriada a este fim. Trata-se dos registros de troca de mensagens, durante 26 meses, no sítio de relacionamento Facebook (http: //www. facebook.com/) antes de sua abertura à participação universal. Sua utilidade deve-se a esse período, quando as contas no sistema eram necessariamente associadas a e-mails oficiais fornecidos por uma instituição de ensino superior. Assim, há maior confiança de que os perfis correspondem a indivíduos.

Como os dados obtidos contém centenas de universidades e milhões de usuários, para viabilizar sua computação restringiu-se o estudo a uma delas, consequentemente evitando complicações adicionais por efeito de interações entre diferentes instituições. Dentre aquelas de maior atividade, escolheu-se uma cuja distribuição de graus era mais homogênea, ou seja, onde a participação no serviço era melhor distribuída entre os usuários.

Os dados disponíveis contém registros de três tipos de relação: declarações de amizades, mensagens trocadas e toques trocados. Como observaram Golder, Wilkinson e Huberman [Golder et al., 2006] num estudo sobre esse mesmo conjunto de dados, os toques, que são mensagens sem conteúdo, além de menos frequentes que as mensagens são frequentemente utilizados como uma forma de jogo, podendo distorcer seu significado. Já as declarações de amizade, por serem públicas, sofrerem outras distorçoes de ordem social, amplificadas por não requerer esforço para serem mantidas. O mesmo estudo destacou que as mensagens só eram trocadas entre uma fração dos declarados amigos. Portanto conclui-se que, dentro os três conjuntos, as mensagens trocadas são o indicador mais fiel da força de relacionamentos.

Outra vantagem da rede de mensagens é reportar a assimetria no relacionamento entre dois indivíduos, uma característica evidente em redes de influência social. Há, contudo, que se optar pela direção da influência implicada nas mensagens. Neste trabalho escolhe-se considerar uma mensagem de Alice para Beto como indicação de que Beto pode influenciar Alice. Pode parecer pouco intuitivo a mensagem ser transmitida na direção oposta da influência, contudo confia-se ser esse o caso típico em redes de relacionamento, onde o conteúdo das mensagens é secundário ao seu efeito de chamar a atenção. Esse fato revela-se diretamente no sucesso dos toques [Golder et al., 2006], mas reflete também a noção de que uma relação é mais significativa para quem investe mais esforço nela [Granovetter, 1973], no caso, para quem enviou a 
mensagem. Nisso espelha-se também a dinâmica do modelo, onde a cada turno é o influenciável que busca um contato influenciante para interagir.

\subsubsection{Características}

Antes de processados, os dados foram filtrados de usuários e mensagens atípicos ou indicativos de interferência de propaganda. Foram excluídos: mensagens múltiplas de um mesmo usuário enviadas em intervalos menores que cinco segundos; usuários que enviaram menos de duas mensagens; usuários que receberam menos de duas mensagens. A primeira prescrição vai de acordo com [Golder et al., 2006], as demais devem-se à necessidade de um mínimo de informação a respeito dos sujeitos do processo de contágio, tomando já uma posição bastante permissiva. Feito isso, a rede contém 38407 vértices e 1943459 arestas, logo uma densidade de 50.6 mensagens por indivíduo.

No grafo que será utilizado nas simulações, os vértices correspondem aos usuários do sistema e as arestas às mensagens trocadas entre eles. Arestas paralelas serão desconsideradas. Ao invés delas, o número de arestas paralelas será utilizado no cálculo da influência $\beta\left(v_{i}, v_{i^{\prime}}\right)$ da seguinte maneira:

$$
\beta\left(v_{i}, v_{i^{\prime}}\right)=\frac{\text { número de mensagens de } v_{i} \text { para } v_{i^{\prime}}}{\text { total de mensagens enviadas por } v_{i}}
$$

Ainda considerando as arestas paralelas, portanto correspondendo uma aresta a cada mensagem trocada, a rede apresenta uma distribuição de graus alongada mas bem distante de uma lei de potência, como mostrado à esquerda na Figura3.5.1. A cauda desta distribuição reflete as diferenças na frequência de uso do sistema, entre poucos usuários muito assíduos e muitos ocasionais, mas com um expressivo grupo intermediário.

À direita, na mesma Figura3.5.1, mostra-se a forte correlação entre graus de entrada e saída, isto é, entre o número de mensagens enviadas e recebidas. Como cada
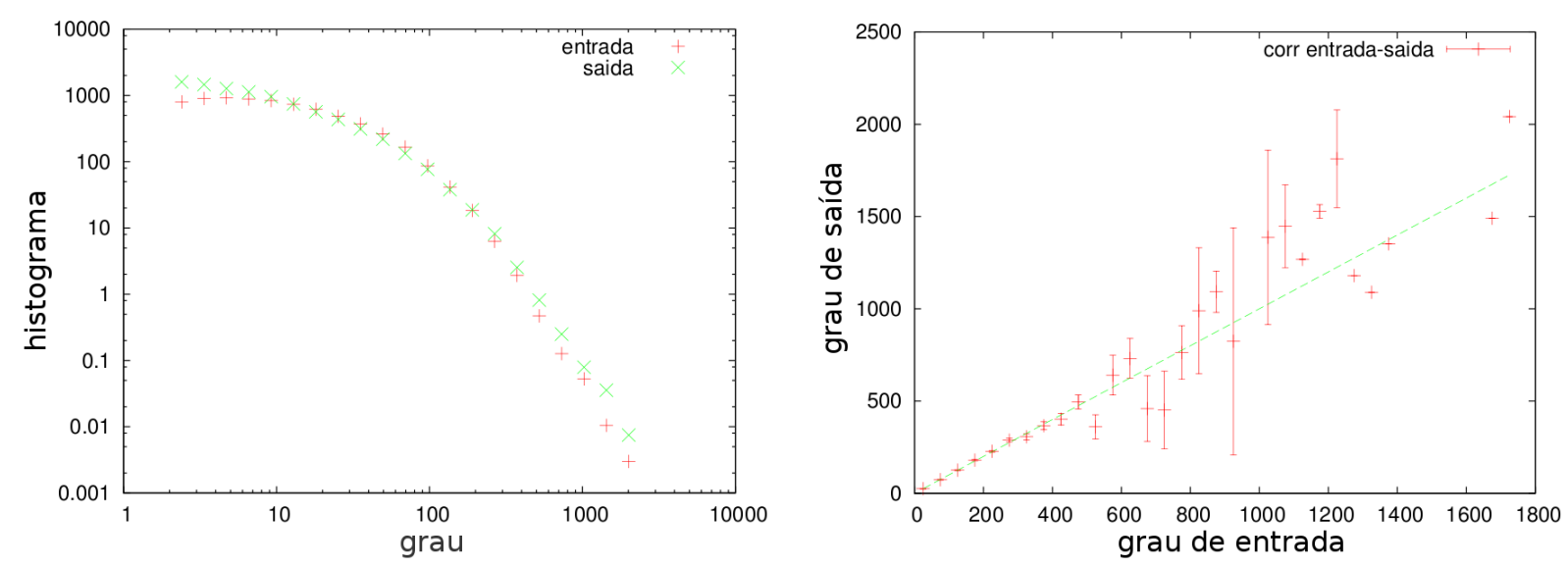

Figura 3.5.1: À esquerda, a distribuição de graus de entrada e saída. À direita, o grau de saída médio para cada grau de entrada dos vértices. Considerase arestas paralelas. 
indivíduo envia um número de mensagens semelhante ao que recebe, a rede está de acordo com a expectativa de interações entre iguais e pode-se excluir a existência de uma dinâmica de mídia de massa, onde poucos falariam para muitos que falam pouco.

A figura 3.5.2 apresenta algumas correlações de grau entre vizinhos na rede. Notase que as curvas em cada gráfico acompanham razoavelmente uma a outra, em acordo com a correlação entre os graus de um mesmo vértice observada na Figura 3.5.1. $\mathrm{O}$ gráfico à esquerda diz respeito ao grau de quem recebeu mensagens de um vértice, portanto vê-se que vértices de grau maior mandaram mensagens para vértices que em média tem grau menor. Apesar do grau dos destinatários crescer com o grau do remetente, esse crescimento eventualmente estagna.

Correspondentemente, o gráfico à direita diz respeito ao grau de quem um vértice recebeu mensagens. O crescimento neste caso é mais acentuado, indicando ser necessário receber muitas mensagens para em média receber mensagens de usuários menos ativos. Há também uma distinção maior entre as duas curvas, revelando uma tendência mais acentuada para receber mensagens de quem envia mais do que para mandar mensagens a quem recebe mais. Em ambos os gráficos, contudo, flutuações tornam-se comuns para graus muito altos que, segundo a distribuição na Figura 3.5.1, tem poucos representantes.

Considerando enfim a eliminação das arestas paralelas na rede, que produz um grafo com 863964 arestas e portanto uma densidade de 22.5, a Figura 3.5.3 mostra dois gráficos de espalhamento, o primeiro do número de mensagens recebidas contra o número de vizinhos de quem recebeu-se e o segundo do número de mensagens enviadas contra o número de vizinhos a quem enviou-se. Estes são os vizinhos, respectivamente de entrada e saída, no grafo simples obtido após a eliminação das arestas, e seus números serão os novos graus de entrada e saída dos vértices.

Vê-se nestes espalhamentos que o número de vizinhos cresce de acordo com o número de mensagens de forma semelhante para ambos os casos, exceto por um
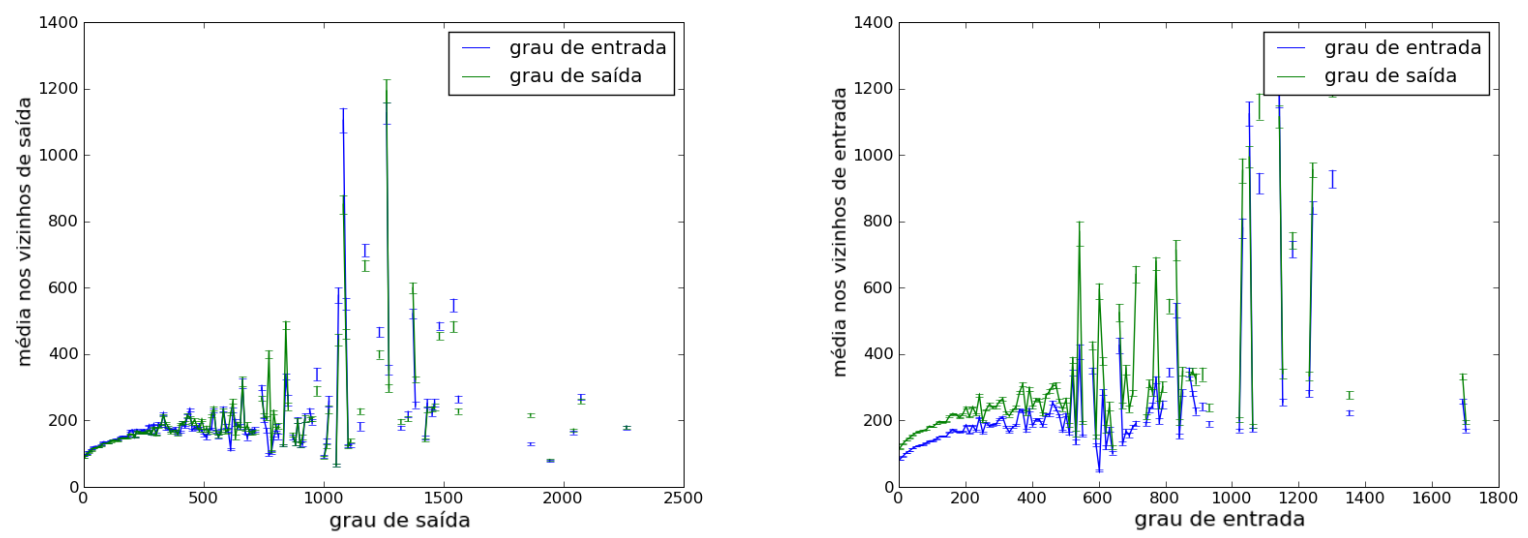

Figura 3.5.2: Os graus de entrada e saída médios dos vizinhos de entrada de vértices com um mesmo grau de entrada, à esquerda, e o mesmo para os vizinhos de saída de vértices com um mesmo grau de saída, à direita. Considera-se arestas paralelas. 


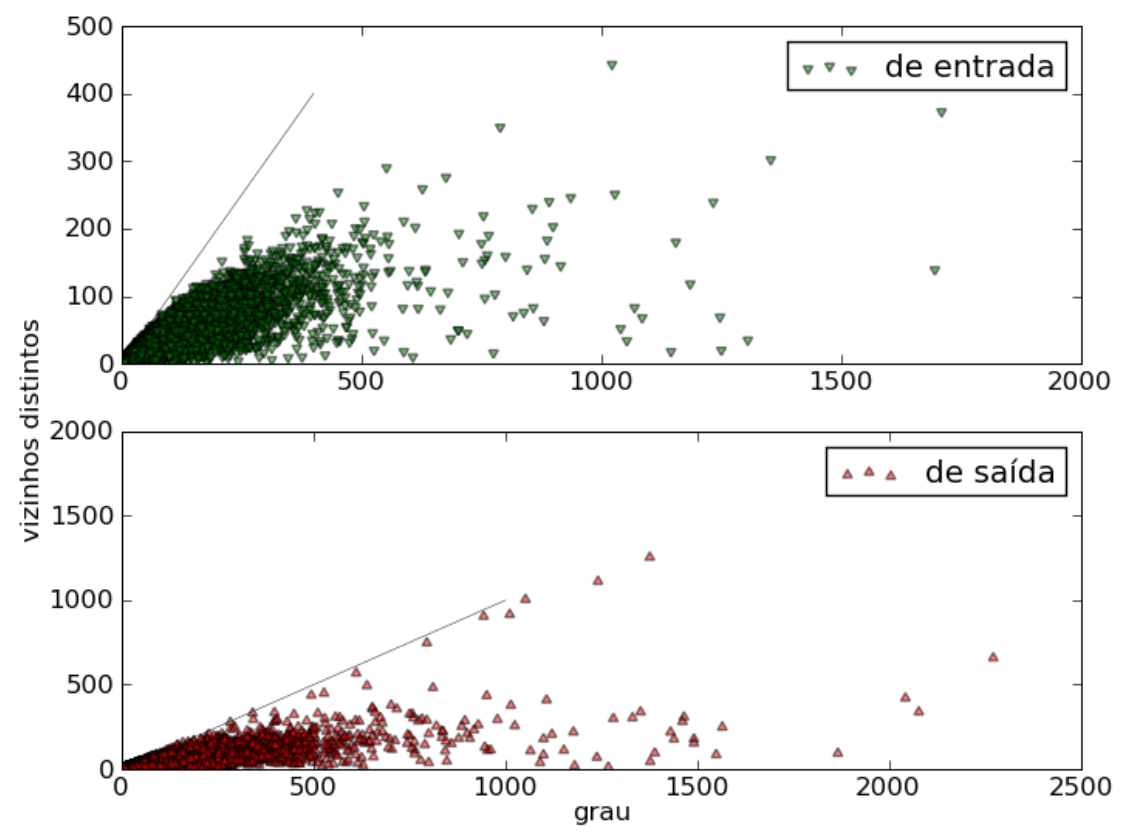

Figura 3.5.3: Espalhamento do número de mensagens enviadas contra número de pessoas a quem elas foram entregues e do número de mensagens recebidas contra o número de pessoas de quem recebeu-se elas. Corresponde, no grafo ainda com arestas paralelas, às diferenças entre o grau e o número de vizinhos, respectivamente de saída e entrada. 
grupo de vértices com número desproporcional de vizinhos de saída. É possível imaginar que esses vértices, mandando mensagens sempre para destinatários diferentes, sejam alguma interferência de propaganda, mas como as mensagens não foram enviadas em rajadas seria precipitado eliminá-los. Nota-se que para cada grau há sempre uma pluralidade de padrões de atividade, ao mesmo tempo em que pareçe haver um limite natural para o número de pessoas com quem mesmo os usuários mais ativos se comunicam, em torno de 150 contatos para recebimento e 250 para envio, excetuado um grupo muito restrito de hiperativos que em ambos os gráficos contam com menos de 50 pessoas. O limite maior no caso do envio pode ser expilcado pela autonomia na ação de enviar mensagens para pessoas diferentes, enquanto para receber mensagens de novos contatos depende-se de uma escolha destes.

Por fim, o perfil de aglomeração da rede é apresentado na figura Figura 3.5.4, contrastado à rede reembaralhada que será discutida a seguir.

\subsubsection{A rede embaralhada}

Além da rede de mensagens, será estudado o modelo na rede obtida através do seu embaralhamento, preservando as correlações de grau, conforme o algoritmo descrito na Seção 2.7.2. O embaralhamento sendo realizado antes da eliminação de arestas paralelas para o cálculo de $\beta$.

Esta rede embaralhada serve assim como um modelo nulo à rede original, permitindo compreender melhor o papel da topologia adicional aos vínculos de correlações de grau através do impacto sobre as estratégias das mudanças nas propriedades e suas correlações.

A Figura 3.5.4 mostra o perfil de aglomeração da rede embaralhada, contrastandoo à rede original. Uma mudança significativa é visível, destacadamente para graus pequenos, com valores de $C_{k}^{1}$ decrescendo enquanto $C_{k}^{3}$ aumenta com o reembaralhamento. Além das consequências dinâmicas detalhadas adiante, isso indica a existência de algum mecanismo adicional para aglomeração entre indivíduos pouco
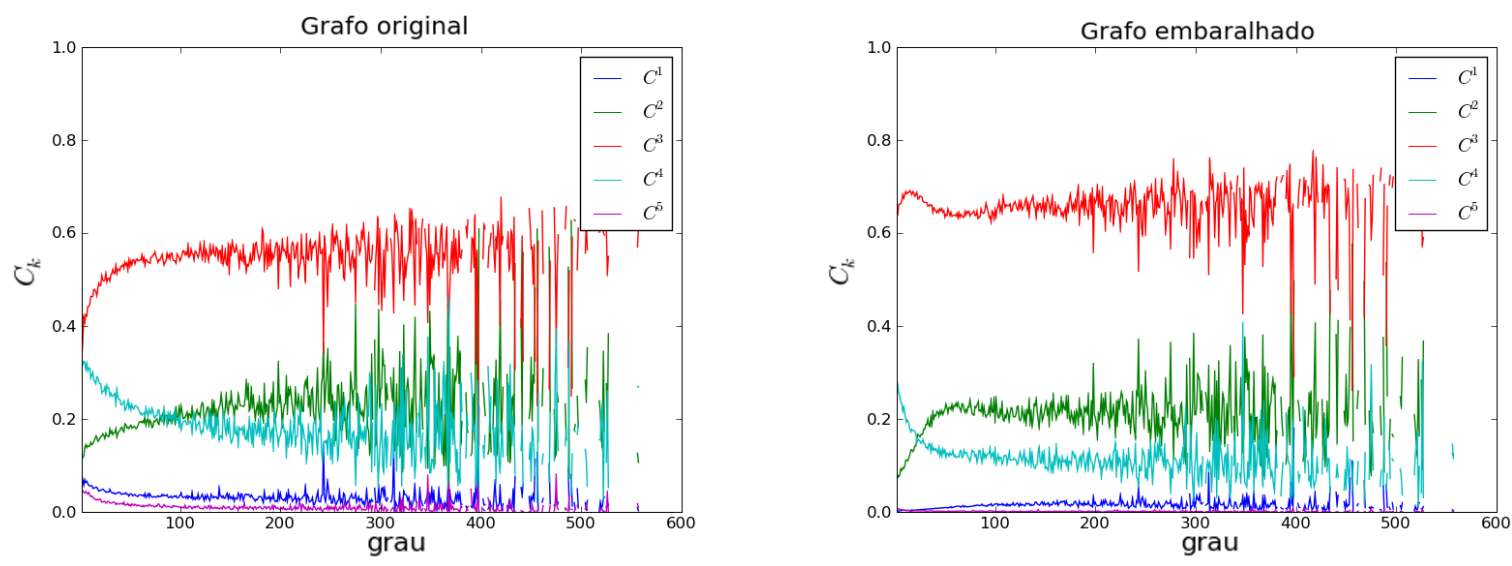

Figura 3.5.4: À esquerda, o perfil de aglomeração da rede original e à direita da rede embaralhada. Observa-se migração da aglomeração para graus pequenos. 
conectados, que pode estar associado ao uso menos frequente do serviço. Já a distribuição e correlações de grau da rede embaralhada são, por construção, as mesmas apresentadas na Figura 3.5.1.

\subsection{Estratégias de semeadura}

As estratégias estudadas serão escolhidas segundo critérios simples de aplicabilidade e relevância. Devem portanto basear-se em combinações de propriedades topológicas mensuráveis localmente e amostragens de fácil realização, priorizando propriedades de importância reconhecida.

O objetivo não será encontrar a melhor estratégia, mas entender como melhor compará-las e quais conclusões pode-se tirar a respeito da relação entre as quantidades topológicas investigadas e o processo de contágio.

\subsubsection{Amostragens}

Um processo amostral geralmente simples e que não privilegia propriedades é escolher aleatoriamente indivíduos da população. Por tais características, essa será a primeira estratégia e servirá como parâmetro de comparação.

Outro processo amostral é o chamado caminhante aletório [Noh and Rieger, 2004]. A viabilidade prática deste processo amostral pode ser comprovada nos vários estudos por amostragem guiada por entrevistados, uma variação do caminhante aleatório, realizadas para estudar prevalência de doenças em populações ocultas [Malekinejad et al., 2008].

Apesar de não ser necessário para aplicar o processo, cabe observar que, para o caminhante aleatório no caso de um grafo não-dirigido, é possível determinar com exatidão sua propriedade privilegiada. A distribuição estacionária da posição de um caminhante aleatório é linearmente proporcional ao grau dos vértices [Noh and Rieger, 2004]. Num grafo dirigido, contudo, não é possível determinar localmente essa propriedade, podendo ela inclusive ficar mal-definida [Page et al., 1999]. Ainda assim, em primeira aproximação, pode-se esperar uma correlação positiva com o grau de entrada de cada vértice.

O terceiro processo amostral será a seleção por ordem de uma propriedade. Escolhida uma propriedade, semeia-se aqueles vértices onde ela é maior, ou menor, elegendo aleatoriamente entre empates. Esse processo não é necessariamente prático, mas é a forma mais direta de entender o que se atinge ao focar a escolha em uma característica.

Um último processo amostral considerado seria a busca em largura, porém ele não será apresentado aqui. Partindo de um vértice $v$, percorre-se inicialmente todos os vértices à distância 1 de $v$, prossegue-se aos vértices à distância 2 e assim por diante. O interesse desse processo seria explorar grupos de vértices próximos, em relação a outros processos onde a escolha pode resultar esparsa. Há, contudo, dois motivos para deixá-lo de lado. Por um lado, algumas simulações com a estratégia mais simples, semeando diretamente os vértices percorridos, apresentou resultados muito fracos se comparada às demais. Por outro, considerar sementes dessa maneira necessariamente transfere o problema para o âmbito de semear comunidades e gru- 
pos coesos, que introduz uma série de outras considerações além do escopo deste estudo. Optou-se assim por não prosseguir com esse processo amostral.

\subsubsection{Propriedades}

As propriedades locais mais interessantes de um vértice em um grafo dirigido, como será qualquer rede de influência, são o grau de entrada, pela relação direta com a probabilidade do vértice ser escolhido como influenciante; o coeficiente de aglomeração, como estudado no Capítulo 2; e uma medida de reciprocidade que será definida a seguir.

A importância do coeficiente de aglomeração vem da sua relação simultânea com redundância e reforço do contágio. Redundância pois, no caso extremo de transmissão instantânea e sem memória nem recuperação, um alto coeficiente de algomeração desacelera a difusão, pois implica uma alta probabilidade da influência ser retransmitida entre indivíduos já Infectados. E reforço pois, à medida que se afasta dessas condições, essa influência redundante pode desempenhar papel importante em facilitar que suficiente influência concentre-se para superar os limiares.

O papel da reciprocidade, cujo conceito é medir o quanto arestas de um grafo dirigido são correspondidas por arestas de pontas iguais mas sentido oposto, assemelhase ao da aglomeração, como observado na Seção 2.3. Porém ela executa-o de forma mais direta e menos abrangente, identificando retornos imediatos de relações entre o vértice e cada vizinho isoladamente. A reciprocidade pode ser abordada de várias maneiras dependendo da aplicação, a definição de reciprocidade utilizada aqui será em função das mensagens trocadas entre os usuários da rede, sendo $m(v, w)$ o número de mensagens enviadas de $v$ para $w$ :

$$
\rho(v)=1-\frac{\sum_{w \in N_{\text {in }}(v) \cup N_{\text {out }}(v)}|m(v, w)-m(w, v)|}{\delta_{\text {in }}(v)+\delta_{\text {out }}(v)}
$$

Assim definida, a reciprocidade $\rho(v)$ varia entre 0 , quando os vizinhos de entrada e saída de $v$ são disjuntos, e 1, quando todos os vizinhos receberam de $v$ o mesmo número de mensagens que lhe enviaram, variando nos casos intermediários linearmente com o módulo da diferença entre esses valores para cada vizinho.

Outras medidas individuais importantes, como centralidade intermediária, centralidade autovetorial e centralidade proximal, não serão investigadas neste trabalho pois requerem informação global da rede [Borgatti, 2005]. Nota-se que estas, no entanto, em primeira ordem tendem a reduzir-se aos graus.

\subsubsection{Definição das estratégias}

A partir de combinações dos processos e propriedades listados formam-se as estratégias de semeadura que serão estudadas.

Abaixo define-se explicitamente quais e como cada estratégia será realizada para a escolha de $n$ vértices. A palavra sorteio será utilizada no sentido de amostragem com probabilidades iguais. Aglomeração refere-se ao coeficiente estendido, com comparação decrescente em suas ordens, por exemplo $(0.1,0.3,0.2, \ldots)>(0.1,0.2,0.7, \ldots)$.

aleatória Sorteia-se $n$ vértices entre todos. 
alto-vizi Escolhe-se os $n$ vértices de maior número de vizinhos de entrada, sorteando em caso de empate.

alto-mens Escolhe-se os $n$ vértices que receberam o maior número de mensagens, sorteando em caso de empate.

alto-reci Escolhe-se os $n$ vértices de maior reciprocidade, sorteando em caso de empate.

alto-aglo Escolhe-se os $n$ vértices de maior aglomeração, sorteando em caso de empate.

anti-aglo Escolhe-se os $n$ vértices de menor aglomeração, sorteando em caso de empate.

andarilho Sorteia-se um vértice e partindo dele caminha-se 5 passos por vizinhos de saída, escolhendo-os proporcionalmente à sua influência sobre o vizinho anterior. Escolhe-se o vértice final.

anda-aglo Caminha-se 5 passos como na estratégia andarilho. Caminha-se mais 5 passos e dentre esses últimos escolhe-se o de maior aglomeração.

Nas estratégias envolvendo caminhos aleatórios, a escolha do número 5 baseia-se na quantidade de passos para as características discutidas na próxima seção estabilizaremse, medida em simulações. A Tabela 3.5 apresentará esses resultados.

\subsubsection{Características}

Cada estratégia definida induz diferentes características topológicas no conjunto semeado. O Apêndice A apresenta os gráficos das distribuições de propriedades desses conjuntos, para crescentes números de sementes, que serão relevantes na discussão dos resultados das simulações. As tabelas abaixo sintetizam essas informações apresentado as médias das distribuições obtidas para diferentes números de sementes nas redes original e embaralhada.

As propriedades são: o número de mensagens recebidas, o número de vizinhos de entrada, as primeira e segunda ordens do coeficiente de aglomeração como definido no Capítulo 2 e a reciprocidade definida pela Equação 3.6.1. Em cada caso, as propriedades dos vértices são calculadas considerando-se a topologia do grafo completo.

Os valores são sempre médias em 10 realizações da estratégia em questão. As tabelas apresentam ainda uma média total, de todos os vértices do grafo.

As Tabelas 3.1 e 3.3 apresentam médias das propriedades para semeaduras de 100 e 3000 vértices na rede original e as Tabelas 3.2 e 3.4 para semeaduras na rede embaralhada.

A observação mais importante a partir desses dados é que, na rede embaralhada, a correspondência entre grau, aglomeração e reciprocidade inverte-se com relação à rede original. Enquanto originalmente alta aglomeração ou alta reciprocidade implicam baixo grau, o embaralhamento passa a associar alta aglomeração ou alta reciprocidade com graus acima da média. Contudo, a estratégia de baixa aglomeração continua associada a graus muito pequenos. 
Essa inversão, que por si justifica o estudo da rede embaralhada, será instrumental como contraste a esclarecer o papel do grau no sucesso das estratégias, adiante na Seção 3.8.2. 


\begin{tabular}{l|ccccc} 
Estratégia & $\mathrm{n}^{\circ}$ mens. & $\mathrm{n}^{\circ}$ vizs. & $C^{1}$ & $C^{2}$ & $\rho$ \\
\hline total & 50.60 & 22.49 & 0.045 & 0.17 & 0.58 \\
\hline aleatória & 54.50 & 23.76 & 0.044 & 0.17 & 0.57 \\
alto-vizi & 520.52 & 192.58 & 0.01 & 0.24 & 0.56 \\
alto-mens & 728.58 & 142.25 & 0.02 & 0.26 & 0.61 \\
alto-reci & 3.06 & 1.95 & 0.06 & 0.10 & 1.00 \\
alto-aglo & 7.98 & 2.06 & 0.95 & 0.04 & 0.72 \\
anti-aglo & 4.69 & 1.35 & 0.00 & 0.00 & $0.84(0.005)$ \\
andarilho & 133.89 & 47.61 & 0.034 & 0.19 & 0.59 \\
anda-aglo & 85.58 & 29.96 & 0.069 & 0.24 & 0.60
\end{tabular}

Tabela 3.1: Rede original. Médias das propriedades induzidas no conjunto semeado por cada estratégia, com 100 sementes, em 10 realizações independentes. Por total entenda-se a média em todos os vértices do grafo.

\begin{tabular}{l|ccccc} 
Estratégia & $\mathrm{n}^{\text {o }}$ mens. & $\mathrm{n}^{\circ}$ vizs. & $C^{1}$ & $C^{2}$ & $\rho$ \\
\hline total & 50.60 & 32.75 & 0.0074 & 0.16 & 0.17 \\
\hline aleatória & 51.22 & 32.62 & 0.0075 & 0.16 & 0.17 \\
alto-vizi & 568.29 & 238.98 & 0.0097 & 0.20 & 0.48 \\
alto-mens & 728.58 & 186.60 & 0.018 & 0.22 & 0.55 \\
alto-reci & 314.62 & 38.12 & 0.036 & 0.19 & 0.84 \\
alto-aglo & 139.20 & 32.63 & 0.13 & 0.37 & 0.42 \\
anti-aglo & 2.99 & 2.99 & 0.00 & 0.00 & 0.0033 \\
andarilho & 137.09 & 66.72 & 0.012 & 0.20 & 0.34 \\
anda-aglo & 145.43 & 64.77 & 0.024 & 0.24 & 0.41
\end{tabular}

Tabela 3.2: Rede embaralhada. Médias das propriedades induzidas no conjunto semeado por cada estratégia, com 100 sementes, em 10 realizações independentes. Por total entenda-se a média em todos os vértices do grafo. 


\begin{tabular}{l|ccccc} 
Estratégia & $\mathrm{n}^{\circ}$ mens. & $\mathrm{n}^{\mathrm{o}}$ vizs. & $C^{1}$ & $C^{2}$ & $\rho$ \\
\hline total & 50.60 & 22.49 & 0.045 & 0.17 & 0.58 \\
\hline aleatória & 50.50 & 22.46 & 0.044 & 0.17 & 0.58 \\
alto-vizi & 198.26 & 80.67 & 0.025 & 0.23 & 0.57 \\
alto-mens & 222.77 & 73.72 & 0.030 & 0.23 & 0.61 \\
alto-reci & 45.61 & 11.29 & 0.068 & 0.15 & 0.86 \\
alto-aglo & 23.53 & 8.79 & 0.22 & 0.24 & 0.60 \\
anti-aglo & 8.06 & 4.10 & 0.00 & 0.0034 & 0.61 \\
andarilho & 117.35 & 43.93 & 0.035 & 0.19 & 0.59 \\
anda-aglo & 83.15 & 30.48 & 0.070 & 0.24 & 0.60
\end{tabular}

Tabela 3.3: Rede original. Médias das propriedades induzidas no conjunto semeado por cada estratégia, com 3000 sementes, em 10 realizações independentes. Por total entenda-se a média em todos os vértices do grafo.

\begin{tabular}{l|ccccc} 
Estratégia & $\mathrm{n}^{\text {o }}$ mens. & nº vizs. & $C^{1}$ & $C^{2}$ & $\rho$ \\
\hline total & 50.60 & 32.75 & 0.0074 & 0.16 & 0.17 \\
\hline aleatória & 50.85 & 32.93 & 0.0074 & 0.16 & 0.17 \\
alto-vizi & 200.77 & 102.30 & 0.013 & 0.21 & 0.43 \\
alto-mens & 222.77 & 94.89 & 0.017 & 0.21 & 0.49 \\
alto-reci & 174.49 & 68.48 & 0.020 & 0.22 & 0.61 \\
alto-aglo & 102.69 & 46.20 & 0.035 & 0.25 & 0.37 \\
anti-aglo & 6.44 & 6.09 & 0.00 & 0.015 & 0.0069 \\
andarilho & 118.71 & 60.59 & 0.011 & 0.20 & 0.32 \\
anda-aglo & 129.28 & 61.43 & 0.022 & 0.23 & 0.40
\end{tabular}

Tabela 3.4: Rede embaralhada. Médias das propriedades induzidas no conjunto semeado por cada estratégia, com 3000 sementes, em 10 realizações independentes. Por total entenda-se a média em todos os vértices do grafo. 
Sobre a questão do número de passos da estratégia andarilha, comparou-se a versão utilizada de 5 passos com uma alternativa de 10 - anda-10 - e também com a distribuição de uma estratégia que sorteia vértices proporcionalmente ao número de mensagens recebidas - prop-mens.

Como mostra a Tabela 3.5, as propriedades mostram-se equivalentes entre as três, com o que também conclui-se que o grau de entrada é um bom preditor da distribuição estacionária de um caminhante aleatório nesta rede. Apresenta-se somente o caso de 100 sementes na rede original, mas resultados semelhantes foram obtidos para 500, 1000 e 3000 sementes tanto na rede original quanto na embaralhada.

\begin{tabular}{l|ccccc} 
Estratégia & no mens. & no vizs. $^{\text {o }}$ & $C^{1}$ & $C^{2}$ & $\rho$ \\
\hline andarilho & 133.89 & 47.61 & 0.034 & 0.19 & 0.59 \\
anda-10 & 135.21 & 47.81 & 0.035 & 0.21 & 0.59 \\
prop-mens & 135.07 & 46.63 & 0.036 & 0.20 & 0.60
\end{tabular}

Tabela 3.5: Comparação das propriedades confirmando estabilização do andarilho em 5 passos. 


\subsection{Resultados}

O resultado das simulações consiste no menor número de sementes para que uma estratégia atinja adesão significativa em equilíbrio estável para dada combinação de parâmetros.

Na prática, considera-se atingida tal meta de equilíbrio significativo quando, executadas 10 realizações independentes do processo de semeadura, após 1000 iterações do modelo de contágio 9 delas obtém adesões à condição Infectado maiores que um terço da população, com a diferença entre suas adesões não ultrapassando $1.25 \%$ do total de indivíduos e com menos de 1\% de variação desse total nos últimos 50 passos de cada uma.

Obtém-se o menor número de sementes a garantir os requisitos acima através de uma busca binária, assumindo para isso que em média o alcance da infecção cresce com o número de sementes.

Os valores investigados dos parâmetros do sistema estão na Tabela 3.6 e todas as suas combinações foram avaliadas para cada estratégia.

As tabelas no Apêndice B mostram com detalhe os valores obtidos. Nelas, os valores inteiros para cada estratégia são o menor número de sementes a atingir os requisitos de equilíbrio significativo enunciados na Seção 3.7 e as porcentagens são a fração média da rede na condição Infectada ao final das suas realizações. Sem qualquer pretensão de rigor, o primeiro valor corresponde a um estado de equilíbrio instável do sistema e o valor percentual corresponde ao equilíbrio estável atingido a partir dele.

Considera-se apenas semeaduras com menos de 12,5\% dos vértices totais da rede, ou seja 4800 deles, valor já acima do que se espera praticável. Quando esse valor não é suficiente, indica-se nas tabelas por um travessão na célula correspondente ao número de sementes e o valor percentual apresentado corresponderá à média dos picos de contágio das realizações para aqueles parâmetros com semeadura de $12,5 \%$ da rede, descartada a realização de menor máximo por compatibilidade com a prescrição de equilíbrio.

Um limite deste estudo é a escolha de valores homogêneos constantes para os parâmetros - iguais para todos os vértices - e de um único valor para $d$ e $T$. A homogeneidade evita inroduzir mais variações dinâmicas e permite, ainda que distanciando-se da realidade, focar a discussão nas propriedades topológicas das estratégias. Quanto à escolha de um único $d$ e $T$, viu-se na Seção 3.4.2 que ambos estão ligados aos valores de $D^{*}$. Como a resistência ao contágio depende de repetidas doses $d$ ultrapassarem $D^{*}$, variar um ou o outro, dada a escolha prévia por valores

\begin{tabular}{|l|r|}
\hline$p$ & $0.2,0.5,0.8$ \\
\hline$r$ & $0.0,0.5,0.8$ \\
\hline$d$ & 1 \\
\hline$\left(T, D^{*}\right)$ & $(4,1),(4,2),(4,3)$ \\
\hline$\tau$ & $-8,-2,1,2,8,64$ \\
\hline
\end{tabular}

Tabela 3.6: Considerou-se as combinações destes valores para os parâmetros. 
constantes, é intercambiável. Já a escolha do valor para $T$, restringindo o estudo a sociedades pouco conservadoras, deveu-se à necessidade de reduzir o tempo computacional.

Um caso onde simulações para $T$ maior serão importantes será analisado na Seção 3.8, com resultados complementares apresentados diretamente na discussão.

Por conveniência, aos três valores possíveis para cada um de $p, r$ e $D^{*}$ referir-se-á por valor baixo, médio e alto daquele parâmetro. 


\subsection{Discussão}

A partir dos dados obtidos, pode-se observar relações entre propriedades topológicas, estratégias e parâmetros do modelo. Nesta seção, recortes dos dados que apresentam resultados relevantes são destacados junto à sua análise.

\subsubsection{Desimportância da topologia quando $D^{*}=1$ e $r=0$ para qualquer $T$}

O primeiro fato a observar-se nos dados é a desimportância tanto da riqueza estrutural da rede com relação ao reembaralhamento quanto das estratégias de semeadura no caso de contágio epidemiológico sem taxa de recuperação. Tanto na rede embaralhada quanto na original e para qualquer escolha de $p$ e $\tau$ a meta de difusão é atingida com um número de sementes muito próximo de 1 . Tais condições correspondem às primeira, quarta e sétima colunas das Tabelas onde $D^{*}=1$ : B.1, B.2, B.3, B.4, B.5 e B.6, para a rede original, e B.19, B.20, B.21, B.22, B.23 e B.24, para a rede embaralhada.

Isso independe do valor ou eventual heterogeneidade de memória $T$, uma vez que ela torna-se irrelevante com essa combinação de valores de $D^{*}$ e $r$ pois uma única dose basta para tornar o indivíduo Infectado e não há possibilidade de recuperação.

Evidentemente, à medida que $p$ tender a zero a difusão tenderá a falhar. Mas o fato que $p=0.2$ garante difusão independente de detalhes da rede, do balanço de tempo ou da população afetada sugere que, supondo-se a fidelidade apenas das correlações de grau nesta rede estudada, a contenção de epidemias virais crônicas, caso de doenças sexualmente transmissíveis como a AIDS, depende fundamentalmente de reduzir drasticamente a taxa de exposição, o que seria representado nesse exemplo pelo uso da camisinha.

Em contágios sociais, essa observação reforça a proposta [Watts and Dodds, 2007] de que um dos principais caminhos para o contágio em populações heterogêneas é através de subredes de indivíduos de baixo limiar.

\subsubsection{Dominância do grau sob balanço de tempo $\tau$ desequilibrado}

O fato mais marcante revelado pelos dados para $D^{*}>1$ é o efeito do grau de entrada das estratégias em sua vantagem relativa às demais, assim como a subordinação desse efeito ao valor do parâmetro $\tau$.

Para discriminar esse efeito, agrupa-se as estratégias segundo seu grau de entrada, caracterizado na Seção 3.6.4. Exceto para as estratégias de grau alto, esse agrupamento dependerá do embaralhamento da rede.

- alto: alto-mens, alto-vizi

- intermediário (original): aleatória, andarilho, anda-aglo

- baixo (original): anti-aglo, alto-algo, alto-reci

- intermediário (embaralhada): andarilho, anda-aglo, alto-algo, alto-reci

- baixo (embaralhada): aleatória, anti-aglo 
Com essa classificação, sintetiza-se as informações das tabelas do Apêndice B na Tabela 3.7, que descreve o comportamento das estratégias com a variação do balanço de tempo nas duas redes com diferentes condições de limiar. Cada entrada, portanto, corresponde a uma tabela do apêndice.

Representa-se ali os diferentes regimes observados por letras maiúsculas que correspondem às descrições a seguir. Nelas, sucesso representa o inverso da posição da estratégia numa ordenação que parta da estratégia que requer menos sementes para atingir a meta de difusão até a estratégia que requer mais e, então, dentre as estratégias que não atingem a meta no limite de sementes, parta da que atinge um maior número de vértices Infectados para a que atinge o menor. Ou seja, quanto maior o sucesso de uma estratégia, mais eficiente foi a difusão partindo daquelas sementes.

- A: o sucesso das estratégias é proporcional ao grau.

- B: o grupo alto não é de maior sucesso que os demais.

- C: vale B e o grupo baixo não é de menor sucesso que os demais.

- D: o sucesso das estratégias é inversamente proporcional ao grau.

- - não ocorre difusão.

Com a síntese da Tabela 3.7, pode-se afirmar que o grau de entrada é o fator determinante para o sucesso das estratégias quado $\tau$ está fora de uma faixa estreita contendo $\tau=1$. Outras grandezas como a aglomeração e a reciprocidade não podem contabilizar indiretamente a variação observada fora de tal faixa pois, como destacado na Seção 3.6.4, o grau de entrada médio das estratégias focadas nessas grandezas inverte-se com o embaralhamento e, assim, onde fossem mais determinantes que o grau, quebrariam a identidade no padrão observado para ambas as estratégias.

\begin{tabular}{r|cc|cc} 
& \multicolumn{4}{|c}{$D^{*}$} \\
& 2 & 3 & 2 & 3 \\
\hline$\tau$ & \multicolumn{3}{|c|}{ original } & \multicolumn{2}{l}{ embaral. } \\
\hline 64 & $A$ & $A$ & $A$ & $A$ \\
8 & $A$ & $A$ & $A$ & $A$ \\
2 & $A$ & $A$ & $A$ & $B$ \\
1 & $B$ & $C$ & $C$ & $C$ \\
-2 & $C$ & $D$ & $D$ & $D$ \\
-8 & $D$ & - & $D$ & -
\end{tabular}

Tabela 3.7: Síntese dos resultados para $D^{*}>1$. Cada entrada corresponde a uma tabela do Apêndice B. Evidencia-se a transição, com o decréscimo de $\tau$, dos regimes de sucesso proporcional ao grau $(A)$ para os regimes de sucesso inversamente proporcional ao grau $(B)$. 
O que parece ocorrer é uma transição na qual, além da difusão genericamente tornar-se mais difícil com os limites impostos pelo balanço de tempo menor, a contribuição de vértices de grau alto é prejudicada à medida em que a contribuição dos vértices de grau baixo é alavancada.

Observando-se a variação com $\tau$ do número de sementes com que cada estratégia atinge a meta, esperaria-se que para uma mesma estratégia esse número crescesse com o decréscimo do parâmetro. Contudo, no caso do grupo baixo, ao transitar do regime A para o regime $\mathbf{B}$ passa-se a precisar de menos sementes do que antes. Nesses casos, portanto, a difusão é facilitada ao diminuir-se o balanço de tempo.

Essa transição, apesar de pouco intuitiva, pode ser entendida em termos da dinâmica do processo de contágio. Com $\tau \gg 1$, vértices com grau de entrada alto terão sempre maior chance de serem escolhidos influenciantes por outros e assim, se infectados, exporão um número maior deles à infecção. O balanço de tempo confere apenas vantagem a estes quando podem influenciar parceiros irrestritamente numa mesma unidade de tempo.

À medida que essa capacidade é restringida com a diminuição de $\tau$, a vantagem diminui, ao ponto que quando $\tau \approx 1$ o efeito será invertido na presença de limiar significativo. Isso ocorre porque vértices muito conectados, sendo requisitados por indivíduos diferentes, em condições de menor disponibilidade acabam diluindo sua influência e as doses que cada parceiro recebe não são suficientes para levá-los ou mantê-los acima do limiar.

Por fim, a indisponibilidade dos vértices de alto grau aumenta as chances dos vértices de menor grau de entrada serem escolhidos como influenciantes, explicando como a difusão numa estratégia que prefira graus menores pode ser facilitada com o decrescimento de $\tau$ : basta que esse ganho no potencial das sementes seja maior que a dificuldade imposta sobre o sistema como um todo.

Essas conclusões estão de acordo com os argumentos de Gibson em [Gibson, 2005], que a partir da observação da evolução temporal dos graus de uma dinâmica com características de $\tau=1$, entre uma rede aleatória e uma rede livre de escala, propõe que vértices de grau alto sejam gargalos da difusão nessa condição de $\tau$, que ele chama de agendamento ou scheduling.

\subsubsection{Reforço, reciprocidade e aglomeração}

A investigação do papel da redundância nas estratégias dá-se através das propriedades de reciprocidade e do coeficiente de aglomeração estendido. Essas quantidades expressam redundância no sentido da capacidade de um vértice Infectado garantir que receberá doses de reforço a partir dos vizinhos que ele infectar. Não representa, assim, a facilidade dele aglutinar forças para contagiar outros vértices, estando a princípio mais ligada à taxa de recuperação que ao limiar.

O coeficiente de aglomeração usual, como apresentado no início do Capítulo 2, requer tornar o grafo não dirigido e com isso confunde os efeitos de reforço e aglutinação. Por isso utiliza-se o coeficiente estendido definido na Seção 2.3 que, por tratar ciclos mínimos observando o sentido das arestas, permite isolar o efeito de reforço de outros efeitos de redundância.

A análise dessas medidas de reforço, porém, é dificultada por alguns fatores que 
tornam ambígua a interpretação dos dados obtidos para as estratégias alto-reci, altoaglo e anti-aglo, escolhidas com o intuito de estudar esse efeito. Os principais fatores são:

1. a dominância do grau, como discutida na Seção 3.8.2, em situações de balanço de tempo desequilibrado

2. a opção por estudar uma memória curta, $T=4$, pois indivíduos de resposta rápida podem não esperar o reforço surtir efeito

3. as correlações entre estratégias que privilegiam grau e as propriedades de reforço e entre as estratégias que privilegiam essas propriedades e o grau, como vê-se nos dados da Seção 3.6.4

Sobre a relevância de estudar efeitos de reforço, além da combinação de balanço de tempo equilibrado e memória alta sugestivamente representar muitos processos de interesse, atenta-se que eles podem ainda ser relevantes em outras redes de influência que não tenham uma distribuição alongada dos graus de entrada, pois o efeito do grau seria então menos expressivo.

Assim, para contornar esses três itens, realizou-se algumas simulações adicionais aos dados descritos na seção 3.7, em condições que buscam isolar os problemas, respectivamente:

1. $\tau=1$

2. $T=32$

3. comparação das estratégias andarilho e anda-aglo, pois nesta o grau dos vértices é sacrificado em relação àquela em favor de uma pequena vantagem na aglomeração, usando a rede original em que grau e aglomeração estão correlacionados negativamente

Dessa maneira, uma vantagem da estratégia anda-aglo sobre a andarilha nessas condições poderia evidenciar o efeito do reforço sobre a dinâmica. Abaixo resultado de algumas simulações nessas condições, seguindo as mesmas prescrições anteriores.

\begin{tabular}{l|cc|cc}
\multicolumn{4}{c}{$\tau=1|T=32| D^{*}=4$} \\
\hline \multicolumn{4}{c}{ Rede de mensagens } \\
\hline$p$ & \multicolumn{2}{|c}{0.5} & \multicolumn{2}{c}{0.8} \\
\hline$r$ & 0.5 & 0.8 & 0.5 & 0.8 \\
\hline andarilho & 314 & 596 & 3 & 4 \\
anda-aglo & $99.1 \%$ & $99.1 \%$ & $99.8 \%$ & $99.8 \%$ \\
& 259 & 399 & 3 & 3 \\
& $99.2 \%$ & $99.1 \%$ & $99.8 \%$ & $99.8 \%$
\end{tabular}

Apesar de parecerem positivos, deve-se observá-los com cuidado, em luz da incerteza a respeito do balanço $\tau=1$ corresponder ao ponto onde o grau não teria importância. 
Para verificar isso, conduziu-se algumas análises temporais, contrastando a evolução do conjunto inicialmente semeado ao longo do tempo. As figuras abaixo mostram, para o conjunto inicialmente semeado pela estratégia andarilho na condição $p=0.5$ e $r=0.8$ dos dados acima, a distribuição de mensagens recebidas e de reciprocidade de 600 vértices semeados, contrapondo os que após 200 iterações permanecem Infectados aos que se tornaram Susceptíveis.
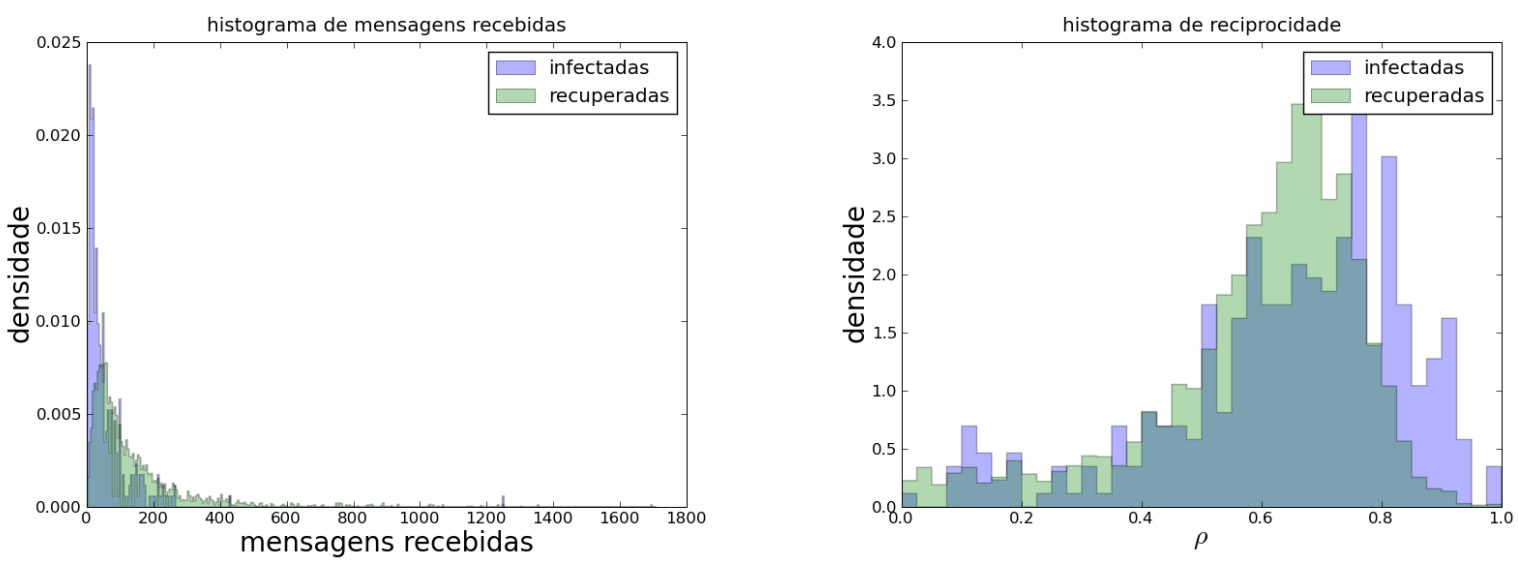

Vê-se assim que o efeito do grau em $\tau=1$ ao invés de equilibrado já foi invertido, com as sementes de grau mais alto deixando a difusão. Isso explica a diferença entre as duas estratégias, ao invés de alguma propriedade de reforço, pois anda-aglo tende a amostrar mais vértices de grau menor. Contudo, é possível por esse método buscar o valor de $\tau$ que anula o efeito do grau e as figuras abaixo mostram dados para $\tau=3$ quando isso ocorre. Verificou-se também que esses resultados mantém-se em variações do número de sementes e para a estratégia anda-aglo.
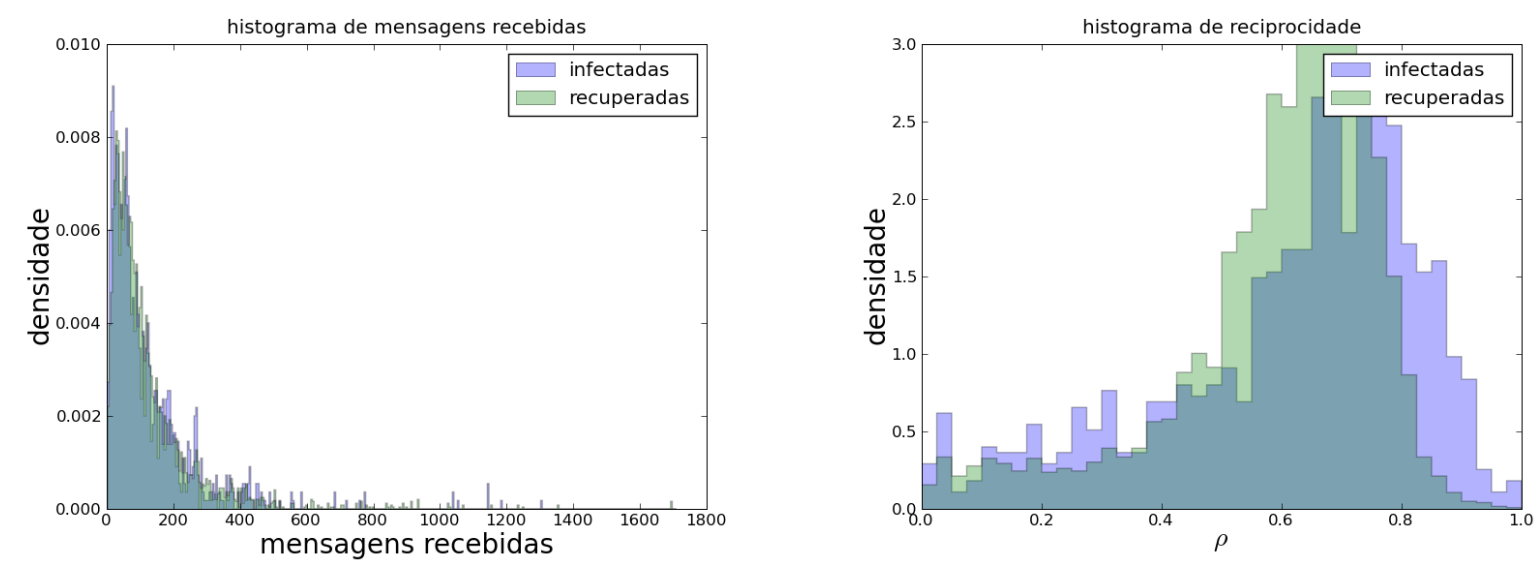

Para $\tau=3$ não há viés para sementes manterem-se Infectadas dependendo de seu grau e, enquanto as distribuições de grau se alteraram, tem-se que as sementes de maior reciprocidade mantém-se proporcionalmente mais Infectadas nessas condições, confirmando o efeito de reforço que se buscava. Tendência análoga verifica-se para o coeficiente de aglomeração. 
Realizados esses mesmos cálculos para a rede embaralhada, constata-se que o ponto de anulação do grau é o mesmo, sugerindo que esse ponto dependa mais de correlações de grau que de outros detalhes da topologia da rede.

É bastante consequente, contudo, que o valor de $\tau$ que anule o efeito do grau seja maior que 1. Isso contrasta com o observado nos resultados para pequena memória, $T=4$, onde o grau só perde seu efeito em escalas de tempo mais próximas de 1 . Assim, seria preciso um estudo mais abrangente do efeito da memória alta, $T=32$, para afirmar isso com maior segurança. Contudo, se de fato for assim, tem como consequência que o grau é nada importante em um conjunto ainda maior de aplicações quado a memória é alta, correspondendo até a balanços de tempo onde o influenciável investe o triplo de atenção que o influenciador.

\subsubsection{Mensagens recebidas ou vizinhos?}

Uma questão relevante para formular estratégias, dado o papel positivo do grau em certas circunstâncias, é optar entre o número de vizinhos ou algum indicador de influência como o número de mensagens recebidas. Nos dados obtidos, a grande maioria das situações em que há uma diferença significativa entre as estratégias alto-vizi e alto-mens favorece a segunda.

Apesar das diferenças serem pequenas, há de lembrar-se que essas estratégias são baseadas na seleção pela ordem da propriedade, um processo inviável na realidade. Como mostram as Figuras A.0.3,A.0.4,A.0.5 e A.0.6, em ambas as redes a correlação entre essas duas propriedades cairá à medida que a precisão na sua avaliação é perdida. Passa a ser relevante, assim, em amostragens realistas, a opção pela mais eficiente.

Extrapolando o resultado para a realidade, o que está longe de ser possível pelo presente estudo, a prevalência de alto-mens sobre alto-vizi significaria que a reputação de um indivíduo é mais importante que sua conectividade, apesar de ambas frequentemente andarem juntas. Num exemplo anedótico, haveria mais chances de difundir uma mensagem por um blog com muitos comentários do que um blog com muitos visitantes.

Deve-se ressaltar, contudo, que essas estratégias só oferecem vantagem naqueles processos em que os indivíduos sejam mais disponíveis para o ato de influenciar do que para o de serem influenciados, como exposto na Seção 3.8.2.

\subsubsection{Desenhando caminhadas}

A estratégia andarilho, baseada no princípio da distribuição de equilíbrio de um caminhante aleatório, é uma estratégia simples e facilmente implementável que não requer nenhum conhecimento da rede. É interessante, portanto, notar que ela deu resutados bastante positivos.

Quanto a seu número de passos para atingir o equilíbrio, o valor de 5 passos estipulado para a rede de mensagens está dentro do já praticado empiricamente em métodos de amostragem de populações ocultas que utilizam idéias semelhantes [Malekinejad et al., 2008].

Como visto na Tabela 3.5, o grau médio dessa estratégia é muito próximo de uma 
amostragem dos vértices com probabilidade proporcional ao número de mensagens recebidas. Verificou-se ainda que as distribuições todas como mostradas nas figuras da Seção 3.6.4 coincidem para ambas. Portanto pode-se esperar que, em redes semelhantes, a distribuição de graus de entrada e as correlações com esta de demais propriedades especifiquem também as propriedades da andarilho.

Ao mesmo tempo, a estratégia anda-aglo apresentar diferenças significativas em suas propriedades da estratégia original e tem efeitos opostos sobre o grau entre a rede de mensagens e a embaralhada, mostrando que aplicar modificações no caminho aleatório pode ter efeitos interessantes como manipular a distribuição dessas grandezas, com igualmente pouco ou nenhum conhecimento da rede.

Fica portanto posto aqui o problema interessante de formular caminhadas aleatórias que com um mínimo de conhecimento de uma rede, preferencialmente local e idealmente nenhum, percorram conjuntos de valor para dados processos. A possibilidade de aplicar essas idéias nos tais estudos concretos de populações ocultas, muitas vezes ligadas a riscos de doenças como usuários de drogas e doenças sexualmente transmissíveis e portanto também alvos para difusão de práticas e conhecimentos de saúde pública, abre portas interessantes para um campo experimental que pode enriquecer o entendimento dos processos de contágio como um todo.

\subsection{Crítica e dificuldades deste estudo}

Uma deficiência deste estudo, mais do que os limiares homogêneos, é a opção por estudar uma única rede estática. A possibilidade de embaralhá-la permitiu observar com maior clareza algumas tendências, isolando suas causas por contraste entre características. Mas os limites dessa abordagem advertem contra generalizações quanto às estratégias, ao que a própria rede embaralhada nos sugere que afirmações podem inverter-se com a troca de correlações entre propriedades, ainda que se preserve todas as correlações de grau da rede. Talvez sugira-se assim que, mais do que generalizações, é importante buscar maneiras melhores de investigar cada situação específica.

Outra limitação é a falta de bases claras para comparação entre as estratégias ou propriedades. Uma crítica fácil de ser feita é da ausência de comparações de uma estratégia com uma versão de controle dela, onde tentaria-se preservar a característica mais marcante ao mesmo tempo em que se neutraliza as demais. O problema dessa proposta, além da ambiguidade em definir-se o neutro, é muitas vezes a impossibilidade de realizá-la na própria rede. Para dar um exemplo, não é possível escolher um número arbitrário de vértices com graus proporcionais à distribuição da rede cujos $C^{1}$ correspondam aos valores obtidos para um mesmo número através da estratégia anti-aglo. Simplesmente não existem esses vértices.

Por fim, a crítica mais fundamental a este trabalho coloca-se diante da abordagem desses problemas pelo ponto de vista da teoria da otimização, como realizada em [Kempe et al., 2003, Kempe et al., 2005]. A justificativa dada na Seção 3.3 para evitar esse caminho foi a complexidade maior do modelo aqui discutido e o interesse de buscar estratégias aplicáveis em termos de propriedades mensuráveis localmente, sem conhecimento de toda a rede. Mas um outro caminho a seguir diante disso é buscar formas de calcular a estratégia ótima, ou aproximadamente ótima, e calcular 
dela propriedades topológicas locais para então verificar se vértices escolhidos por essas propriedades tem efeito semelhante ao ótimo.

Apesar dessas mesmas referências também demonstrarem que a solução do problema para modelos gerais como este pertencerem à mais dura classe de complexidade computacional, dos não polinomiais completos, nada garante que uma heurística de complexidade polinomial para buscar a semeadura ótima não daria resultados pelo menos melhores que todas as estratégias aqui apresentadas ou razoavelmente concebíveis. Contudo, estimou-se que tais heurísticas estavam além das capacidades computacionais disponíveis então, devido ao volume desta rede de mensagens que optou-se estudar, e preferiu-se naquele momento seguir o caminho aqui apresentado. Fica assim, como um passo para o futuro, investir nessa outra abordagem do problema. 


\section{Capítulo 4}

\section{Conclusões}

Os temas desenvolvidos nesta tese compartilham o objetivo de entender efeitos de detalhes da topologia de redes complexas. Mais do que isso, buscou-se mostrar que esses detalhes frequentemente são características fundamentais, ocultadas pelas escolha de medidas e formalismo utilizado para tratar o sistema. Não trata-se das escolhas serem por si incorretas, mas de haver nessa área uma tendência a fazer afirmações sobre uma suposta universalidade que não existe nem em sólidos ou gases e que está em clara contradição com a realidade.

Os "detalhes" aqui estudados, a extensão do coeficiente de aglomeração e a introdução do balanço de tempo no modelo de contágio, são de difícil tratamento. $\mathrm{O}$ primeiro envolve um problema de minimização em grafos e o segundo introduz descontinuidades dinâmicas. Seguiu-se então uma análise pedestre mas segura e fiel à proposta de expôr algumas surpresas no caminho para descrições de processos em rede mais fiéis à realidade.

\section{Do primeiro capítulo}

Os resultados obtidos no primeiro capítulo mostram a utilidade de considerar com mais detalhe a topologia local dos ciclos numa rede para qualificar modelos de crescimento, conjuntos de dados e a entendê-los melhor diante de outros vínculos da rede, ao mesmo tempo que expôe o risco de conclusões prematuras ou enviesadas ao ignorar esses detalhes da topologia. A diversidade de trabalhos na área torna cada vez mais necessário um vocabulário rico e coerente para identificar com eficiência sistemas semelhantes em dimensões básicas como a topológica. Diante disso, permitese observar que o coeficiente de aglomeração estendido - ou alguma das alternativas nessa direção - deveria por bem tornar-se uma ferramenta padrão na descrição inicial de redes complexas. Algumas vantagens do coeficiente aqui proposto são sua simplicidade conceitual e interpretativa, sua relação natural como extensão de uma medida reconhecida, preservando as propriedades esperadas, sua complementariedade a outras medidas interessantes e sua visualização fácil e informativa na forma do perfil de aglomeração.

Ao mesmo tempo, os resultados apontam para a necessidade de distinguir entre medidas básicas e medidas específicas. Diferente de outros sistemas físicos onde os objetos tem propriedades comuns, sejam micro ou macroscópicas, os processos em rede não podem ser reduzidos a um conjunto de medidas essenciais. Numa analo- 
gia completamente leviana, é como se cada processo tivesse sua própria carga: a carga de movimento orbital, a carga de movimento pendular e outras, que apesar de poderem ser comparadas e relacionadas seriam irredutíveis a equações de movimento gerais em consequência do espaço heterogêneo, dinâmico e descontínuo onde ocorrem. Continuando a analogia para ser mais claro, sistemas da mecânica estatística são estudados tipicamente em espaços descontínuos, estáticos e homogêneos, sistemas da relatividade geral em espaços contínuos, dinâmicos e homogêneos, sistemas mecânicos em espaços contínuos, estáticos e heterogêneos. Enquanto a pesquisa nessas áreas avança com a introdução em cada um desses espaços de crescente descontinuidade, dinâmica e heterogeneidade, o estudo de redes complexas já prevê essas três características de partida.

\section{Do segundo capítulo}

O estudo de contágio revela alguns fatos interessantes e pouquíssimo discutidos, como o papel inescapavelmente central do balanço de tempo na dinâmica de difusão em promover ou reduzir a eficiência dos indivíduos nesses processos segundo seu grau de conectividade. Pode parecer surpreendente que, na história dos modelos de contágio social, somente recentemente surgiu a idéia de tratar o tempo disponível aos agentes coerentemente com a realidade. Quando propôs-se inicialmente essa idéia ao então co-orientador do estudo, Duncan Watts, e este referiu-se ao trabalho de Gibson sobre agendamento, esperava-se encontrar um trabalho de décadas anteriores. Qual senão foi o espanto ao ver o quão recente e o quão pouco o tema havia sido abordado na literatura.

Sem pretender o rigor de um sociólogo da ciência, mas apenas da vivência e reflexão sobre o meio, parece plausível a seguinte causa para esse fenômeno: físicos e matemáticos gostam de apropriar-se de modelos de outras disciplinas, mas muitas vezes detém-se no que foi estabelecido em suas origens; do outro lado, sociólogos e economistas conhecem os detalhes do processo, mas acabam fazendo simplificações inconsequentes por terem dificuldade de tratá-los formalmente. Nesse sentido, foi fortuito ter optado pelo estágio no exterior em um departamento de sociologia, assim como ter trocado preteza na conclusão deste programa de pós-graduação pela diversidade de participação em ambientes diversos onde há profundo interesse prático em questões dinâmicas de redes.

O estudo apresentou também uma série de comparações entre estratégias de intervenção por semeadura para difundir uma informação, hábito ou produto em uma sociedade. As conclusões aí são certamente específicas à combinação de estratégias escolhidas, à rede em questão e até ao modelo utilizado, mas avançou-se a metodologia e o desenvolvimento de ferramentas para estudar esses processos em casos reais. Destaca-se daí as observações sobre a relevância de diferenças topológicas dependerem do limiar, o efeito já mencionado do balanço de tempo e o monitoramento desse efeito através de dados temporais do conjunto semeado, permitindo encontrar uma situação equilibrada para elucidar a participação de outras propriedades ao ajustar-se para uma situação de balanço onde o efeito de grau não domina.

Por fim, a partir dos resultados obtidos pode-se oferecer algumas propostas de continuidade ao tema tanto práticas como teóricas, como o desenvolvimento de variações do caminhante aleatório com propriedades interessantes para difusão e a busca 
de heurísticas para a semeadura formulada como problema de otimização, cujos resultados possam ser dissecados para formulação de estratégias práticas. 


\section{Apêndice A}

\section{Gráficos das propriedades topológicas das estratégias de semeadura}

Este apêndice contém os gráficos das distribuições de propriedades topológicas dos conjuntos semeados pelas diferentes estratégias de semeadura estudadas no Capítulo 3.

As propriedades são: o número de mensagens recebidas, o número de vizinhos de entrada, as primeira e segunda ordens do coeficiente de aglomeração como definido no Capítulo 2 e a reciprocidade definida pela Equação 3.6.1.

Em cada caso, as propriedades dos vértices são calculadas considerando-se a topologia do grafo completo, em médias de 10 realizações da estratégia em questão e apresentadas para crescentes números de sementes.

Cada imagem contém ainda, para comparação, o histograma da propriedade em questão contendo todos os vértices do grafo.

Mostra-se, em sequência, um conjunto de figuras para a rede original e outro para a rede embaralhada.

A Seção 3.6.4 apresenta tabelas com médias sintetizando os gráficos deste apêndice. 

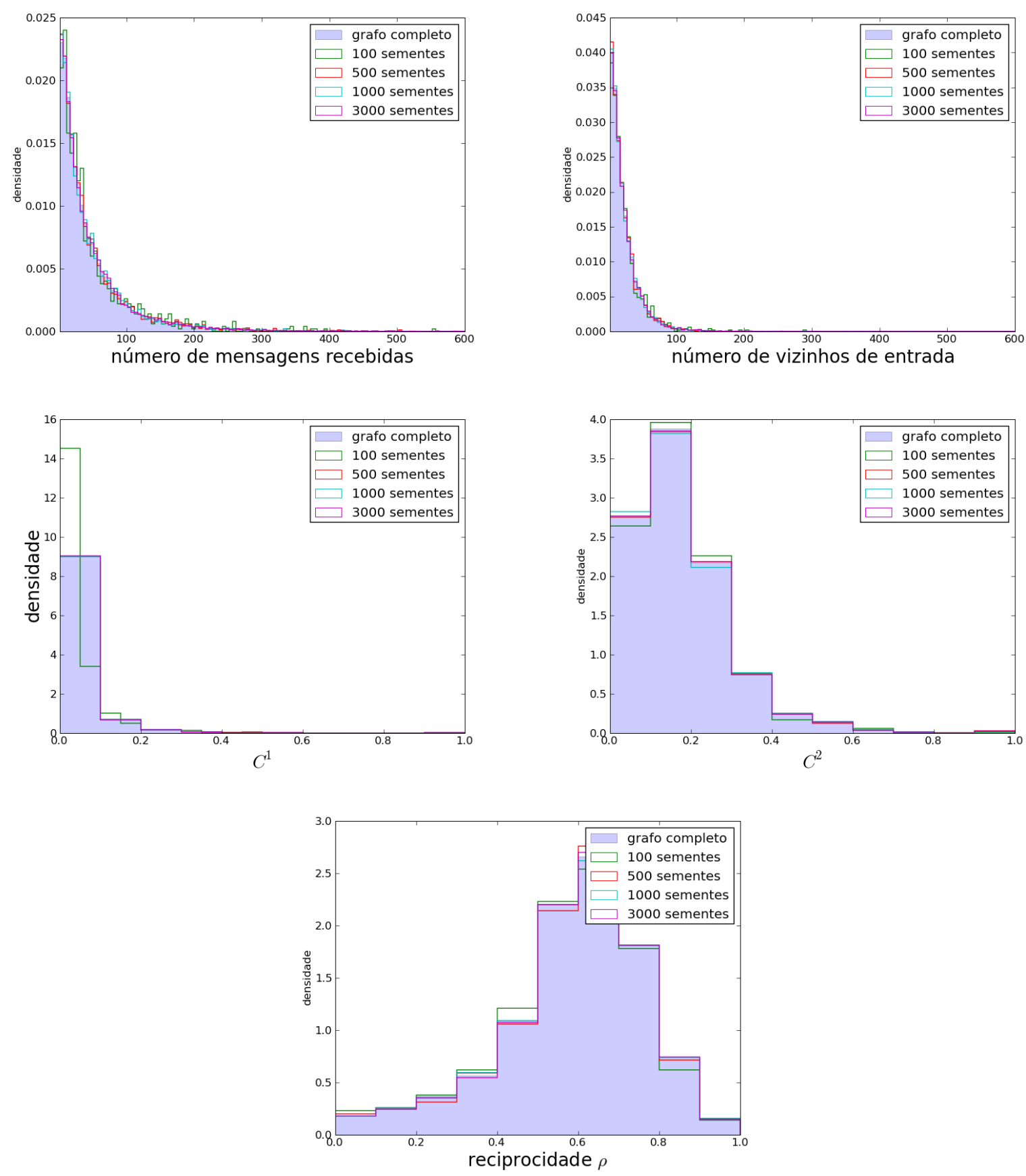

Figura A.0.1: Estratégia aleatória na rede original. 

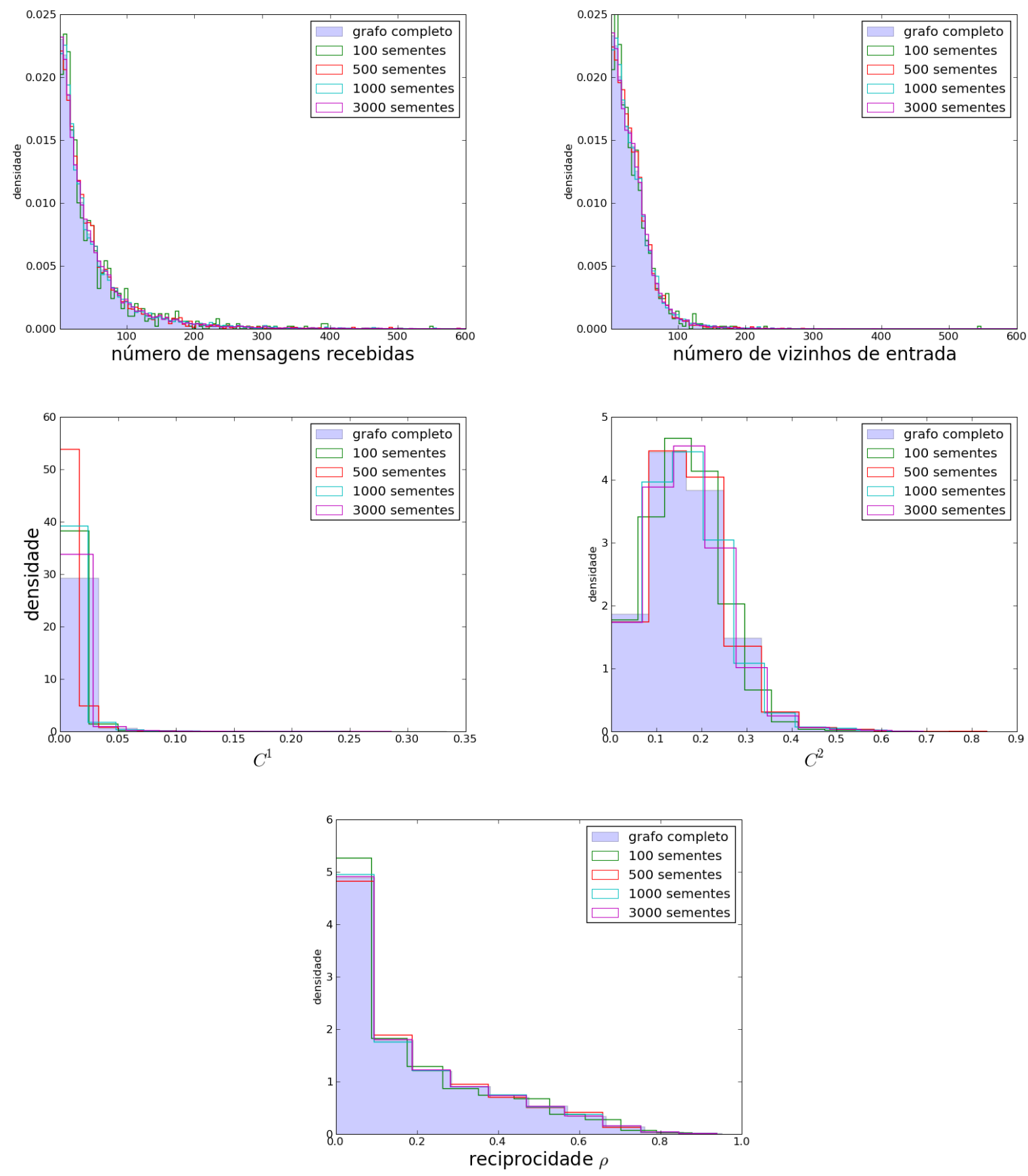

Figura A.0.2: Estratégia aleatória na rede embaralhada. 

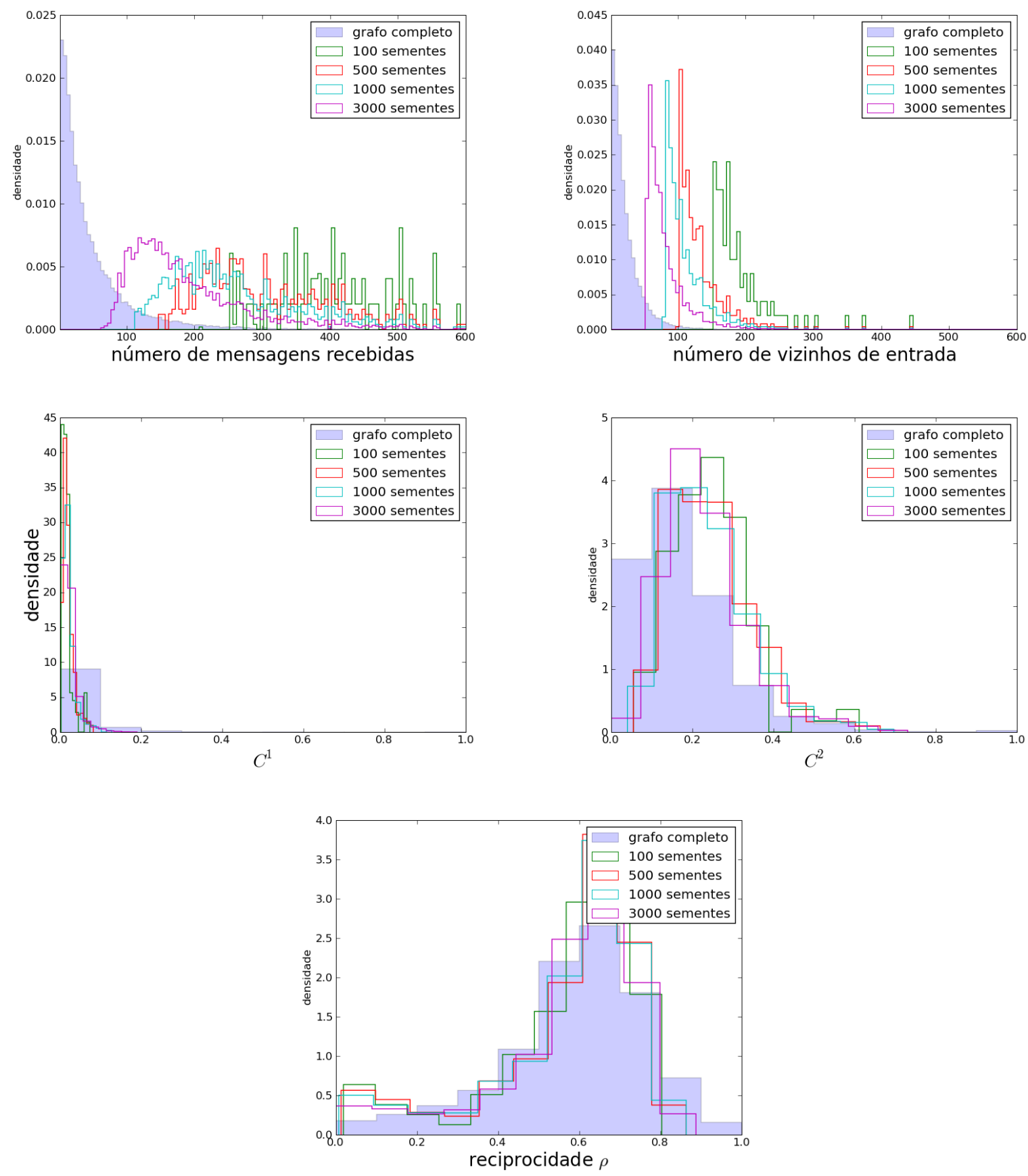

Figura A.0.3: Estratégia alto-vizi na rede original. 

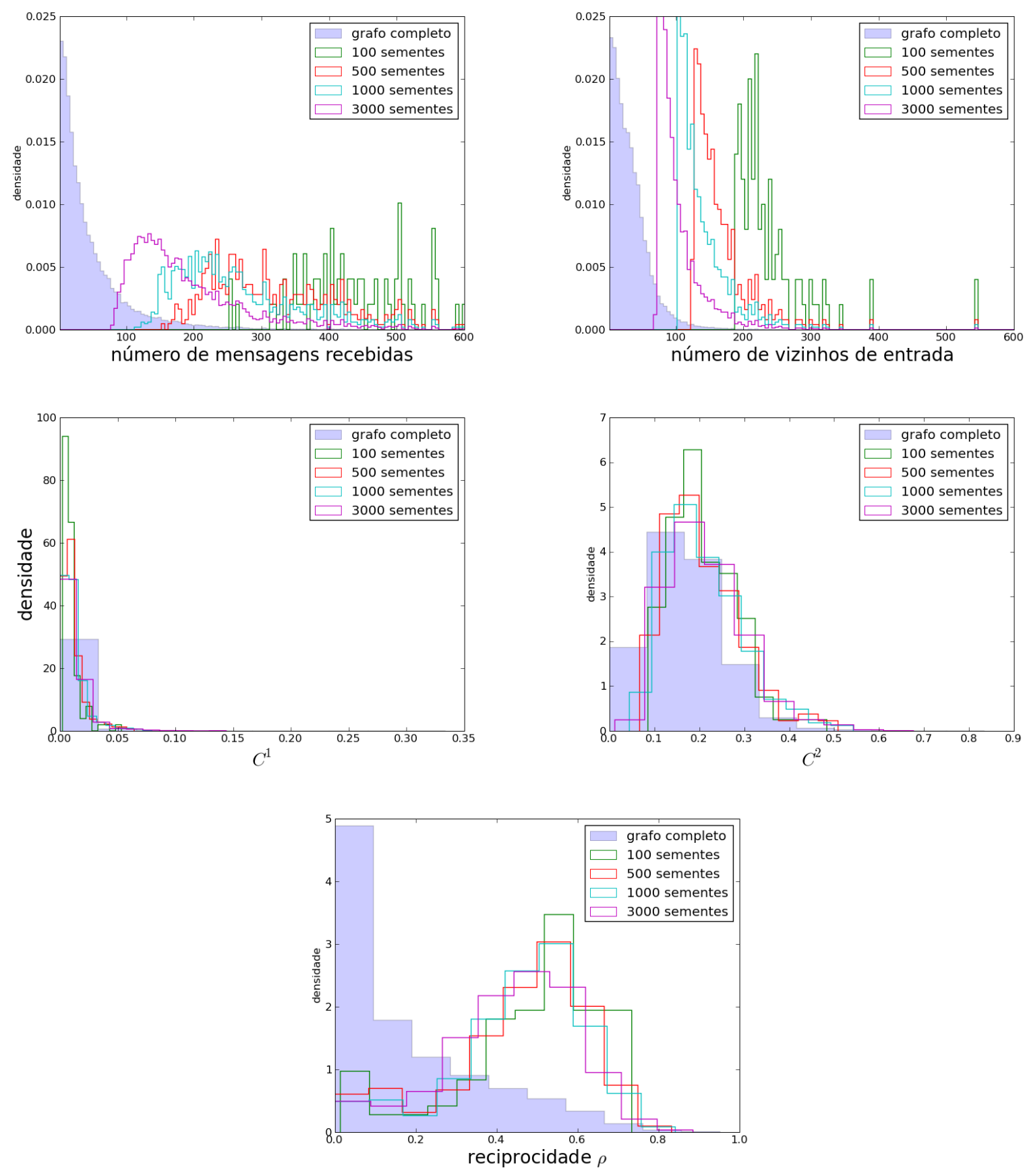

Figura A.0.4: Estratégia alto-vizi na rede embaralhada. 

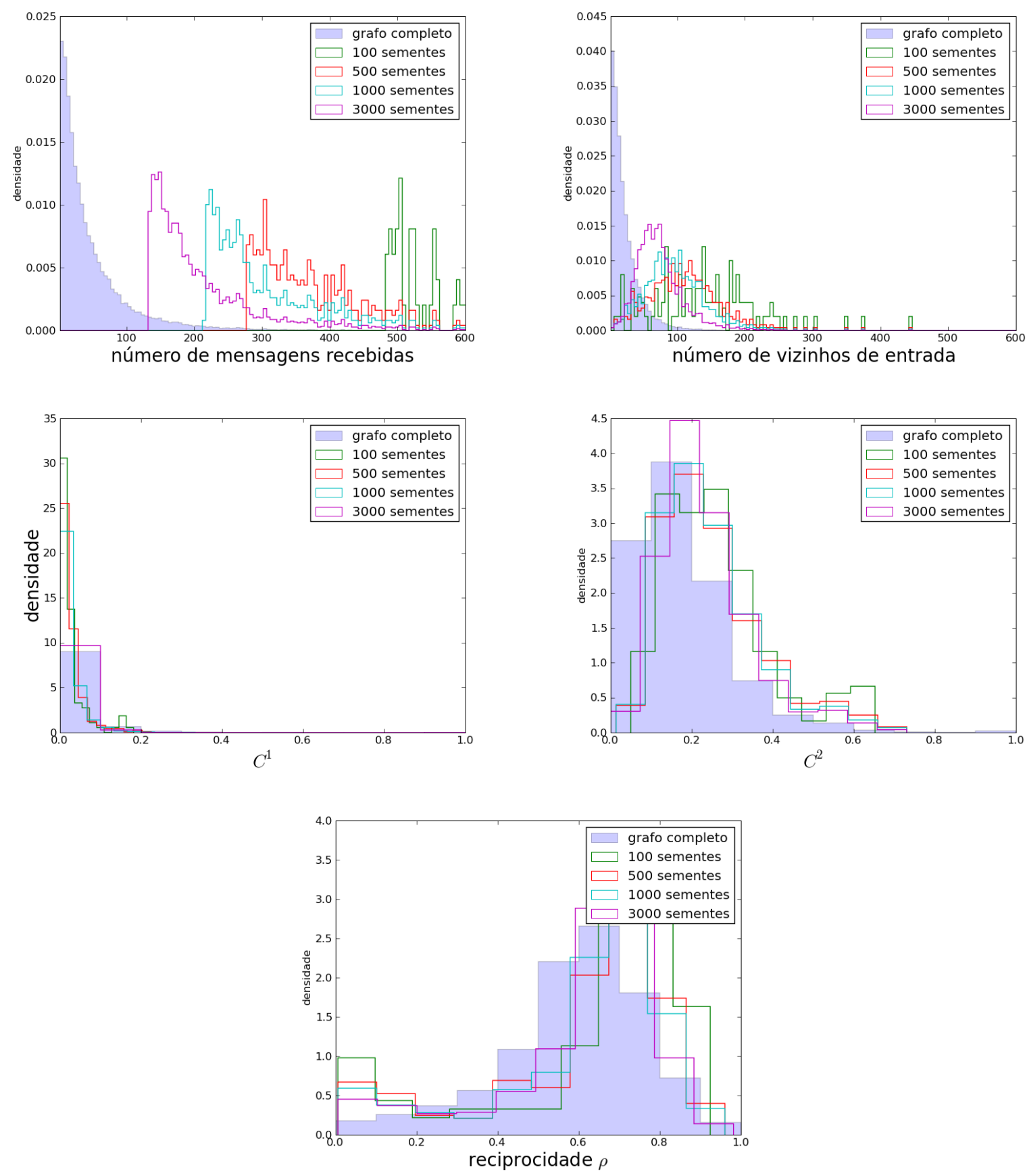

Figura A.0.5: Estratégia alto-mens na rede original. 

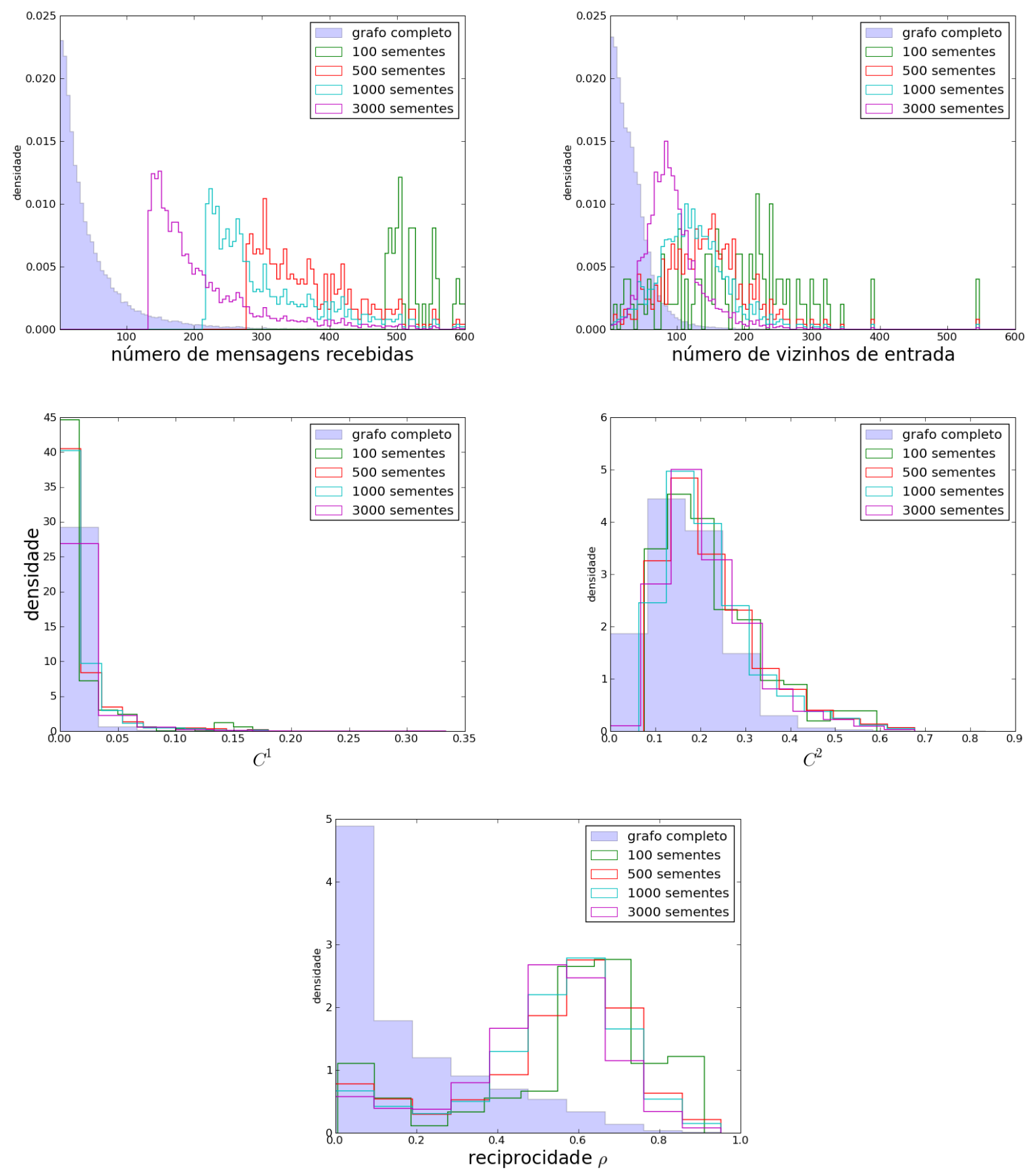

Figura A.0.6: Estratégia alto-mens na rede embaralhada. 

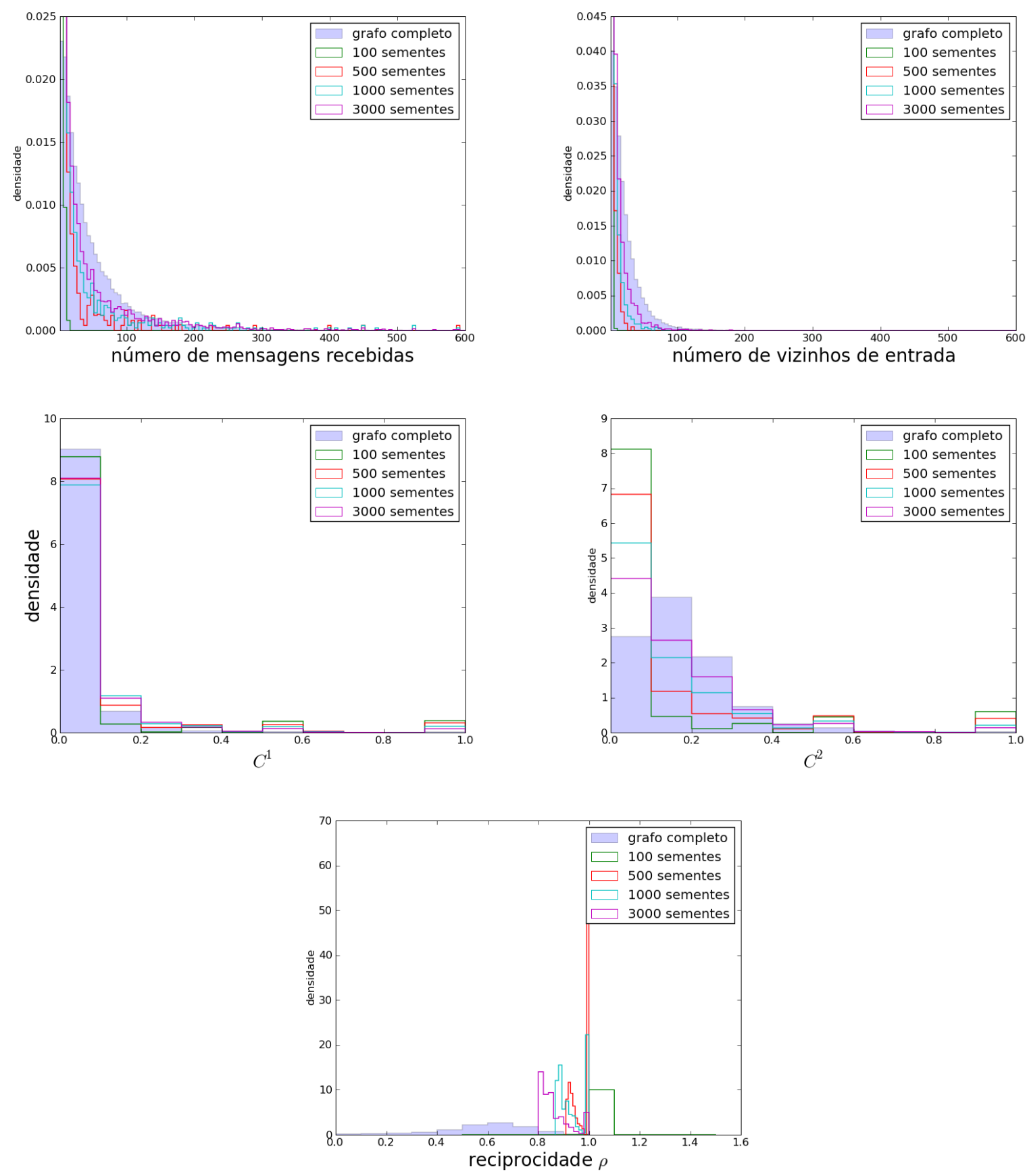

Figura A.0.7: Estratégia alto-reci na rede original. 

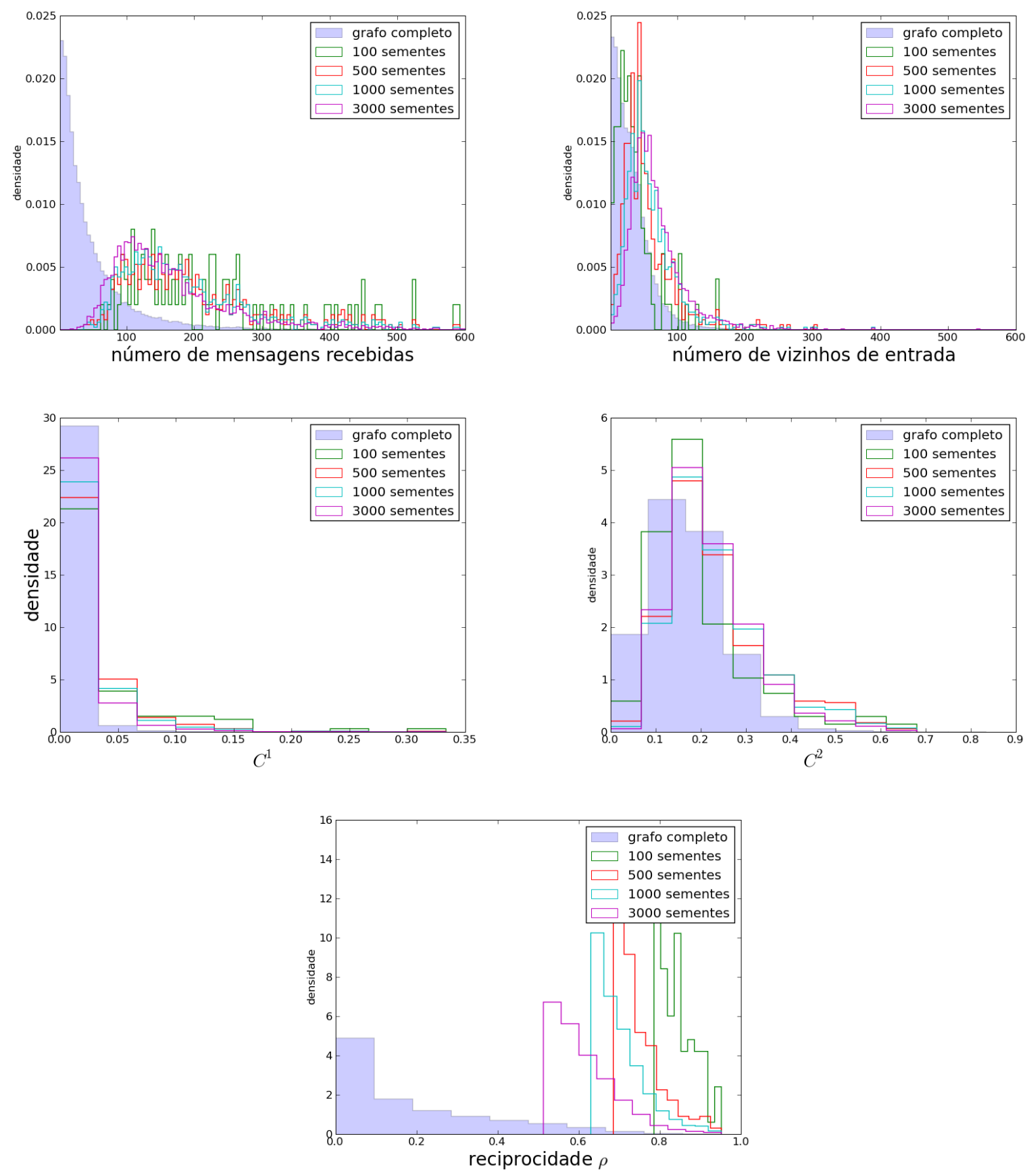

Figura A.0.8: Estratégia alto-reci na rede embaralhada. 

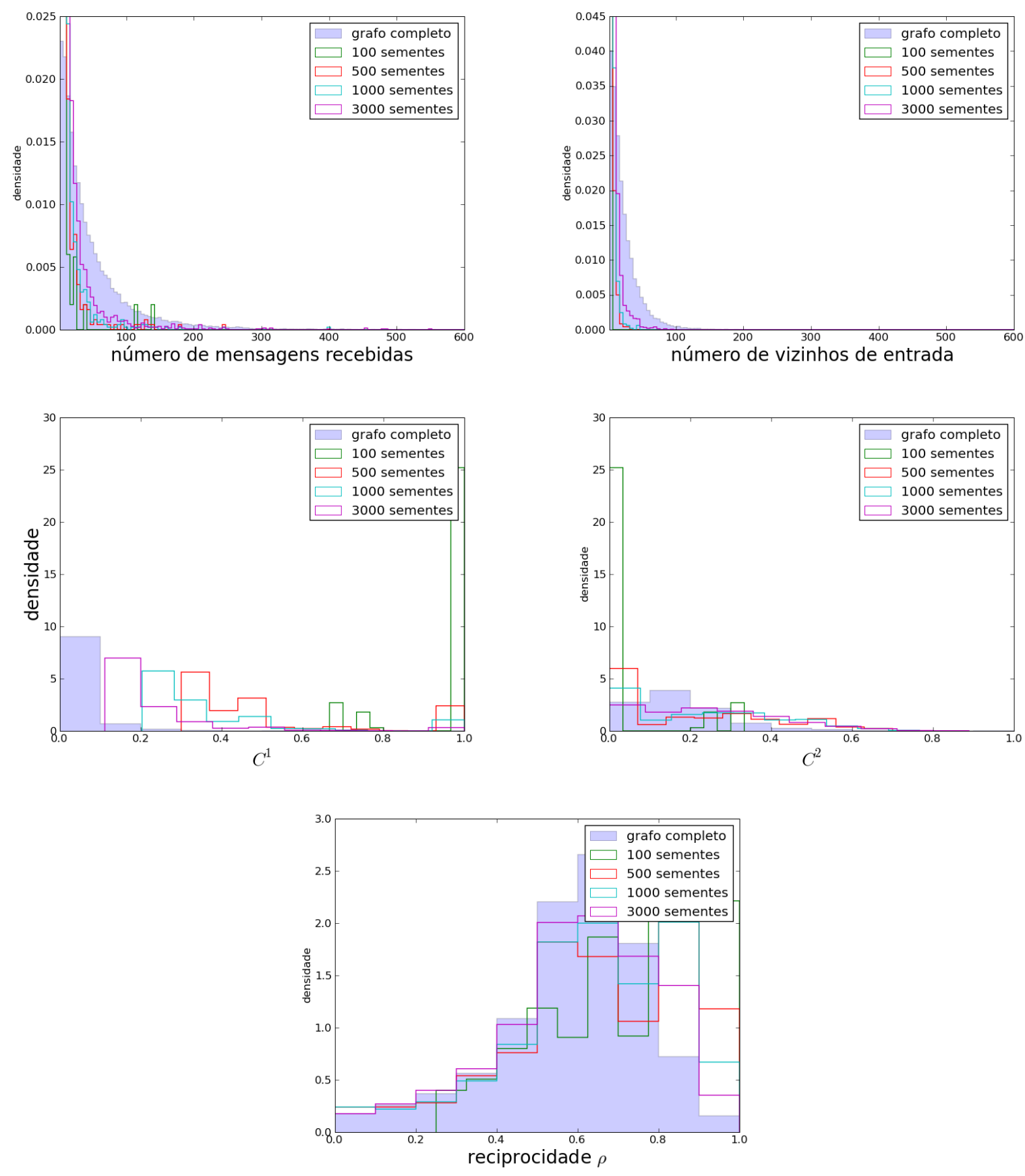

Figura A.0.9: Estratégia alto-aglo na rede original. 

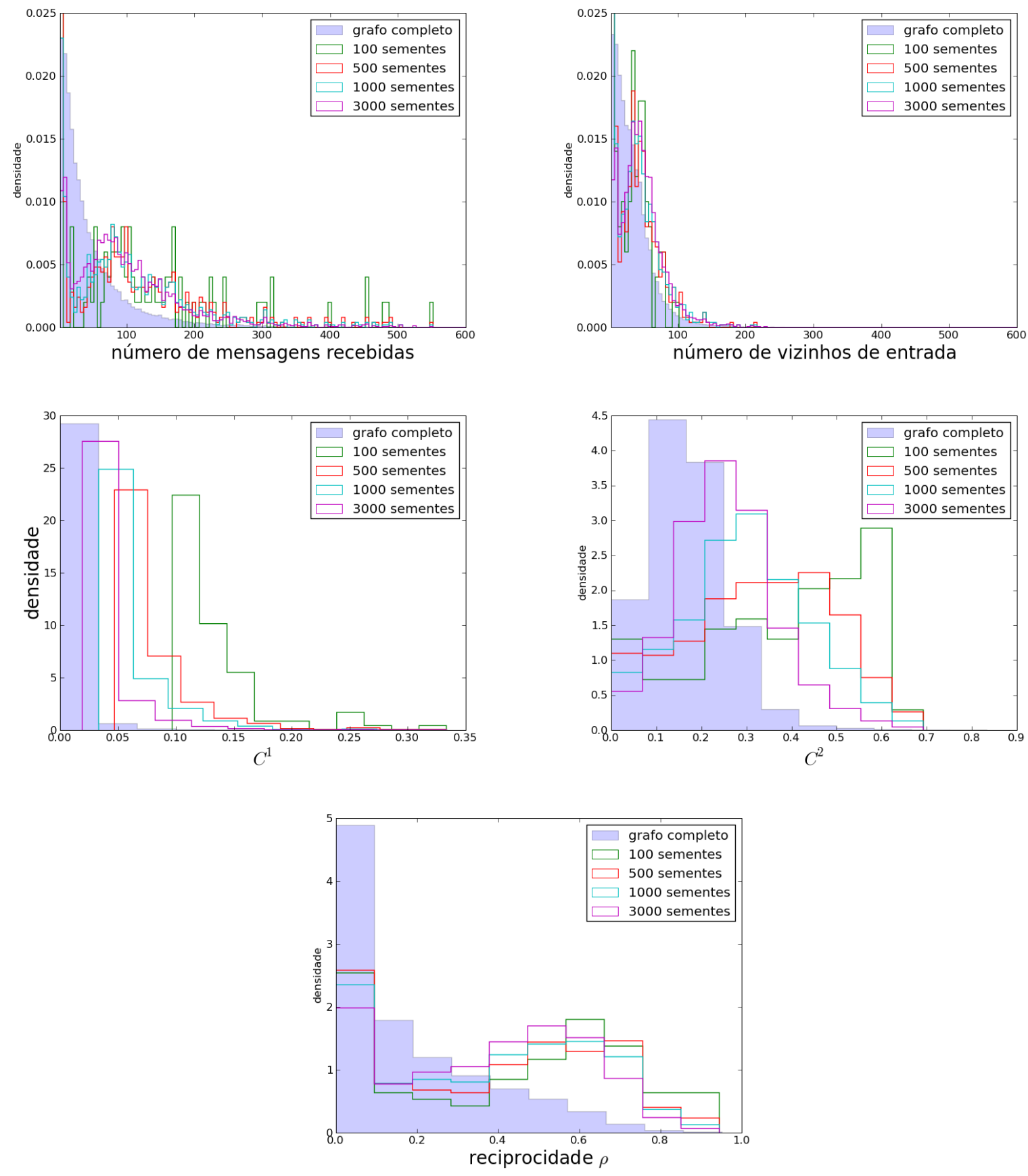

Figura A.0.10: Estratégia alto-aglo na rede embaralhada. 

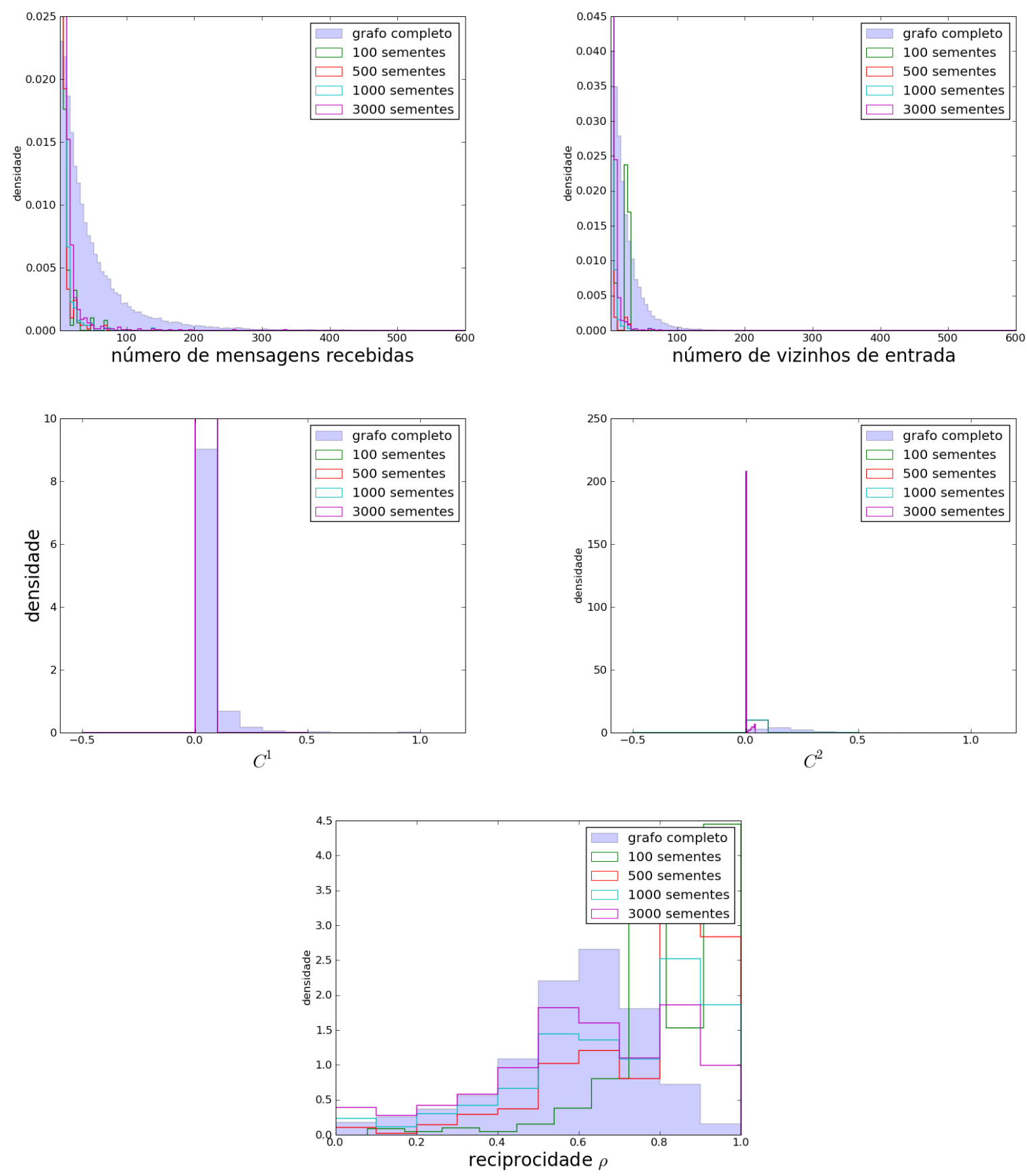

Figura A.0.11: Estratégia anti-aglo na rede original. 

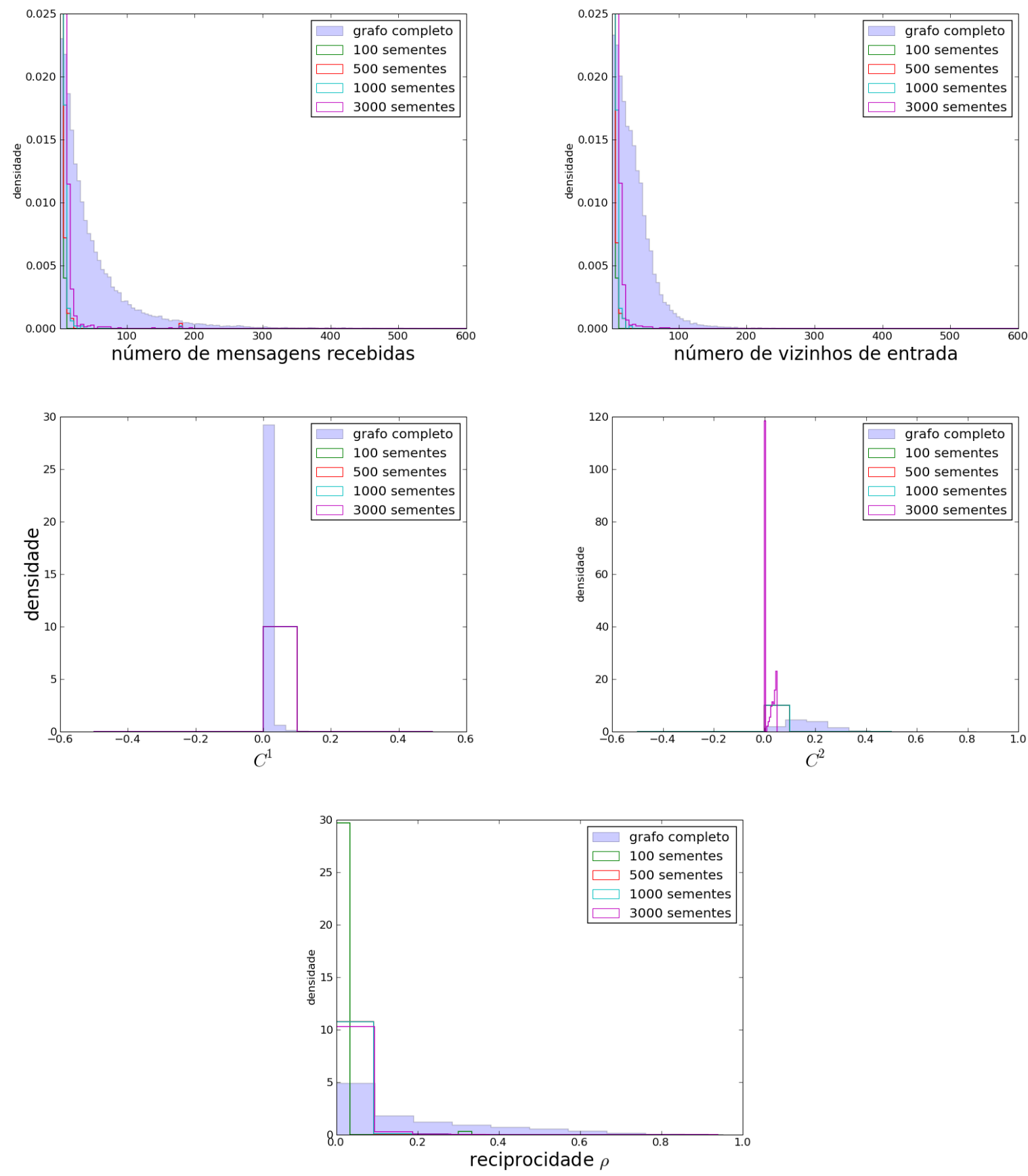

Figura A.0.12: Estratégia anti-aglo na rede embaralhada. 

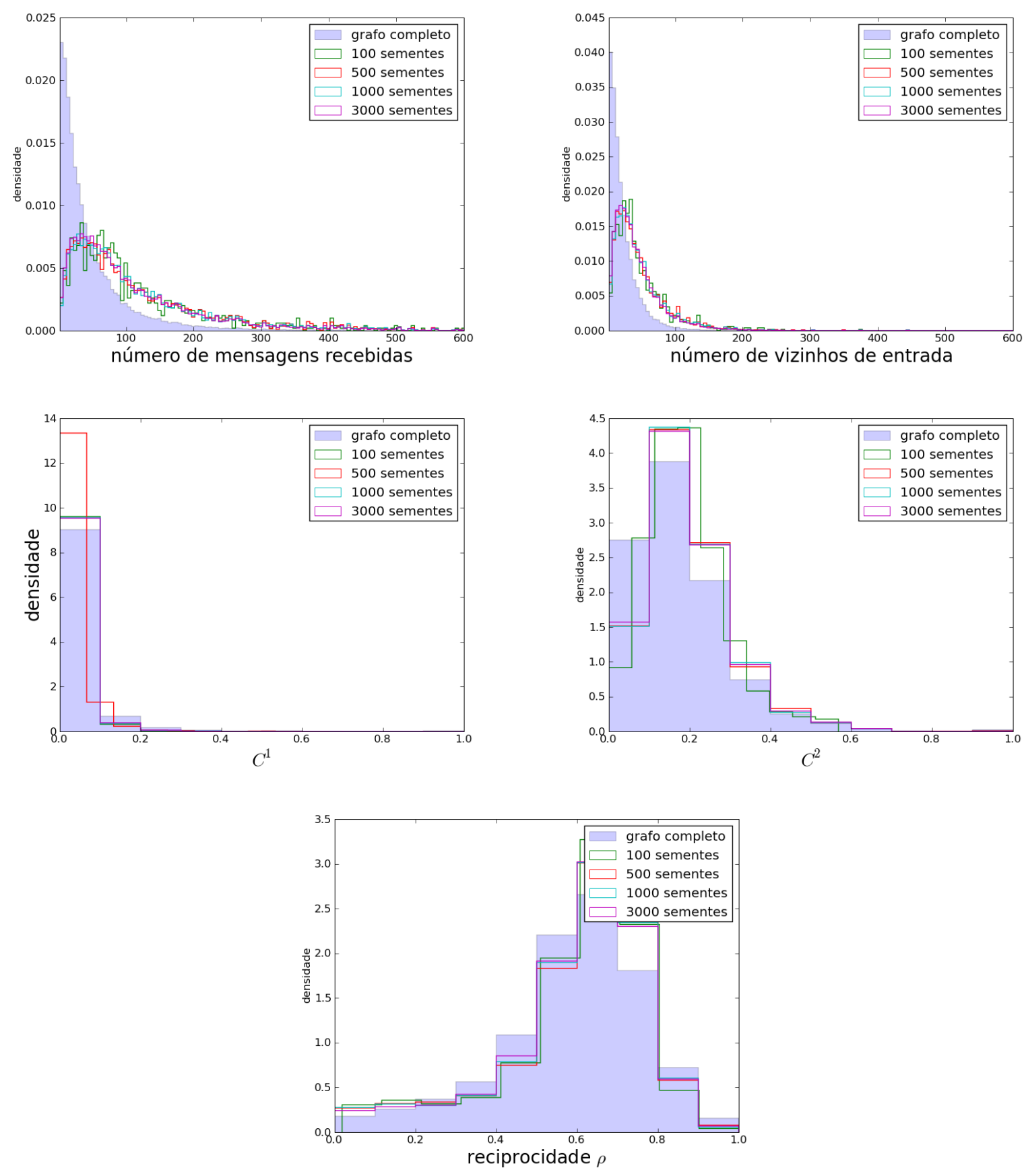

Figura A.0.13: Estratégia andarilho na rede original. 

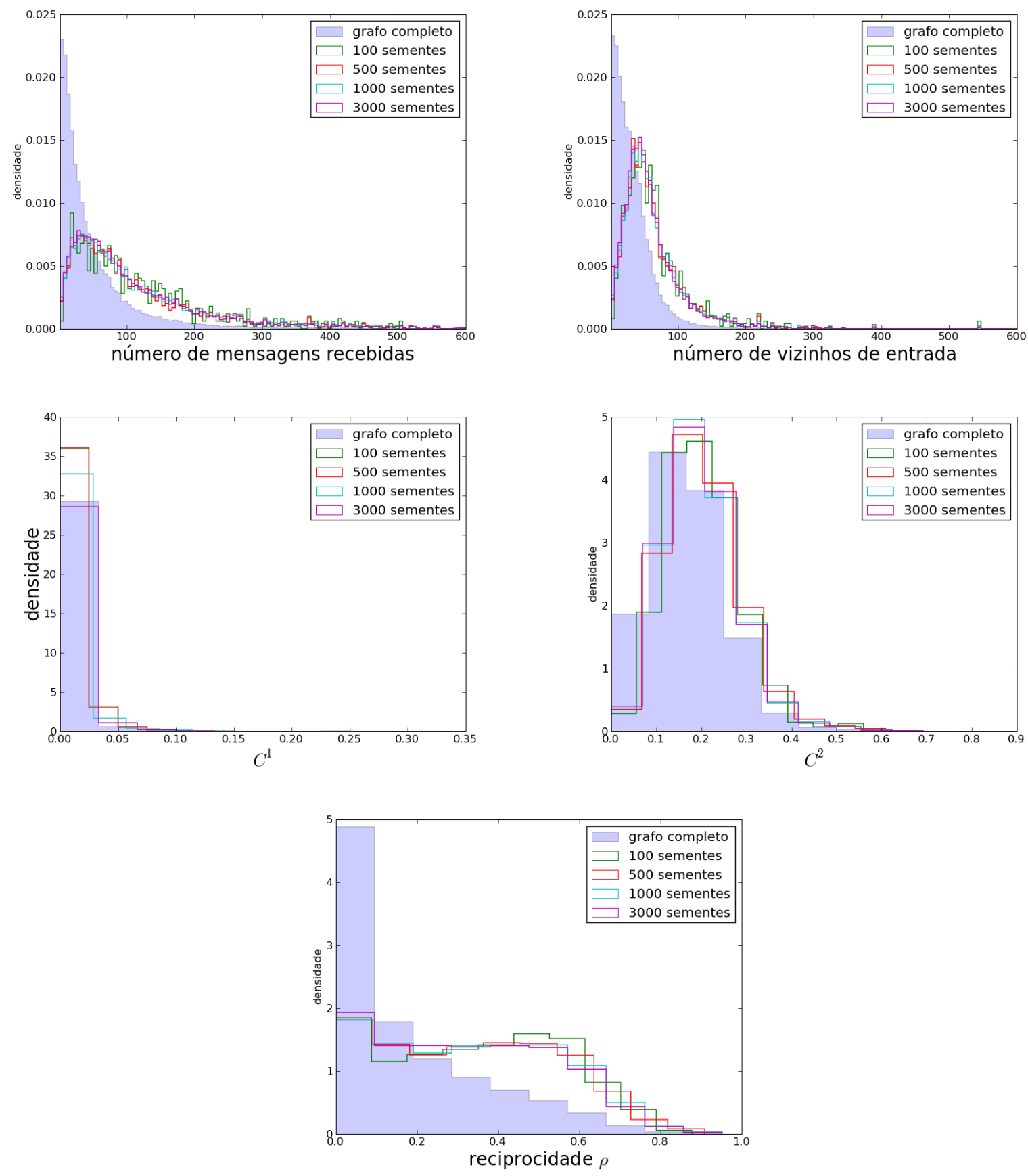

Figura A.0.14: Estratégia andarilho na rede embaralhada. 

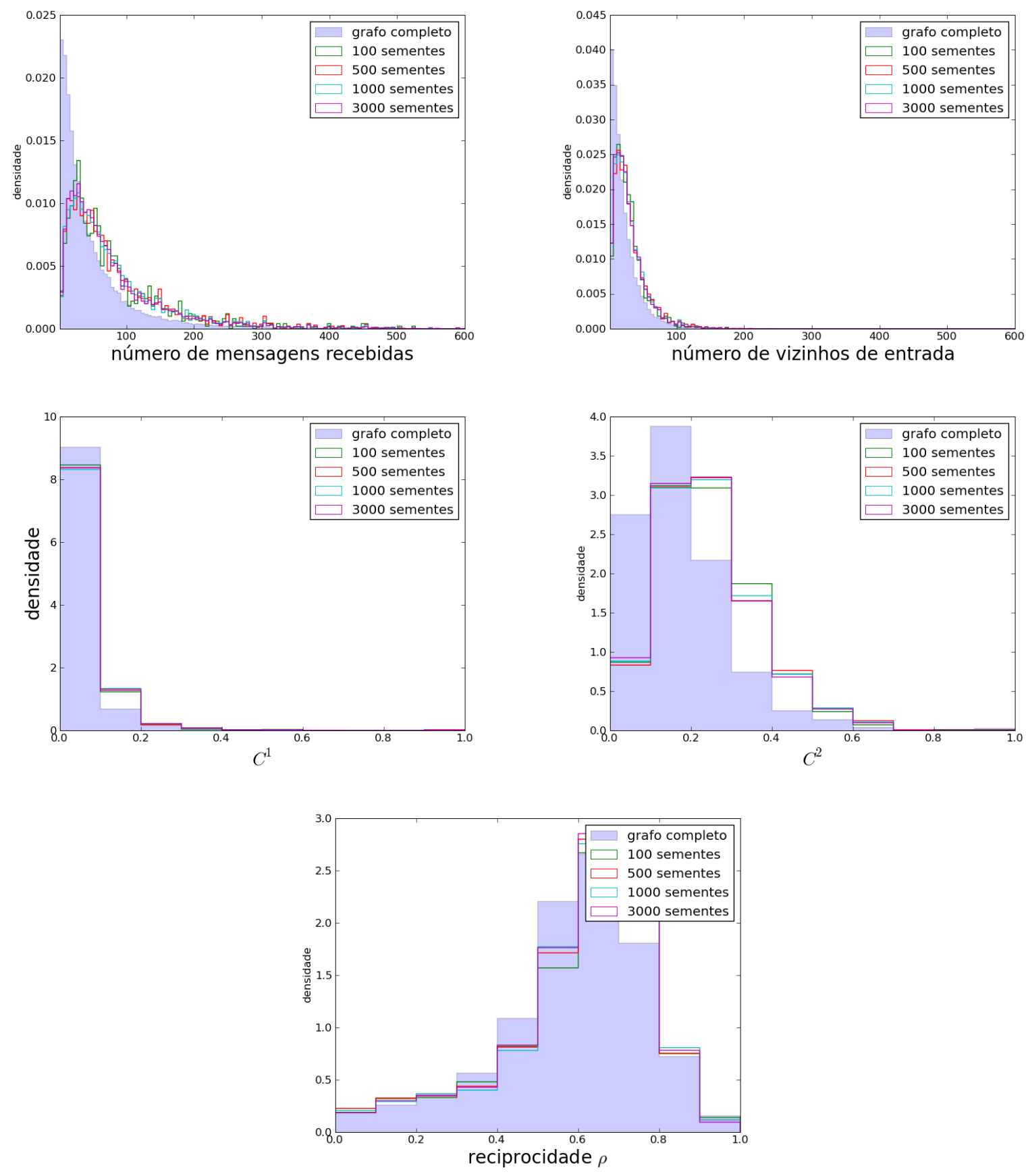

Figura A.0.15: Estratégia anda-aglo na rede original. 

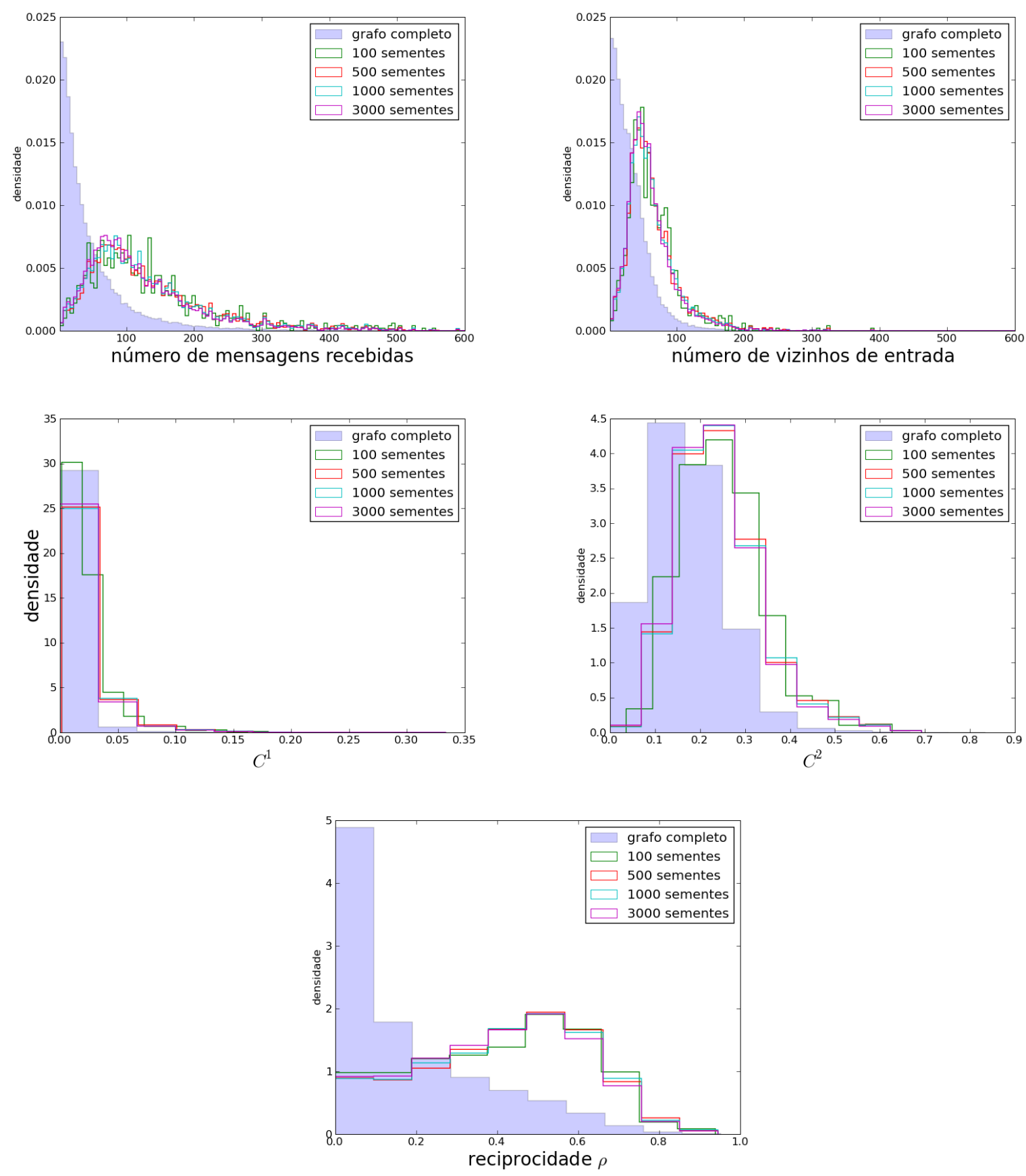

Figura A.0.16: Estratégia anda-aglo na rede embaralhada. 


\section{Apêndice B}

\section{Tabelas dos resultados das simulações}

As tabelas a seguir apresentam os valores obtidos nas simulações para cada estratégia e combinação de parâmetros, na rede original e embaralhada.

Nelas, os valores inteiros para cada estratégia são o menor número de sementes a atingir os requisitos de equilíbrio significativo enunciados na Seção 3.7 e as porcentagens são a fração média da rede na condição Infectada ao final das suas realizações.

Como já observado, sem pretensão de rigor, o primeiro valor corresponde a um estado de equilíbrio instável do sistema e o valor percentual corresponde ao equilíbrio estável atingido a partir dele.

\section{B.1 Rede de mensagens}

Destacam-se alguns fatos dos resultados para a rede de mensagens.

Nas tabelas para as seguintes combinações de parâmetros nenhum elemento atinge o equilíbrio, mas serão apresentadas por completeza:

- Tabela B.12: $\tau=-8, T=4, D^{*}=2$

- Tabela B.17: $\tau=-2, T=4, D^{*}=3$

- Tabela B.18: $\tau=-8, T=4, D^{*}=3$

Muitas das colunas para taxas de recuperação positivas, especialmente para probabilidades de exposição pequenas, também não atingem um equilíbrio. Nesses casos, o valor do pico atingido com o máximo de sementes, apresentado então porcentagem, pode ser informativo.

Como se esperaria, o aumento do limiar e da taxa de recuperação, assim como de maneira geral a diminuição do balanço de tempo, especialmente em valores negativos deste, dificultam a difusão. A questão do balanço de tempo e suas consequências menos intuitivas é discutida na Seção 3.8.2. 
Tabela B.1

\begin{tabular}{l|ccc|cccc|ccc}
\multicolumn{1}{c}{$\tau=64$} & $T=4$ & $D^{*}=1$ \\
\hline$p$ & & 0.2 & & \multicolumn{3}{c}{0.5} & 0.5 & \multicolumn{3}{c}{0.8} \\
\hline$r$ & 0.0 & 0.5 & 0.8 & 0.0 & 0.5 & 0.8 & 0.0 & 0.5 & 0.8 \\
\hline aleatória & 1 & - & - & 1 & 4 & 3 & 1 & 3 & 2 \\
& $100.0 \%$ & $19.8 \%$ & $19.7 \%$ & $100.0 \%$ & $94.6 \%$ & $92.2 \%$ & $100.0 \%$ & $99.9 \%$ & $99.8 \%$ \\
alto-vizi & 1 & - & - & 1 & 1 & 1 & 1 & 1 & 1 \\
& $100.0 \%$ & $32.5 \%$ & $29.3 \%$ & $100.0 \%$ & $94.7 \%$ & $92.2 \%$ & $100.0 \%$ & $99.9 \%$ & $99.9 \%$ \\
alto-mens & 1 & - & - & 1 & 1 & 1 & 1 & 1 & 1 \\
alto-reci & $100.0 \%$ & $33.1 \%$ & $29.5 \%$ & $100.0 \%$ & $94.5 \%$ & $91.9 \%$ & $100.0 \%$ & $99.9 \%$ & $99.9 \%$ \\
alto-aglo & 3 & - & - & 2 & 16 & 18 & 1 & 12 & 7 \\
& $100.0 \%$ & $18.0 \%$ & $18.0 \%$ & $100.0 \%$ & $94.6 \%$ & $92.2 \%$ & $100.0 \%$ & $99.9 \%$ & $99.8 \%$ \\
anti-aglo & 3 & - & - & 1 & 22 & 14 & 1 & 9 & 7 \\
& $100.0 \%$ & $15.6 \%$ & $15.6 \%$ & $100.0 \%$ & $94.7 \%$ & $92.2 \%$ & $100.0 \%$ & $99.9 \%$ & $99.8 \%$ \\
andarilho & 3 & - & - & 3 & 15 & 9 & 1 & 4 & 12 \\
& $100.0 \%$ & $14.5 \%$ & $14.5 \%$ & $100.0 \%$ & $94.6 \%$ & $92.2 \%$ & $100.0 \%$ & $99.9 \%$ & $99.8 \%$ \\
anda-aglo & 1 & - & - & 1 & 2 & 2 & 1 & 1 & 3 \\
& $100.0 \%$ & $25.9 \%$ & $25.3 \%$ & $100.0 \%$ & $94.6 \%$ & $92.2 \%$ & $100.0 \%$ & $99.9 \%$ & $99.8 \%$ \\
& 1 & - & - & 1 & 3 & 2 & 1 & 2 & 2 \\
& $100.0 \%$ & $21.3 \%$ & $21.2 \%$ & $100.0 \%$ & $94.6 \%$ & $92.3 \%$ & $100.0 \%$ & $99.9 \%$ & $99.8 \%$
\end{tabular}

Tabela B.2

\begin{tabular}{l|ccc|c|cc|ccc}
\multicolumn{1}{c}{$\tau=8$} & $T=4$ & $D^{*}=1$ \\
\hline$p$ & & 0.2 & & \multicolumn{7}{c|}{0.5} & & & 0.8 & \\
\hline$r$ & 0.0 & 0.5 & 0.8 & 0.0 & 0.5 & 0.8 & 0.0 & 0.5 & 0.8 \\
\hline aleatória & 1 & - & - & 1 & 3 & 3 & 1 & 4 & 4 \\
& $100.0 \%$ & $19.8 \%$ & $19.8 \%$ & $100.0 \%$ & $94.6 \%$ & $92.2 \%$ & $100.0 \%$ & $99.9 \%$ & $99.8 \%$ \\
alto-vizi & 1 & - & - & 1 & 1 & 1 & 1 & 1 & 1 \\
& $100.0 \%$ & $32.0 \%$ & $29.0 \%$ & $100.0 \%$ & $94.6 \%$ & $92.2 \%$ & $100.0 \%$ & $99.9 \%$ & $99.8 \%$ \\
alto-mens & 1 & - & - & 1 & 1 & 1 & 1 & 1 & 1 \\
& $100.0 \%$ & $32.8 \%$ & $29.4 \%$ & $100.0 \%$ & $94.7 \%$ & $92.4 \%$ & $100.0 \%$ & $99.9 \%$ & $99.8 \%$ \\
alto-reci & 3 & - & - & 2 & 9 & 17 & 1 & 7 & 7 \\
& $100.0 \%$ & $18.1 \%$ & $18.1 \%$ & $100.0 \%$ & $94.6 \%$ & $92.2 \%$ & $100.0 \%$ & $99.9 \%$ & $99.8 \%$ \\
alto-aglo & 2 & - & - & 1 & 5 & 11 & 1 & 8 & 11 \\
& $100.0 \%$ & $15.6 \%$ & $15.6 \%$ & $100.0 \%$ & $94.7 \%$ & $92.2 \%$ & $100.0 \%$ & $99.9 \%$ & $99.8 \%$ \\
anti-aglo & 4 & - & - & 1 & 13 & 15 & 1 & 11 & 11 \\
& $100.0 \%$ & $14.6 \%$ & $14.6 \%$ & $100.0 \%$ & $94.6 \%$ & $92.2 \%$ & $100.0 \%$ & $99.9 \%$ & $99.8 \%$ \\
andarilho & 1 & - & - & 1 & 1 & 2 & 1 & 3 & 1 \\
& $100.0 \%$ & $25.7 \%$ & $25.2 \%$ & $100.0 \%$ & $94.5 \%$ & $92.1 \%$ & $100.0 \%$ & $99.9 \%$ & $99.8 \%$ \\
anda-aglo & 1 & - & - & 1 & 3 & 3 & 1 & 2 & 2 \\
& $100.0 \%$ & $21.4 \%$ & $21.4 \%$ & $100.0 \%$ & $94.6 \%$ & $92.2 \%$ & $100.0 \%$ & $99.9 \%$ & $99.8 \%$
\end{tabular}


Tabela B.3

\begin{tabular}{l|ccc|c|cc|ccc}
\multicolumn{1}{c}{$\tau=2$} & $T=4$ & $D^{*}=1$ \\
\hline$p$ & & 0.2 & & \multicolumn{3}{c|}{0.5} & & \multicolumn{3}{c}{0.8} & \\
\hline$r$ & 0.0 & 0.5 & 0.8 & 0.0 & 0.5 & 0.8 & 0.0 & 0.5 & 0.8 \\
\hline aleatória & 1 & - & - & 1 & 1 & 4 & 1 & 2 & 2 \\
& $100.0 \%$ & $19.7 \%$ & $19.6 \%$ & $100.0 \%$ & $94.1 \%$ & $91.5 \%$ & $100.0 \%$ & $99.8 \%$ & $99.7 \%$ \\
alto-vizi & 1 & - & - & 1 & 1 & 1 & 1 & 1 & 1 \\
& $100.0 \%$ & $24.2 \%$ & $24.0 \%$ & $100.0 \%$ & $94.1 \%$ & $91.3 \%$ & $100.0 \%$ & $99.8 \%$ & $99.7 \%$ \\
alto-mens & 1 & - & - & 1 & 1 & 1 & 1 & 1 & 1 \\
& $100.0 \%$ & $24.3 \%$ & $24.0 \%$ & $100.0 \%$ & $94.4 \%$ & $91.6 \%$ & $100.0 \%$ & $99.7 \%$ & $99.7 \%$ \\
alto-reci & 2 & - & - & 2 & 11 & 5 & 2 & 4 & 10 \\
& $100.0 \%$ & $17.9 \%$ & $17.9 \%$ & $100.0 \%$ & $94.1 \%$ & $91.5 \%$ & $100.0 \%$ & $99.8 \%$ & $99.7 \%$ \\
alto-aglo & 1 & - & - & 1 & 9 & 10 & 1 & 7 & 8 \\
& $100.0 \%$ & $16.4 \%$ & $16.4 \%$ & $100.0 \%$ & $94.1 \%$ & $91.4 \%$ & $100.0 \%$ & $99.8 \%$ & $99.7 \%$ \\
anti-aglo & 3 & - & - & 2 & 14 & 11 & 2 & 7 & 8 \\
& $100.0 \%$ & $15.2 \%$ & $15.2 \%$ & $100.0 \%$ & $94.1 \%$ & $91.4 \%$ & $100.0 \%$ & $99.8 \%$ & $99.7 \%$ \\
andarilho & 1 & - & - & 1 & 1 & 1 & 1 & 1 & 1 \\
& $100.0 \%$ & $22.6 \%$ & $22.5 \%$ & $100.0 \%$ & $94.2 \%$ & $91.5 \%$ & $100.0 \%$ & $99.7 \%$ & $99.7 \%$ \\
anda-aglo & 1 & - & - & 1 & 2 & 1 & 1 & 1 & 1 \\
& $100.0 \%$ & $21.0 \%$ & $21.0 \%$ & $100.0 \%$ & $94.1 \%$ & $91.4 \%$ & $100.0 \%$ & $99.8 \%$ & $99.7 \%$
\end{tabular}

Tabela B.4

\begin{tabular}{l|ccc|c|cc|ccc}
\multicolumn{1}{c}{$\tau=1$} & $T=4$ & $D^{*}=1$ \\
\hline$p$ & & 0.2 & & \multicolumn{7}{c|}{0.5} & & & 0.8 & \\
\hline$r$ & 0.0 & 0.5 & 0.8 & 0.0 & 0.5 & 0.8 & 0.0 & 0.5 & 0.8 \\
\hline aleatória & 1 & - & - & 1 & 1 & 1 & 1 & 1 & 1 \\
& $100.0 \%$ & $18.7 \%$ & $18.6 \%$ & $100.0 \%$ & $88.1 \%$ & $83.4 \%$ & $100.0 \%$ & $98.3 \%$ & $97.7 \%$ \\
alto-vizi & 1 & - & - & 1 & 1 & 1 & 1 & 1 & 1 \\
& $100.0 \%$ & $18.9 \%$ & $19.0 \%$ & $100.0 \%$ & $88.2 \%$ & $82.9 \%$ & $100.0 \%$ & $98.2 \%$ & $97.7 \%$ \\
alto-mens & 1 & - & - & 1 & 1 & 1 & 1 & 1 & 1 \\
& $100.0 \%$ & $18.9 \%$ & $18.8 \%$ & $100.0 \%$ & $88.2 \%$ & $83.1 \%$ & $100.0 \%$ & $98.2 \%$ & $97.6 \%$ \\
alto-reci & 1 & - & - & 1 & 1 & 3 & 1 & 3 & 2 \\
& $100.0 \%$ & $17.4 \%$ & $17.4 \%$ & $100.0 \%$ & $88.1 \%$ & $83.5 \%$ & $100.0 \%$ & $98.2 \%$ & $97.7 \%$ \\
alto-aglo & 2 & - & - & 1 & 3 & 4 & 1 & 2 & 4 \\
& $100.0 \%$ & $17.3 \%$ & $17.2 \%$ & $100.0 \%$ & $88.1 \%$ & $83.5 \%$ & $100.0 \%$ & $98.3 \%$ & $97.7 \%$ \\
anti-aglo & 1 & - & - & 1 & 5 & 8 & 1 & 4 & 4 \\
& $100.0 \%$ & $16.6 \%$ & $16.6 \%$ & $100.0 \%$ & $88.1 \%$ & $83.4 \%$ & $100.0 \%$ & $98.2 \%$ & $97.7 \%$ \\
andarilho & 1 & - & - & 1 & 1 & 1 & 1 & 1 & 1 \\
& $100.0 \%$ & $19.2 \%$ & $19.3 \%$ & $100.0 \%$ & $88.2 \%$ & $83.6 \%$ & $100.0 \%$ & $98.2 \%$ & $97.7 \%$ \\
anda-aglo & 1 & - & - & 1 & 1 & 2 & 1 & 1 & 1 \\
& $100.0 \%$ & $19.0 \%$ & $18.9 \%$ & $100.0 \%$ & $88.2 \%$ & $83.5 \%$ & $100.0 \%$ & $98.2 \%$ & $97.7 \%$
\end{tabular}


Tabela B.5

\begin{tabular}{|c|c|c|c|c|c|c|c|c|c|}
\hline \multicolumn{10}{|c|}{$\tau=-2 \mid T=4$} \\
\hline$p$ & \multicolumn{3}{|c|}{0.2} & \multicolumn{3}{|c|}{0.5} & \multicolumn{3}{|c|}{0.8} \\
\hline$r$ & 0.0 & 0.5 & 0.8 & 0.0 & 0.5 & 0.8 & 0.0 & 0.5 & 0.8 \\
\hline \multirow[t]{2}{*}{ aleatória } & 1 & - & - & 1 & - & - & 1 & 1 & 1 \\
\hline & $100.0 \%$ & $16.8 \%$ & $16.8 \%$ & $100.0 \%$ & $35.1 \%$ & $23.8 \%$ & $100.0 \%$ & $87.7 \%$ & $84.2 \%$ \\
\hline \multirow[t]{2}{*}{ alto-vizi } & 1 & - & - & 1 & - & - & 1 & 1 & 1 \\
\hline & $100.0 \%$ & $16.7 \%$ & $16.7 \%$ & $100.0 \%$ & $35.3 \%$ & $23.5 \%$ & $100.0 \%$ & $87.4 \%$ & $84.2 \%$ \\
\hline \multirow[t]{2}{*}{ alto-mens } & 1 & - & - & 1 & - & - & 1 & 1 & 1 \\
\hline & $100.0 \%$ & $16.6 \%$ & $16.6 \%$ & $100.0 \%$ & $35.2 \%$ & $23.4 \%$ & $100.0 \%$ & $87.6 \%$ & $84.0 \%$ \\
\hline \multirow[t]{2}{*}{ alto-reci } & 2 & - & - & 1 & - & - & 1 & 1 & 2 \\
\hline & $100.0 \%$ & $16.1 \%$ & $16.1 \%$ & $100.0 \%$ & $35.3 \%$ & $22.1 \%$ & $100.0 \%$ & $87.5 \%$ & $84.1 \%$ \\
\hline \multirow{2}{*}{ alto-aglo } & 1 & - & - & 1 & - & - & 1 & 1 & 1 \\
\hline & $100.0 \%$ & $16.2 \%$ & $16.2 \%$ & $100.0 \%$ & $35.3 \%$ & $22.3 \%$ & $100.0 \%$ & $87.6 \%$ & $84.3 \%$ \\
\hline \multirow[t]{2}{*}{ anti-aglo } & 1 & - & - & 2 & - & - & 2 & 3 & 1 \\
\hline & $100.0 \%$ & $15.8 \%$ & $15.8 \%$ & $100.0 \%$ & $35.3 \%$ & $21.5 \%$ & $100.0 \%$ & $87.7 \%$ & $84.1 \%$ \\
\hline \multirow[t]{2}{*}{ andarilho } & 1 & - & - & 1 & - & - & 1 & 1 & 1 \\
\hline & $100.0 \%$ & $16.9 \%$ & $16.9 \%$ & $100.0 \%$ & $35.3 \%$ & $24.3 \%$ & $100.0 \%$ & $87.7 \%$ & $84.2 \%$ \\
\hline \multirow[t]{2}{*}{ anda-aglo } & 1 & - & - & 1 & - & - & 1 & 1 & 1 \\
\hline & $100.0 \%$ & $16.8 \%$ & $16.8 \%$ & $100.0 \%$ & $35.3 \%$ & $23.9 \%$ & $100.0 \%$ & $87.6 \%$ & $84.2 \%$ \\
\hline
\end{tabular}

Tabela B.6

\begin{tabular}{|c|c|c|c|c|c|c|c|c|c|}
\hline \multicolumn{10}{|c|}{$\tau=-8$} \\
\hline$p$ & \multicolumn{3}{|c|}{0.2} & \multicolumn{3}{|c|}{0.5} & \multicolumn{3}{|c|}{0.8} \\
\hline$r$ & 0.0 & 0.5 & 0.8 & 0.0 & 0.5 & 0.8 & 0.0 & 0.5 & 0.8 \\
\hline \multirow[t]{2}{*}{ aleatória } & 2 & - & - & 1 & - & - & 1 & - & - \\
\hline & $99.8 \%$ & $14.7 \%$ & $14.7 \%$ & $100.0 \%$ & $18.0 \%$ & $18.0 \%$ & $100.0 \%$ & $21.4 \%$ & $21.5 \%$ \\
\hline \multirow[t]{2}{*}{ alto-vizi } & 1 & - & - & 1 & - & - & 1 & - & - \\
\hline & $99.7 \%$ & $14.4 \%$ & $14.5 \%$ & $100.0 \%$ & $17.5 \%$ & $17.5 \%$ & $100.0 \%$ & $20.7 \%$ & $20.7 \%$ \\
\hline \multirow[t]{2}{*}{ alto-mens } & 1 & - & - & 1 & - & - & 1 & - & - \\
\hline & $99.7 \%$ & $14.4 \%$ & $14.4 \%$ & $100.0 \%$ & $17.4 \%$ & $17.4 \%$ & $100.0 \%$ & $20.5 \%$ & $20.5 \%$ \\
\hline \multirow[t]{2}{*}{ alto-reci } & 2 & - & - & 1 & - & - & 2 & - & - \\
\hline & $99.7 \%$ & $14.4 \%$ & $14.4 \%$ & $100.0 \%$ & $17.4 \%$ & $17.4 \%$ & $100.0 \%$ & $20.4 \%$ & $20.4 \%$ \\
\hline \multirow[t]{2}{*}{ alto-aglo } & 2 & - & - & 1 & - & - & 1 & - & - \\
\hline & $99.7 \%$ & $14.5 \%$ & $14.5 \%$ & $100.0 \%$ & $17.5 \%$ & $17.5 \%$ & $100.0 \%$ & $20.5 \%$ & $20.5 \%$ \\
\hline \multirow[t]{2}{*}{ anti-aglo } & 3 & - & - & 2 & - & - & 1 & - & - \\
\hline & $99.8 \%$ & $14.5 \%$ & $14.5 \%$ & $100.0 \%$ & $17.5 \%$ & $17.5 \%$ & $100.0 \%$ & $20.5 \%$ & $20.5 \%$ \\
\hline \multirow[t]{2}{*}{ andarilho } & 1 & - & - & 1 & - & - & 1 & - & - \\
\hline & $99.7 \%$ & $14.6 \%$ & $14.6 \%$ & $100.0 \%$ & $17.9 \%$ & $17.9 \%$ & $100.0 \%$ & $21.4 \%$ & $21.3 \%$ \\
\hline \multirow[t]{2}{*}{ anda-aglo } & 2 & - & - & 1 & - & - & 1 & - & - \\
\hline & $99.8 \%$ & $14.6 \%$ & $14.6 \%$ & $100.0 \%$ & $17.8 \%$ & $17.8 \%$ & $100.0 \%$ & $21.2 \%$ & $21.2 \%$ \\
\hline
\end{tabular}


Tabela B.7

\begin{tabular}{|c|c|c|c|c|c|c|c|c|c|}
\hline \multicolumn{10}{|c|}{$\tau=64|T=4| D^{*}=2$} \\
\hline$p$ & \multicolumn{3}{|c|}{0.2} & \multicolumn{3}{|c|}{0.5} & \multicolumn{3}{|c|}{0.8} \\
\hline$r$ & 0.0 & 0.5 & 0.8 & 0.0 & 0.5 & 0.8 & 0.0 & 0.5 & 0.8 \\
\hline \multirow[t]{2}{*}{ aleatória } & 46 & - & - & 2 & - & - & 1 & - & - \\
\hline & $99.8 \%$ & $12.9 \%$ & $12.9 \%$ & $100.0 \%$ & $14.5 \%$ & $14.5 \%$ & $100.0 \%$ & $17.3 \%$ & $17.3 \%$ \\
\hline \multirow[t]{2}{*}{ alto-vizi } & 1 & - & - & 1 & - & - & 1 & 1562 & 3075 \\
\hline & $99.7 \%$ & $14.0 \%$ & $14.0 \%$ & $100.0 \%$ & $22.0 \%$ & $20.7 \%$ & $100.0 \%$ & $97.6 \%$ & $96.1 \%$ \\
\hline \multirow[t]{2}{*}{ alto-mens } & 1 & - & - & 1 & - & - & 1 & 1389 & 2843 \\
\hline & $99.3 \%$ & $14.0 \%$ & $14.0 \%$ & $100.0 \%$ & $22.5 \%$ & $20.8 \%$ & $100.0 \%$ & $97.6 \%$ & $96.1 \%$ \\
\hline \multirow[t]{2}{*}{ alto-reci } & 298 & - & - & 6 & - & - & 4 & - & - \\
\hline & $99.8 \%$ & $12.8 \%$ & $12.8 \%$ & $100.0 \%$ & $14.0 \%$ & $14.0 \%$ & $100.0 \%$ & $16.1 \%$ & $16.1 \%$ \\
\hline \multirow[t]{2}{*}{ alto-aglo } & 196 & - & - & 8 & - & - & 3 & - & - \\
\hline & $99.6 \%$ & $12.6 \%$ & $12.6 \%$ & $100.0 \%$ & $13.2 \%$ & $13.2 \%$ & $100.0 \%$ & $14.2 \%$ & $14.2 \%$ \\
\hline \multirow[t]{2}{*}{ anti-aglo } & 320 & - & - & 4 & - & - & 3 & - & - \\
\hline & $98.9 \%$ & $12.6 \%$ & $12.6 \%$ & $100.0 \%$ & $13.0 \%$ & $13.0 \%$ & $100.0 \%$ & $13.5 \%$ & $13.5 \%$ \\
\hline \multirow[t]{2}{*}{ andarilho } & 18 & - & - & 2 & - & - & 1 & 3451 & - \\
\hline & $99.8 \%$ & $13.4 \%$ & $13.4 \%$ & $100.0 \%$ & $17.5 \%$ & $17.5 \%$ & $100.0 \%$ & $97.6 \%$ & $27.3 \%$ \\
\hline \multirow[t]{2}{*}{ anda-aglo } & 20 & - & - & 2 & - & - & 2 & - & - \\
\hline & $99.7 \%$ & $13.0 \%$ & $13.0 \%$ & $100.0 \%$ & $15.4 \%$ & $15.3 \%$ & $100.0 \%$ & $72.5 \%$ & $19.2 \%$ \\
\hline
\end{tabular}

Tabela B.8

\begin{tabular}{|c|c|c|c|c|c|c|c|c|c|}
\hline \multicolumn{10}{|c|}{$\tau=8 \mid T=4$} \\
\hline$p$ & \multicolumn{3}{|c|}{0.2} & \multicolumn{3}{|c|}{0.5} & \multicolumn{3}{|c|}{0.8} \\
\hline$r$ & 0.0 & 0.5 & 0.8 & 0.0 & 0.5 & 0.8 & 0.0 & 0.5 & 0.8 \\
\hline \multirow[t]{2}{*}{ aleatória } & 44 & - & - & 4 & - & - & 2 & - & - \\
\hline & $99.8 \%$ & $12.9 \%$ & $12.9 \%$ & $100.0 \%$ & $14.5 \%$ & $14.5 \%$ & $100.0 \%$ & $17.3 \%$ & $17.2 \%$ \\
\hline \multirow[t]{2}{*}{ alto-vizi } & 4 & - & - & 1 & - & - & 1 & 1660 & 3164 \\
\hline & $99.7 \%$ & $13.9 \%$ & $13.9 \%$ & $100.0 \%$ & $21.6 \%$ & $20.4 \%$ & $100.0 \%$ & $97.5 \%$ & $96.1 \%$ \\
\hline \multirow[t]{2}{*}{ alto-mens } & 3 & - & 一 & 1 & - & - & 1 & 1494 & 2876 \\
\hline & $99.7 \%$ & $14.0 \%$ & $14.0 \%$ & $100.0 \%$ & $22.3 \%$ & $20.7 \%$ & $100.0 \%$ & $97.6 \%$ & $96.2 \%$ \\
\hline \multirow[t]{2}{*}{ alto-reci } & 291 & - & - & 7 & - & - & 4 & - & - \\
\hline & $99.4 \%$ & $12.8 \%$ & $12.8 \%$ & $100.0 \%$ & $14.0 \%$ & $14.1 \%$ & $100.0 \%$ & $16.2 \%$ & $16.2 \%$ \\
\hline \multirow{2}{*}{ alto-aglo } & 185 & - & - & 6 & - & - & 5 & - & - \\
\hline & $99.7 \%$ & $12.6 \%$ & $12.6 \%$ & $100.0 \%$ & $13.2 \%$ & $13.2 \%$ & $100.0 \%$ & $14.1 \%$ & $14.1 \%$ \\
\hline \multirow[t]{2}{*}{ anti-aglo } & 331 & - & - & 9 & - & - & 5 & - & - \\
\hline & $99.8 \%$ & $12.6 \%$ & $12.6 \%$ & $100.0 \%$ & $12.9 \%$ & $12.9 \%$ & $100.0 \%$ & $13.5 \%$ & $13.5 \%$ \\
\hline \multirow[t]{2}{*}{ andarilho } & 18 & - & - & 1 & - & - & 1 & 3501 & - \\
\hline & $99.9 \%$ & $13.3 \%$ & $13.4 \%$ & $100.0 \%$ & $17.4 \%$ & $17.4 \%$ & $100.0 \%$ & $97.6 \%$ & $26.0 \%$ \\
\hline \multirow[t]{2}{*}{ anda-aglo } & 17 & - & - & 2 & - & - & 1 & - & - \\
\hline & $99.7 \%$ & $13.0 \%$ & $13.0 \%$ & $100.0 \%$ & $15.3 \%$ & $15.4 \%$ & $100.0 \%$ & $47.2 \%$ & $19.2 \%$ \\
\hline
\end{tabular}


Tabela B.9

\begin{tabular}{|c|c|c|c|c|c|c|c|c|c|}
\hline \multicolumn{10}{|c|}{$\tau=2 \mid T=4$} \\
\hline$p$ & \multicolumn{3}{|c|}{0.2} & \multicolumn{3}{|c|}{0.5} & \multicolumn{3}{|c|}{0.8} \\
\hline$r$ & 0.0 & 0.5 & 0.8 & 0.0 & 0.5 & 0.8 & 0.0 & 0.5 & 0.8 \\
\hline \multirow[t]{2}{*}{ aleatória } & 23 & - & - & 2 & - & - & 1 & - & - \\
\hline & $99.6 \%$ & $12.8 \%$ & $12.9 \%$ & $100.0 \%$ & $14.4 \%$ & $14.4 \%$ & $100.0 \%$ & $17.1 \%$ & $17.1 \%$ \\
\hline \multirow[t]{2}{*}{ alto-vizi } & 15 & - & - & 1 & - & - & 1 & 3365 & 一 \\
\hline & $99.5 \%$ & $13.2 \%$ & $13.2 \%$ & $100.0 \%$ & $16.5 \%$ & $16.6 \%$ & $100.0 \%$ & $96.7 \%$ & $24.6 \%$ \\
\hline \multirow[t]{2}{*}{ alto-mens } & 8 & - & - & 1 & - & 一 & 1 & 3232 & 一 \\
\hline & $98.7 \%$ & $13.2 \%$ & $13.2 \%$ & $100.0 \%$ & $16.5 \%$ & $16.5 \%$ & $100.0 \%$ & $96.7 \%$ & $25.4 \%$ \\
\hline \multirow[t]{2}{*}{ alto-reci } & 143 & - & - & 6 & - & - & 4 & - & - \\
\hline & $99.7 \%$ & $12.7 \%$ & $12.7 \%$ & $100.0 \%$ & $13.9 \%$ & $13.9 \%$ & $100.0 \%$ & $15.9 \%$ & $15.9 \%$ \\
\hline \multirow[t]{2}{*}{ alto-aglo } & 108 & - & - & 6 & - & 一 & 6 & 一 & - \\
\hline & $99.6 \%$ & $12.6 \%$ & $12.6 \%$ & $100.0 \%$ & $13.5 \%$ & $13.5 \%$ & $100.0 \%$ & $14.7 \%$ & $14.8 \%$ \\
\hline \multirow[t]{2}{*}{ anti-aglo } & 159 & - & - & 3 & - & - & 4 & 一 & 一 \\
\hline & $99.6 \%$ & $12.6 \%$ & $12.6 \%$ & $100.0 \%$ & $13.1 \%$ & $13.1 \%$ & $100.0 \%$ & $14.0 \%$ & $14.0 \%$ \\
\hline \multirow[t]{2}{*}{ andarilho } & 16 & - & - & 1 & - & - & 1 & 4800 & - \\
\hline & $99.7 \%$ & $13.0 \%$ & $13.1 \%$ & $100.0 \%$ & $15.7 \%$ & $15.7 \%$ & $100.0 \%$ & $96.7 \%$ & $20.1 \%$ \\
\hline \multirow[t]{2}{*}{ anda-aglo } & 15 & - & - & 2 & - & - & 1 & - & - \\
\hline & $99.5 \%$ & $13.0 \%$ & $12.9 \%$ & $100.0 \%$ & $15.1 \%$ & $15.1 \%$ & $100.0 \%$ & $18.8 \%$ & $18.7 \%$ \\
\hline
\end{tabular}

Tabela B.10

\begin{tabular}{|c|c|c|c|c|c|c|c|c|c|}
\hline \multicolumn{10}{|c|}{$\tau=1 \mid T=4$} \\
\hline$p$ & \multicolumn{3}{|c|}{0.2} & \multicolumn{3}{|c|}{0.5} & \multicolumn{3}{|c|}{0.8} \\
\hline$r$ & 0.0 & 0.5 & 0.8 & 0.0 & 0.5 & 0.8 & 0.0 & 0.5 & 0.8 \\
\hline \multirow[t]{2}{*}{ aleatória } & 36 & - & - & 1 & - & - & 1 & - & - \\
\hline & $.8 \%$ & $12.8 \%$ & $12.8 \%$ & $100.0 \%$ & $14.0 \%$ & $14.0 \%$ & $100.0 \%$ & $16.1 \%$ & $16.2 \%$ \\
\hline \multirow[t]{2}{*}{ alto-vizi } & 76 & - & 一 & 1 & - & - & 1 & 一 & 一 \\
\hline & $98.6 \%$ & $12.7 \%$ & $12.7 \%$ & $100.0 \%$ & $13.8 \%$ & $13.8 \%$ & $100.0 \%$ & $15.8 \%$ & $15.9 \%$ \\
\hline \multirow[t]{2}{*}{ alto-mens } & 46 & - & - & 4 & - & - & 2 & - & - \\
\hline & $98.3 \%$ & $12.7 \%$ & $12.7 \%$ & $100.0 \%$ & $13.8 \%$ & $13.8 \%$ & $100.0 \%$ & $15.6 \%$ & $15.6 \%$ \\
\hline \multirow{2}{*}{ alto-reci } & 99 & - & - & 3 & 一 & - & 2 & - & 一 \\
\hline & $99.0 \%$ & $12.7 \%$ & $12.7 \%$ & $100.0 \%$ & $13.8 \%$ & $13.8 \%$ & $100.0 \%$ & $15.5 \%$ & $15.6 \%$ \\
\hline \multirow[t]{2}{*}{ alto-aglo } & 74 & - & 一 & 2 & - & - & 2 & - & - \\
\hline & $98.6 \%$ & $12.7 \%$ & $12.8 \%$ & $100.0 \%$ & $13.8 \%$ & $13.8 \%$ & $100.0 \%$ & $15.6 \%$ & $15.6 \%$ \\
\hline \multirow[t]{2}{*}{ anti-aglo } & & - & 一 & 2 & - & - & 2 & - & - \\
\hline & $98.8 \%$ & $12.7 \%$ & $12.7 \%$ & $100.0 \%$ & $13.6 \%$ & $13.6 \%$ & $100.0 \%$ & $15.1 \%$ & $15.1 \%$ \\
\hline \multirow[t]{2}{*}{ andarilho } & 36 & - & - & 1 & - & - & 1 & - & - \\
\hline & $98.5 \%$ & $12.8 \%$ & $12.8 \%$ & $100.0 \%$ & $14.0 \%$ & $14.0 \%$ & $100.0 \%$ & $16.2 \%$ & $16.2 \%$ \\
\hline \multirow[t]{2}{*}{ anda-aglo } & 35 & - & - & 1 & - & - & 1 & - & - \\
\hline & $98.8 \%$ & $12.8 \%$ & $12.8 \%$ & $100.0 \%$ & $14.1 \%$ & $14.0 \%$ & $100.0 \%$ & $16.4 \%$ & $16.4 \%$ \\
\hline
\end{tabular}




\section{Tabela B.11}

\begin{tabular}{|c|c|c|c|c|c|c|c|c|c|}
\hline \multicolumn{10}{|c|}{$\tau=-2|T=4| D^{*}=2$} \\
\hline$p$ & \multicolumn{3}{|c|}{0.2} & \multicolumn{3}{|c|}{0.5} & \multicolumn{3}{|c|}{0.8} \\
\hline$r$ & 0.0 & 0.5 & 0.8 & 0.0 & 0.5 & 0.8 & 0.0 & 0.5 & 0.8 \\
\hline \multirow[t]{2}{*}{ aleatória } & 3154 & - & - & 5 & - & - & 2 & - & - \\
\hline & $95.6 \%$ & $12.6 \%$ & $12.6 \%$ & $99.5 \%$ & $13.2 \%$ & $13.2 \%$ & $100.0 \%$ & $14.2 \%$ & $14.3 \%$ \\
\hline \multirow[t]{2}{*}{ alto-vizi } & 4060 & - & - & 14 & - & - & 4 & - & - \\
\hline & $95.7 \%$ & $12.6 \%$ & $12.6 \%$ & $98.7 \%$ & $13.0 \%$ & $13.0 \%$ & $100.0 \%$ & $13.8 \%$ & $13.8 \%$ \\
\hline \multirow{2}{*}{ alto-mens } & 4095 & - & - & 7 & - & - & 2 & - & 一 \\
\hline & $95.7 \%$ & $12.6 \%$ & $12.6 \%$ & $98.7 \%$ & $13.0 \%$ & $13.0 \%$ & $100.0 \%$ & $13.7 \%$ & $13.7 \%$ \\
\hline \multirow[t]{2}{*}{ alto-reci } & 3619 & - & - & 10 & - & - & 2 & - & - \\
\hline & $96.0 \%$ & $12.6 \%$ & $12.6 \%$ & $99.6 \%$ & $13.2 \%$ & $13.2 \%$ & $100.0 \%$ & $14.2 \%$ & $14.2 \%$ \\
\hline \multirow[t]{2}{*}{ alto-aglo } & 3145 & - & - & 6 & - & - & 2 & - & - \\
\hline & $95.3 \%$ & $12.6 \%$ & $12.6 \%$ & $99.5 \%$ & $13.2 \%$ & $13.2 \%$ & $100.0 \%$ & $14.3 \%$ & $14.3 \%$ \\
\hline \multirow[t]{2}{*}{ anti-aglo } & 3637 & - & - & 9 & - & - & 4 & - & - \\
\hline & $96.5 \%$ & $12.6 \%$ & $12.6 \%$ & $99.2 \%$ & $13.2 \%$ & $13.2 \%$ & $100.0 \%$ & $14.3 \%$ & $14.3 \%$ \\
\hline \multirow[t]{2}{*}{ andarilho } & 3314 & - & - & 5 & - & - & 1 & - & - \\
\hline & $95.4 \%$ & $12.6 \%$ & $12.6 \%$ & $99.2 \%$ & $13.1 \%$ & $13.1 \%$ & $100.0 \%$ & $14.0 \%$ & $14.0 \%$ \\
\hline \multirow[t]{2}{*}{ anda-aglo } & 3248 & - & - & 6 & - & - & 1 & - & - \\
\hline & $95.6 \%$ & $12.6 \%$ & $12.6 \%$ & $99.5 \%$ & $13.1 \%$ & $13.1 \%$ & $100.0 \%$ & $14.1 \%$ & $14.1 \%$ \\
\hline
\end{tabular}

\section{Tabela B.12}

\begin{tabular}{|c|c|c|c|c|c|c|c|c|c|}
\hline \multicolumn{10}{|c|}{$\tau=-8 \mid T=4$} \\
\hline$p$ & \multicolumn{3}{|c|}{0.2} & \multicolumn{3}{|c|}{0.5} & \multicolumn{3}{|c|}{0.8} \\
\hline$r$ & 0.0 & 0.5 & 0.8 & 0.0 & 0.5 & 0.8 & 0.0 & 0.5 & 0.8 \\
\hline \multirow[t]{2}{*}{ aleatória } & - & - & - & - & - & - & - & - & - \\
\hline & $13.3 \%$ & $12.5 \%$ & $12.5 \%$ & $16.8 \%$ & $12.5 \%$ & $12.5 \%$ & $22.0 \%$ & $12.6 \%$ & $12.6 \%$ \\
\hline \multirow[t]{2}{*}{ alto-vizi } & - & - & - & - & 一 & - & - & 一 & - \\
\hline & $12.5 \%$ & $12.5 \%$ & $12.5 \%$ & $12.5 \%$ & $12.5 \%$ & $12.5 \%$ & $12.5 \%$ & $12.5 \%$ & $12.5 \%$ \\
\hline \multirow[t]{2}{*}{ alto-mens } & - & 一 & - & 一 & 一 & 一 & - & 一 & 一 \\
\hline & $12.5 \%$ & $12.5 \%$ & $12.5 \%$ & $12.5 \%$ & $12.5 \%$ & $12.5 \%$ & $12.5 \%$ & $12.5 \%$ & $12.5 \%$ \\
\hline \multirow[t]{2}{*}{ alto-reci } & - & - & - & - & - & - & - & - & - \\
\hline & $13.5 \%$ & $12.5 \%$ & $12.5 \%$ & $16.9 \%$ & $12.6 \%$ & $12.6 \%$ & $21.2 \%$ & $12.6 \%$ & $12.6 \%$ \\
\hline \multirow[t]{2}{*}{ alto-aglo } & - & - & - & - & 一 & 一 & - & - & - \\
\hline & $14.0 \%$ & $12.5 \%$ & $12.5 \%$ & $19.7 \%$ & $12.6 \%$ & $12.6 \%$ & $27.5 \%$ & $12.7 \%$ & $12.7 \%$ \\
\hline \multirow[t]{2}{*}{ anti-aglo } & - & - & - & - & - & - & - & - & - \\
\hline & $14.0 \%$ & $12.5 \%$ & $12.5 \%$ & $19.4 \%$ & $12.6 \%$ & $12.6 \%$ & $27.0 \%$ & $12.7 \%$ & $12.7 \%$ \\
\hline \multirow[t]{2}{*}{ andarilho } & - & - & - & - & - & - & - & - & - \\
\hline & $12.7 \%$ & $12.5 \%$ & $12.5 \%$ & $13.7 \%$ & $12.5 \%$ & $12.5 \%$ & $15.2 \%$ & $12.5 \%$ & $12.5 \%$ \\
\hline \multirow[t]{2}{*}{ anda-aglo } & - & - & - & - & - & - & - & - & - \\
\hline & $12.9 \%$ & $12.5 \%$ & $12.5 \%$ & $14.6 \%$ & $12.5 \%$ & $12.5 \%$ & $17.5 \%$ & $12.5 \%$ & $12.5 \%$ \\
\hline
\end{tabular}


Tabela B.13

\begin{tabular}{|c|c|c|c|c|c|c|c|c|c|}
\hline \multicolumn{10}{|c|}{$\tau=64 \mid T=4$} \\
\hline$p$ & \multicolumn{3}{|c|}{0.2} & \multicolumn{3}{|c|}{0.5} & \multicolumn{3}{|c|}{0.8} \\
\hline$r$ & 0.0 & 0.5 & 0.8 & 0.0 & 0.5 & 0.8 & 0.0 & 0.5 & 0.8 \\
\hline \multirow[t]{2}{*}{ aleatória } & - & - & - & 479 & - & - & 21 & - & - \\
\hline & $37.8 \%$ & $12.5 \%$ & $12.5 \%$ & $99.7 \%$ & $12.7 \%$ & $12.7 \%$ & $99.9 \%$ & $13.2 \%$ & $13.2 \%$ \\
\hline \multirow[t]{2}{*}{ alto-vizi } & 3375 & - & - & 30 & 一 & - & 1 & 一 & - \\
\hline & $96.5 \%$ & $12.6 \%$ & $12.6 \%$ & $99.7 \%$ & $13.4 \%$ & $13.4 \%$ & $99.9 \%$ & $17.3 \%$ & $16.4 \%$ \\
\hline \multirow[t]{2}{*}{ alto-mens } & 3171 & - & - & 23 & 一 & - & 1 & - & - \\
\hline & $97.1 \%$ & $12.6 \%$ & $12.6 \%$ & $99.5 \%$ & $13.5 \%$ & $13.5 \%$ & $99.9 \%$ & $17.8 \%$ & $16.6 \%$ \\
\hline \multirow[t]{2}{*}{ alto-reci } & - & - & - & 813 & - & - & 175 & - & - \\
\hline & $29.0 \%$ & $12.5 \%$ & $12.5 \%$ & $99.5 \%$ & $12.6 \%$ & $12.6 \%$ & $99.9 \%$ & $13.1 \%$ & $13.1 \%$ \\
\hline \multirow{2}{*}{ alto-aglo } & - & - & - & 1195 & - & - & 100 & - & - \\
\hline & $18.9 \%$ & $12.5 \%$ & $12.5 \%$ & $98.7 \%$ & $12.6 \%$ & $12.6 \%$ & $99.9 \%$ & $12.7 \%$ & $12.7 \%$ \\
\hline \multirow[t]{2}{*}{ anti-aglo } & - & - & - & 2690 & - & - & 117 & - & - \\
\hline & $15.4 \%$ & $12.5 \%$ & $12.5 \%$ & $99.2 \%$ & $12.5 \%$ & $12.5 \%$ & $99.9 \%$ & $12.6 \%$ & $12.6 \%$ \\
\hline \multirow[t]{2}{*}{ andarilho } & 4693 & - & - & 174 & - & - & 10 & - & - \\
\hline & $97.3 \%$ & $12.5 \%$ & $12.5 \%$ & $99.7 \%$ & $13.0 \%$ & $13.0 \%$ & $99.9 \%$ & $14.6 \%$ & $14.6 \%$ \\
\hline \multirow[t]{2}{*}{ anda-aglo } & - & - & - & 234 & - & - & 10 & - & - \\
\hline & $76.4 \%$ & $12.5 \%$ & $12.5 \%$ & $99.5 \%$ & $12.8 \%$ & $12.8 \%$ & $99.9 \%$ & $13.6 \%$ & $13.6 \%$ \\
\hline
\end{tabular}

\section{Tabela B.14}

\begin{tabular}{|c|c|c|c|c|c|c|c|c|c|}
\hline \multicolumn{10}{|c|}{$\tau=8$} \\
\hline$p$ & \multicolumn{3}{|c|}{0.2} & \multicolumn{3}{|c|}{0.5} & \multicolumn{3}{|c|}{0.8} \\
\hline$r$ & 0.0 & 0.5 & 0.8 & 0.0 & 0.5 & 0.8 & 0.0 & 0.5 & 0.8 \\
\hline \multirow[t]{2}{*}{ aleatória } & - & - & - & 518 & - & - & 22 & - & - \\
\hline & $37.1 \%$ & $12.5 \%$ & $12.5 \%$ & $99.8 \%$ & $12.7 \%$ & $12.7 \%$ & $99.9 \%$ & $13.2 \%$ & $13.2 \%$ \\
\hline \multirow[t]{2}{*}{ alto-vizi } & 3390 & - & - & 44 & - & - & 3 & - & - \\
\hline & $96.2 \%$ & $12.6 \%$ & $12.6 \%$ & $99.1 \%$ & $13.4 \%$ & $13.4 \%$ & $99.9 \%$ & $16.9 \%$ & $16.3 \%$ \\
\hline \multirow[t]{2}{*}{ alto-mens } & 3176 & - & - & 26 & - & - & 2 & - & - \\
\hline & $96.7 \%$ & $12.6 \%$ & $12.6 \%$ & $99.3 \%$ & $13.5 \%$ & $13.5 \%$ & $100.0 \%$ & $17.5 \%$ & $16.6 \%$ \\
\hline \multirow{2}{*}{ alto-reci } & - & - & - & 783 & - & - & 125 & - & - \\
\hline & $29.2 \%$ & $12.5 \%$ & $12.5 \%$ & $99.4 \%$ & $12.6 \%$ & $12.6 \%$ & $99.9 \%$ & $13.1 \%$ & $13.1 \%$ \\
\hline \multirow[t]{2}{*}{ alto-aglo } & - & - & - & 1134 & - & - & 96 & - & - \\
\hline & $19.3 \%$ & $12.5 \%$ & $12.5 \%$ & $99.6 \%$ & $12.6 \%$ & $12.6 \%$ & $99.8 \%$ & $12.8 \%$ & $12.8 \%$ \\
\hline \multirow[t]{2}{*}{ anti-aglo } & - & - & - & 2669 & - & - & 123 & - & - \\
\hline & $15.3 \%$ & $12.5 \%$ & $12.5 \%$ & $99.6 \%$ & $12.5 \%$ & $12.5 \%$ & $99.9 \%$ & $12.6 \%$ & $12.6 \%$ \\
\hline \multirow[t]{2}{*}{ andarilho } & 4601 & - & - & 174 & - & - & 10 & - & - \\
\hline & $96.8 \%$ & $12.5 \%$ & $12.5 \%$ & $99.5 \%$ & $13.0 \%$ & $13.0 \%$ & $99.9 \%$ & $14.5 \%$ & $14.5 \%$ \\
\hline \multirow[t]{2}{*}{ anda-aglo } & - & - & - & 248 & - & - & 11 & - & - \\
\hline & $76.3 \%$ & $12.5 \%$ & $12.5 \%$ & $99.8 \%$ & $12.8 \%$ & $12.8 \%$ & $99.8 \%$ & $13.6 \%$ & $13.6 \%$ \\
\hline
\end{tabular}




\section{Tabela B.15}

\begin{tabular}{|c|c|c|c|c|c|c|c|c|c|}
\hline \multirow[b]{2}{*}{$p$} & \multicolumn{3}{|r|}{$\tau=2$} & \multicolumn{6}{|c|}{$D^{*}=3$} \\
\hline & \multicolumn{3}{|c|}{0.2} & \multicolumn{3}{|c|}{0.5} & \multicolumn{3}{|c|}{0.8} \\
\hline$r$ & 0.0 & 0.5 & 0.8 & 0.0 & 0.5 & 0.8 & 0.0 & 0.5 & 0.8 \\
\hline \multirow[t]{2}{*}{ aleatória } & - & - & - & 357 & - & - & 6 & - & - \\
\hline & $37.7 \%$ & $12.5 \%$ & $12.5 \%$ & $99.3 \%$ & $12.6 \%$ & $12.7 \%$ & $99.9 \%$ & $13.1 \%$ & $13.1 \%$ \\
\hline \multirow{2}{*}{ alto-vizi } & - & - & - & 211 & - & - & 5 & - & - \\
\hline & $89.4 \%$ & $12.5 \%$ & $12.5 \%$ & $99.3 \%$ & $12.8 \%$ & $12.8 \%$ & $99.9 \%$ & $13.9 \%$ & $13.9 \%$ \\
\hline \multirow[t]{2}{*}{ alto-mens } & - & - & - & 117 & - & - & 4 & - & - \\
\hline & $90.0 \%$ & $12.5 \%$ & $12.5 \%$ & $99.0 \%$ & $12.8 \%$ & $12.8 \%$ & $99.9 \%$ & $13.9 \%$ & $13.9 \%$ \\
\hline \multirow[t]{2}{*}{ alto-reci } & - & - & - & 721 & - & - & 36 & - & - \\
\hline & $28.3 \%$ & $12.5 \%$ & $12.5 \%$ & $99.3 \%$ & $12.6 \%$ & $12.6 \%$ & $99.9 \%$ & $13.0 \%$ & $13.0 \%$ \\
\hline \multirow[t]{2}{*}{ alto-aglo } & - & - & - & 816 & - & - & 27 & - & - \\
\hline & $21.8 \%$ & $12.5 \%$ & $12.5 \%$ & $99.3 \%$ & $12.6 \%$ & $12.6 \%$ & $99.9 \%$ & $12.8 \%$ & $12.8 \%$ \\
\hline \multirow[t]{2}{*}{ anti-aglo } & - & - & - & 1293 & - & - & 20 & - & - \\
\hline & $17.5 \%$ & $12.5 \%$ & $12.5 \%$ & $99.5 \%$ & $12.5 \%$ & $12.5 \%$ & $99.8 \%$ & $12.7 \%$ & $12.7 \%$ \\
\hline \multirow[t]{2}{*}{ andarilho } & - & - & - & 229 & - & - & 3 & - & - \\
\hline & $84.1 \%$ & $12.5 \%$ & $12.5 \%$ & $99.4 \%$ & $12.7 \%$ & $12.8 \%$ & $99.9 \%$ & $13.6 \%$ & $13.5 \%$ \\
\hline \multirow[t]{2}{*}{ anda-aglo } & - & - & - & 227 & - & - & 5 & - & - \\
\hline & $67.1 \%$ & $12.5 \%$ & $12.5 \%$ & $99.4 \%$ & $12.7 \%$ & $12.7 \%$ & $99.9 \%$ & $13.4 \%$ & $13.4 \%$ \\
\hline
\end{tabular}

\section{Tabela B.16}

\begin{tabular}{|c|c|c|c|c|c|c|c|c|c|}
\hline \multirow{2}{*}{$p$} & \multicolumn{3}{|r|}{$\tau=1$} & \multicolumn{6}{|c|}{$D^{*}=3$} \\
\hline & \multicolumn{3}{|c|}{0.2} & \multicolumn{3}{|c|}{0.5} & \multicolumn{3}{|c|}{0.8} \\
\hline$r$ & 0.0 & 0.5 & 0.8 & 0.0 & 0.5 & 0.8 & 0.0 & 0.5 & 0.8 \\
\hline \multirow[t]{2}{*}{ aleatória } & - & - & - & 406 & - & - & 5 & - & - \\
\hline & $29.7 \%$ & $12.5 \%$ & $12.5 \%$ & $98.2 \%$ & $12.6 \%$ & $12.6 \%$ & $99.7 \%$ & $12.9 \%$ & $12.9 \%$ \\
\hline \multirow[t]{2}{*}{ alto-vizi } & - & - & - & 633 & - & - & 18 & - & - \\
\hline & $30.5 \%$ & $12.5 \%$ & $12.5 \%$ & $98.2 \%$ & $12.6 \%$ & $12.6 \%$ & $99.7 \%$ & $12.7 \%$ & $12.7 \%$ \\
\hline \multirow[t]{2}{*}{ alto-mens } & - & - & - & 554 & - & - & 8 & - & - \\
\hline & $29.8 \%$ & $12.5 \%$ & $12.5 \%$ & $97.7 \%$ & $12.6 \%$ & $12.6 \%$ & $99.7 \%$ & $12.7 \%$ & $12.8 \%$ \\
\hline \multirow[t]{2}{*}{ alto-reci } & - & - & - & 637 & - & - & 11 & - & - \\
\hline & $24.7 \%$ & $12.5 \%$ & $12.5 \%$ & $98.1 \%$ & $12.6 \%$ & $12.6 \%$ & $99.6 \%$ & $12.9 \%$ & $12.9 \%$ \\
\hline \multirow[t]{2}{*}{ alto-aglo } & - & - & - & 522 & - & - & 7 & - & - \\
\hline & $25.8 \%$ & $12.5 \%$ & $12.5 \%$ & $97.9 \%$ & $12.6 \%$ & $12.6 \%$ & $99.6 \%$ & $12.9 \%$ & $12.9 \%$ \\
\hline \multirow[t]{2}{*}{ anti-aglo } & - & - & - & 847 & - & - & 14 & - & - \\
\hline & $22.0 \%$ & $12.5 \%$ & $12.5 \%$ & $98.5 \%$ & $12.6 \%$ & $12.6 \%$ & $99.6 \%$ & $12.8 \%$ & $12.8 \%$ \\
\hline \multirow[t]{2}{*}{ andarilho } & - & - & - & 452 & - & - & 5 & - & - \\
\hline & $32.0 \%$ & $12.5 \%$ & $12.5 \%$ & $98.4 \%$ & $12.6 \%$ & $12.6 \%$ & $99.5 \%$ & $12.8 \%$ & $12.8 \%$ \\
\hline \multirow[t]{2}{*}{ anda-aglo } & - & - & - & 413 & - & - & 5 & - & - \\
\hline & $33.3 \%$ & $12.5 \%$ & $12.5 \%$ & $98.6 \%$ & $12.6 \%$ & $12.6 \%$ & $99.7 \%$ & $12.9 \%$ & $12.9 \%$ \\
\hline
\end{tabular}




\section{Tabela B.17}

\begin{tabular}{|c|c|c|c|c|c|c|c|c|c|}
\hline \multicolumn{10}{|c|}{$\tau=-2|T=4| D^{*}=3$} \\
\hline$p$ & \multicolumn{3}{|c|}{0.2} & \multicolumn{3}{|c|}{0.5} & \multicolumn{3}{|c|}{0.8} \\
\hline$r$ & 0.0 & 0.5 & 0.8 & 0.0 & 0.5 & 0.8 & 0.0 & 0.5 & 0.8 \\
\hline \multirow[t]{2}{*}{ aleatória } & - & - & - & - & - & - & - & - & - \\
\hline & $13.6 \%$ & $12.5 \%$ & $12.5 \%$ & $21.5 \%$ & $12.5 \%$ & $12.5 \%$ & $40.0 \%$ & $12.5 \%$ & $12.5 \%$ \\
\hline \multirow[t]{2}{*}{ alto-vizi } & - & - & - & - & - & - & - & - & - \\
\hline & $12.5 \%$ & $12.5 \%$ & $12.5 \%$ & $12.5 \%$ & $12.5 \%$ & $12.5 \%$ & $12.5 \%$ & $12.5 \%$ & $12.5 \%$ \\
\hline \multirow[t]{2}{*}{ alto-mens } & - & - & - & - & 一 & - & - & 一 & - \\
\hline & $12.5 \%$ & $12.5 \%$ & $12.5 \%$ & $12.5 \%$ & $12.5 \%$ & $12.5 \%$ & $12.7 \%$ & $12.5 \%$ & $12.5 \%$ \\
\hline \multirow[t]{2}{*}{ alto-reci } & - & 一 & - & - & - & - & - & 一 & - \\
\hline & $14.2 \%$ & $12.5 \%$ & $12.5 \%$ & $21.6 \%$ & $12.5 \%$ & $12.5 \%$ & $35.4 \%$ & $12.5 \%$ & $12.5 \%$ \\
\hline \multirow[t]{2}{*}{ alto-aglo } & - & - & - & - & - & - & - & - & - \\
\hline & $14.5 \%$ & $12.5 \%$ & $12.5 \%$ & $27.7 \%$ & $12.5 \%$ & $12.5 \%$ & $50.6 \%$ & $12.5 \%$ & $12.5 \%$ \\
\hline \multirow[t]{2}{*}{ anti-aglo } & - & - & - & - & - & - & - & - & - \\
\hline & $15.3 \%$ & $12.5 \%$ & $12.5 \%$ & $29.0 \%$ & $12.5 \%$ & $12.5 \%$ & $52.1 \%$ & $12.6 \%$ & $12.6 \%$ \\
\hline \multirow[t]{2}{*}{ andarilho } & - & - & - & - & - & - & - & - & - \\
\hline & $12.7 \%$ & $12.5 \%$ & $12.5 \%$ & $14.8 \%$ & $12.5 \%$ & $12.5 \%$ & $20.7 \%$ & $12.5 \%$ & $12.5 \%$ \\
\hline \multirow[t]{2}{*}{ anda-aglo } & - & - & - & - & - & - & - & - & - \\
\hline & $12.9 \%$ & $12.5 \%$ & $12.5 \%$ & $16.7 \%$ & $12.5 \%$ & $12.5 \%$ & $27.2 \%$ & $12.5 \%$ & $12.5 \%$ \\
\hline
\end{tabular}

\section{Tabela B.18}

\begin{tabular}{|c|c|c|c|c|c|c|c|c|c|}
\hline \multicolumn{10}{|c|}{$\tau=-8 \mid T=4$} \\
\hline$p$ & \multicolumn{3}{|c|}{0.2} & \multicolumn{3}{|c|}{0.5} & \multicolumn{3}{|c|}{0.8} \\
\hline$r$ & 0.0 & 0.5 & 0.8 & 0.0 & 0.5 & 0.8 & 0.0 & 0.5 & 0.8 \\
\hline \multirow[t]{2}{*}{ aleatória } & - & - & - & - & - & - & - & - & - \\
\hline & $12.5 \%$ & $12.5 \%$ & $12.5 \%$ & $12.5 \%$ & $12.5 \%$ & $12.5 \%$ & $12.5 \%$ & $12.5 \%$ & $12.5 \%$ \\
\hline \multirow[t]{2}{*}{ alto-vizi } & - & - & - & - & - & - & - & - & - \\
\hline & $12.5 \%$ & $12.5 \%$ & $12.5 \%$ & $12.5 \%$ & $12.5 \%$ & $12.5 \%$ & $12.5 \%$ & $12.5 \%$ & $12.5 \%$ \\
\hline \multirow{2}{*}{ alto-mens } & - & - & - & - & 一 & 一 & - & - & - \\
\hline & $12.5 \%$ & $12.5 \%$ & $12.5 \%$ & $12.5 \%$ & $12.5 \%$ & $12.5 \%$ & $12.5 \%$ & $12.5 \%$ & $12.5 \%$ \\
\hline \multirow[t]{2}{*}{ alto-reci } & - & - & - & - & - & - & - & - & - \\
\hline & $12.5 \%$ & $12.5 \%$ & $12.5 \%$ & $12.5 \%$ & $12.5 \%$ & $12.5 \%$ & $12.6 \%$ & $12.5 \%$ & $12.5 \%$ \\
\hline \multirow[t]{2}{*}{ alto-aglo } & - & - & - & - & - & - & - & 一 & - \\
\hline & $12.5 \%$ & $12.5 \%$ & $12.5 \%$ & $12.5 \%$ & $12.5 \%$ & $12.5 \%$ & $12.5 \%$ & $12.5 \%$ & $12.5 \%$ \\
\hline \multirow[t]{2}{*}{ anti-aglo } & - & - & - & - & - & - & - & - & - \\
\hline & $12.5 \%$ & $12.5 \%$ & $12.5 \%$ & $12.5 \%$ & $12.5 \%$ & $12.5 \%$ & $12.6 \%$ & $12.5 \%$ & $12.5 \%$ \\
\hline \multirow[t]{2}{*}{ andarilho } & - & - & - & - & - & - & - & - & - \\
\hline & $12.5 \%$ & $12.5 \%$ & $12.5 \%$ & $12.5 \%$ & $12.5 \%$ & $12.5 \%$ & $12.5 \%$ & $12.5 \%$ & $12.5 \%$ \\
\hline \multirow[t]{2}{*}{ anda-aglo } & - & - & - & - & - & - & - & - & - \\
\hline & $12.5 \%$ & $12.5 \%$ & $12.5 \%$ & $12.5 \%$ & $12.5 \%$ & $12.5 \%$ & $12.5 \%$ & $12.5 \%$ & $12.5 \%$ \\
\hline
\end{tabular}




\section{B.2 Rede embaralhada}

Valem aqui os mesmos fatos gerais observados para a rede original.

Nas tabelas para as seguintes combinações de parâmetros nenhum elemento atinge o equilíbrio, mas serão apresentadas por completeza:

- Tabela B.30: $\tau=-8, T=4, D^{*}=2$

- Tabela B.35: $\tau=-2, T=4, D^{*}=3$

- Tabela B.36: $\tau=-8, T=4, D^{*}=3$

Tabela B.19

\begin{tabular}{l|ccc|c|c|c|ccc}
\multicolumn{1}{c}{$\tau=64$} & $T=4$ & $D^{*}=1$ \\
\hline$p$ & & 0.2 & & \multicolumn{3}{c}{0.5} & & \multicolumn{3}{c}{0.8} & \\
\hline$r$ & 0.0 & 0.5 & 0.8 & 0.0 & 0.5 & 0.8 & 0.0 & 0.5 & 0.8 \\
\hline aleatória & 1 & - & - & 1 & 4 & 3 & 1 & 2 & 1 \\
& $100.0 \%$ & $19.8 \%$ & $19.9 \%$ & $100.0 \%$ & $94.7 \%$ & $92.4 \%$ & $100.0 \%$ & $99.9 \%$ & $99.9 \%$ \\
alto-vizi & 1 & - & - & 1 & 1 & 1 & 1 & 1 & 1 \\
& $100.0 \%$ & $34.5 \%$ & $30.3 \%$ & $100.0 \%$ & $94.8 \%$ & $92.3 \%$ & $100.0 \%$ & $99.9 \%$ & $99.8 \%$ \\
alto-mens & 1 & - & - & 1 & 1 & 1 & 1 & 1 & 1 \\
alto-reci & $100.0 \%$ & $34.4 \%$ & $30.1 \%$ & $100.0 \%$ & $94.5 \%$ & $92.1 \%$ & $100.0 \%$ & $99.9 \%$ & $99.8 \%$ \\
& 1 & - & - & 1 & 2 & 3 & 1 & 1 & 1 \\
alto-aglo & $100.0 \%$ & $30.2 \%$ & $27.1 \%$ & $100.0 \%$ & $94.8 \%$ & $92.6 \%$ & $100.0 \%$ & $99.9 \%$ & $99.9 \%$ \\
& 1 & - & - & 1 & 2 & 2 & 1 & 2 & 2 \\
anti-aglo & $100.0 \%$ & $21.4 \%$ & $21.4 \%$ & $100.0 \%$ & $94.8 \%$ & $92.2 \%$ & $100.0 \%$ & $99.9 \%$ & $99.9 \%$ \\
& 1 & - & - & 1 & 11 & 10 & 1 & 5 & 6 \\
andarilho & $100.0 \%$ & $14.4 \%$ & $14.4 \%$ & $100.0 \%$ & $94.7 \%$ & $92.5 \%$ & $100.0 \%$ & $99.9 \%$ & $99.9 \%$ \\
& $100.0 \%$ & $26.9 \%$ & $25.5 \%$ & $100.0 \%$ & $94.7 \%$ & $92.3 \%$ & $100.0 \%$ & $99.9 \%$ & $99.9 \%$ \\
anda-aglo & 1 & - & - & 1 & 2 & 2 & 1 & 2 & 1 \\
& $100.0 \%$ & $26.2 \%$ & $24.5 \%$ & $100.0 \%$ & $94.7 \%$ & $92.4 \%$ & $100.0 \%$ & $99.9 \%$ & $99.9 \%$
\end{tabular}


Tabela B.20

\begin{tabular}{l|ccc|c|cc|ccc}
\multicolumn{1}{c}{$\tau=8$} & $T=4$ & $D^{*}=1$ \\
\hline$p$ & & 0.2 & & \multicolumn{3}{c}{0.5} & & \multicolumn{3}{c}{0.8} & \\
\hline$r$ & 0.0 & 0.5 & 0.8 & 0.0 & 0.5 & 0.8 & 0.0 & 0.5 & 0.8 \\
\hline aleatória & 1 & - & - & 1 & 2 & 1 & 1 & 2 & 3 \\
& $100.0 \%$ & $19.9 \%$ & $20.0 \%$ & $100.0 \%$ & $94.8 \%$ & $92.4 \%$ & $100.0 \%$ & $99.9 \%$ & $99.9 \%$ \\
alto-vizi & 1 & - & - & 1 & 1 & 1 & 1 & 1 & 1 \\
& $100.0 \%$ & $34.2 \%$ & $30.2 \%$ & $100.0 \%$ & $94.6 \%$ & $92.4 \%$ & $100.0 \%$ & $99.9 \%$ & $99.9 \%$ \\
alto-mens & 1 & - & - & 1 & 1 & 1 & 1 & 1 & 1 \\
& $100.0 \%$ & $34.2 \%$ & $29.7 \%$ & $100.0 \%$ & $94.8 \%$ & $92.5 \%$ & $100.0 \%$ & $99.9 \%$ & $99.9 \%$ \\
alto-reci & 1 & - & - & 1 & 1 & 1 & 1 & 1 & 1 \\
& $100.0 \%$ & $29.8 \%$ & $26.8 \%$ & $100.0 \%$ & $94.5 \%$ & $92.5 \%$ & $100.0 \%$ & $99.9 \%$ & $99.8 \%$ \\
alto-aglo & 1 & - & - & 1 & 2 & 2 & 1 & 2 & 2 \\
& $100.0 \%$ & $21.5 \%$ & $21.5 \%$ & $100.0 \%$ & $94.7 \%$ & $92.2 \%$ & $100.0 \%$ & $99.9 \%$ & $99.8 \%$ \\
anti-aglo & 1 & - & - & 1 & 1 & 1 & 1 & 1 & 1 \\
& $100.0 \%$ & $14.4 \%$ & $14.4 \%$ & $100.0 \%$ & $94.6 \%$ & $92.1 \%$ & $100.0 \%$ & $99.9 \%$ & $99.9 \%$ \\
andarilho & 1 & - & - & 1 & 1 & 3 & 1 & 1 & 2 \\
& $100.0 \%$ & $26.5 \%$ & $25.3 \%$ & $100.0 \%$ & $94.7 \%$ & $92.5 \%$ & $100.0 \%$ & $99.9 \%$ & $99.9 \%$ \\
anda-aglo & 1 & - & - & 1 & 2 & 1 & 1 & 1 & 2 \\
& $100.0 \%$ & $26.2 \%$ & $24.6 \%$ & $100.0 \%$ & $94.7 \%$ & $92.4 \%$ & $100.0 \%$ & $99.9 \%$ & $99.9 \%$
\end{tabular}

Tabela B.21

\begin{tabular}{l|ccc|c|cc|ccc}
\multicolumn{1}{c}{$\tau=2$} & $T=4$ & $D^{*}=1$ \\
\hline$p$ & & 0.2 & & \multicolumn{3}{c|}{0.5} & & \multicolumn{3}{c}{0.8} & \\
\hline$r$ & 0.0 & 0.5 & 0.8 & 0.0 & 0.5 & 0.8 & 0.0 & 0.5 & 0.8 \\
\hline aleatória & 1 & - & - & 1 & 3 & 2 & 1 & 2 & 3 \\
& $100.0 \%$ & $19.9 \%$ & $19.8 \%$ & $100.0 \%$ & $94.6 \%$ & $92.2 \%$ & $100.0 \%$ & $99.9 \%$ & $99.8 \%$ \\
alto-vizi & 1 & - & - & 1 & 1 & 1 & 1 & 1 & 1 \\
& $100.0 \%$ & $25.9 \%$ & $24.7 \%$ & $100.0 \%$ & $94.7 \%$ & $92.3 \%$ & $100.0 \%$ & $99.8 \%$ & $99.8 \%$ \\
alto-mens & 1 & - & - & 1 & 1 & 1 & 1 & 1 & 1 \\
& $100.0 \%$ & $25.8 \%$ & $24.2 \%$ & $100.0 \%$ & $94.7 \%$ & $92.2 \%$ & $100.0 \%$ & $99.9 \%$ & $99.8 \%$ \\
alto-reci & 1 & - & - & 1 & 1 & 1 & 1 & 1 & 1 \\
& $100.0 \%$ & $24.0 \%$ & $23.2 \%$ & $100.0 \%$ & $94.5 \%$ & $92.1 \%$ & $100.0 \%$ & $99.9 \%$ & $99.8 \%$ \\
alto-aglo & 1 & - & - & 1 & 1 & 1 & 1 & 1 & 1 \\
& $100.0 \%$ & $20.8 \%$ & $20.8 \%$ & $100.0 \%$ & $94.6 \%$ & $92.2 \%$ & $100.0 \%$ & $99.9 \%$ & $99.8 \%$ \\
anti-aglo & 1 & - & - & 1 & 1 & 1 & 1 & 1 & 1 \\
& $100.0 \%$ & $15.0 \%$ & $15.0 \%$ & $100.0 \%$ & $94.6 \%$ & $92.2 \%$ & $100.0 \%$ & $99.9 \%$ & $99.8 \%$ \\
andarilho & 1 & - & - & 1 & 1 & 1 & 1 & 2 & 1 \\
& $100.0 \%$ & $22.7 \%$ & $22.7 \%$ & $100.0 \%$ & $94.5 \%$ & $92.2 \%$ & $100.0 \%$ & $99.9 \%$ & $99.8 \%$ \\
anda-aglo $\%$ & 1 & - & - & 1 & 1 & 1 & 1 & 1 & 2 \\
& $100.0 \%$ & $22.7 \%$ & $22.6 \%$ & $100.0 \%$ & $94.5 \%$ & $92.2 \%$ & $100.0 \%$ & $99.9 \%$ & $99.8 \%$
\end{tabular}


Tabela B.22

\begin{tabular}{l|ccc|c|cc|ccc}
\multicolumn{1}{c}{$\tau=1$} & $T=4$ & $D^{*}=1$ \\
\hline$p$ & & 0.2 & & \multicolumn{7}{c|}{0.5} & & \multicolumn{3}{c}{0.8} & \\
\hline$r$ & 0.0 & 0.5 & 0.8 & 0.0 & 0.5 & 0.8 & 0.0 & 0.5 & 0.8 \\
\hline aleatória & 1 & - & - & 1 & 1 & 2 & 1 & 1 & 1 \\
& $100.0 \%$ & $19.0 \%$ & $19.0 \%$ & $100.0 \%$ & $90.3 \%$ & $86.4 \%$ & $100.0 \%$ & $99.0 \%$ & $98.6 \%$ \\
alto-vizi & 1 & - & - & 1 & 1 & 1 & 1 & 1 & 1 \\
& $100.0 \%$ & $19.3 \%$ & $19.4 \%$ & $100.0 \%$ & $90.5 \%$ & $86.4 \%$ & $100.0 \%$ & $99.0 \%$ & $98.7 \%$ \\
alto-mens & 1 & - & - & 1 & 1 & 1 & 1 & 1 & 1 \\
& $100.0 \%$ & $19.1 \%$ & $19.1 \%$ & $100.0 \%$ & $90.4 \%$ & $86.2 \%$ & $100.0 \%$ & $98.9 \%$ & $98.7 \%$ \\
alto-reci & 1 & - & - & 1 & 1 & 1 & 1 & 1 & 1 \\
& $100.0 \%$ & $18.9 \%$ & $18.9 \%$ & $100.0 \%$ & $90.2 \%$ & $86.5 \%$ & $100.0 \%$ & $98.9 \%$ & $98.6 \%$ \\
alto-aglo & 1 & - & - & 1 & 1 & 1 & 1 & 1 & 1 \\
& $100.0 \%$ & $18.7 \%$ & $18.7 \%$ & $100.0 \%$ & $90.3 \%$ & $86.2 \%$ & $100.0 \%$ & $99.0 \%$ & $98.7 \%$ \\
anti-aglo & 1 & - & - & 1 & 1 & 1 & 1 & 1 & 1 \\
& $100.0 \%$ & $17.0 \%$ & $17.0 \%$ & $100.0 \%$ & $90.1 \%$ & $86.4 \%$ & $100.0 \%$ & $99.0 \%$ & $98.7 \%$ \\
andarilho & 1 & - & - & 1 & 1 & 1 & 1 & 1 & 1 \\
& $100.0 \%$ & $19.5 \%$ & $19.5 \%$ & $100.0 \%$ & $90.3 \%$ & $86.4 \%$ & $100.0 \%$ & $99.0 \%$ & $98.6 \%$ \\
anda-aglo & 1 & - & - & 1 & 1 & 1 & 1 & 1 & 1 \\
& $100.0 \%$ & $19.2 \%$ & $19.1 \%$ & $100.0 \%$ & $90.3 \%$ & $86.5 \%$ & $100.0 \%$ & $99.0 \%$ & $98.7 \%$
\end{tabular}

Tabela B.23

\begin{tabular}{l|ccc|c|c|c|ccc}
\multicolumn{1}{c}{$\tau=-2$} & $T=4$ & $D^{*}=1$ \\
\hline$p$ & & 0.2 & & & 0.5 & & \multicolumn{3}{c}{0.8} \\
\hline$r$ & 0.0 & 0.5 & 0.8 & 0.0 & 0.5 & 0.8 & 0.0 & 0.5 & 0.8 \\
\hline aleatória & 1 & - & - & 1 & 5 & - & 1 & 1 & 1 \\
& $100.0 \%$ & $16.9 \%$ & $16.9 \%$ & $100.0 \%$ & $36.1 \%$ & $24.5 \%$ & $100.0 \%$ & $90.0 \%$ & $86.9 \%$ \\
alto-vizi & 1 & - & - & 1 & 1 & - & 1 & 1 & 1 \\
& $100.0 \%$ & $16.8 \%$ & $16.8 \%$ & $100.0 \%$ & $35.2 \%$ & $24.2 \%$ & $100.0 \%$ & $90.1 \%$ & $86.8 \%$ \\
alto-mens & 1 & - & - & 1 & 1 & - & 1 & 1 & 1 \\
& $100.0 \%$ & $16.7 \%$ & $16.6 \%$ & $100.0 \%$ & $36.2 \%$ & $23.7 \%$ & $100.0 \%$ & $90.1 \%$ & $87.0 \%$ \\
alto-reci & 1 & - & - & 1 & 2 & - & 1 & 1 & 1 \\
& $100.0 \%$ & $16.6 \%$ & $16.6 \%$ & $100.0 \%$ & $35.2 \%$ & $23.4 \%$ & $100.0 \%$ & $90.2 \%$ & $87.1 \%$ \\
alto-aglo & 1 & - & - & 1 & 1 & - & 1 & 1 & 1 \\
& $100.0 \%$ & $16.5 \%$ & $16.5 \%$ & $100.0 \%$ & $35.7 \%$ & $23.2 \%$ & $100.0 \%$ & $90.0 \%$ & $86.8 \%$ \\
anti-aglo & 1 & - & - & 1 & 5 & - & 1 & 1 & 1 \\
& $100.0 \%$ & $16.2 \%$ & $16.2 \%$ & $100.0 \%$ & $35.5 \%$ & $22.8 \%$ & $100.0 \%$ & $90.0 \%$ & $86.9 \%$ \\
andarilho & 1 & - & - & 1 & 6 & - & 1 & 1 & 1 \\
& $100.0 \%$ & $17.0 \%$ & $17.0 \%$ & $100.0 \%$ & $36.3 \%$ & $24.5 \%$ & $100.0 \%$ & $89.9 \%$ & $87.1 \%$ \\
anda-aglo & 1 & - & - & 1 & 5 & - & 1 & 1 & 1 \\
& $100.0 \%$ & $16.7 \%$ & $16.8 \%$ & $100.0 \%$ & $36.0 \%$ & $23.9 \%$ & $100.0 \%$ & $90.0 \%$ & $87.0 \%$
\end{tabular}


Tabela B.24

\begin{tabular}{|c|c|c|c|c|c|c|c|c|c|}
\hline & & & $\tau=$ & $T=$ & $D^{*}$ & & & & \\
\hline$p$ & & 0.2 & & & 0.5 & & & 0.8 & \\
\hline$r$ & 0.0 & 0.5 & 0.8 & 0.0 & 0.5 & 0.8 & 0.0 & 0.5 & 0.8 \\
\hline aleatória & 1 & - & - & 1 & - & - & 1 & - & - \\
\hline & $100.0 \%$ & $14.7 \%$ & $14.7 \%$ & $100.0 \%$ & $18.0 \%$ & $18.1 \%$ & $100.0 \%$ & $21.6 \%$ & $21.6 \%$ \\
\hline alto-vizi & 1 & - & - & 1 & - & - & 1 & - & - \\
\hline & $100.0 \%$ & $14.5 \%$ & $14.5 \%$ & $100.0 \%$ & $17.7 \%$ & $17.7 \%$ & $100.0 \%$ & $21.0 \%$ & $21.0 \%$ \\
\hline alto-mens & 1 & - & - & 1 & - & - & 1 & - & - \\
\hline & $100.0 \%$ & $14.4 \%$ & $14.4 \%$ & $100.0 \%$ & $17.5 \%$ & $17.5 \%$ & $100.0 \%$ & $20.6 \%$ & $20.6 \%$ \\
\hline alto-reci & 1 & - & - & 1 & - & - & 1 & - & - \\
\hline & $100.0 \%$ & $14.4 \%$ & $14.4 \%$ & $100.0 \%$ & $17.3 \%$ & $17.3 \%$ & $100.0 \%$ & $20.4 \%$ & $20.4 \%$ \\
\hline alto-aglo & 1 & - & - & 1 & - & - & 1 & - & - \\
\hline & $100.0 \%$ & $14.4 \%$ & $14.4 \%$ & $100.0 \%$ & $17.3 \%$ & $17.3 \%$ & $100.0 \%$ & $20.4 \%$ & $20.4 \%$ \\
\hline anti-aglo & 1 & - & - & 1 & - & - & 1 & - & - \\
\hline & $100.0 \%$ & $14.6 \%$ & $14.6 \%$ & $100.0 \%$ & $17.8 \%$ & $17.8 \%$ & $100.0 \%$ & $21.1 \%$ & $21.1 \%$ \\
\hline andarilho & 1 & - & - & 1 & - & - & 1 & - & - \\
\hline & $100.0 \%$ & $14.6 \%$ & $14.6 \%$ & $100.0 \%$ & $17.9 \%$ & $17.9 \%$ & $100.0 \%$ & $21.3 \%$ & $21.3 \%$ \\
\hline anda-aglo & 1 & - & - & 1 & - & - & 1 & - & - \\
\hline & $100.0 \%$ & $14.5 \%$ & $14.5 \%$ & $100.0 \%$ & $17.6 \%$ & $17.6 \%$ & $100.0 \%$ & $20.8 \%$ & $20.8 \%$ \\
\hline
\end{tabular}

Tabela B.25

\begin{tabular}{|c|c|c|c|c|c|c|c|c|c|}
\hline \multirow{3}{*}{$\frac{p}{r}$} & \multicolumn{3}{|c|}{$\tau=6$} & \multicolumn{3}{|c|}{$D^{*}=2$} & & \\
\hline & \multicolumn{3}{|c|}{0.2} & \multicolumn{3}{|c|}{0.5} & \multicolumn{3}{|c|}{0.8} \\
\hline & 0.0 & 0.5 & 0.8 & 0.0 & 0.5 & 0.8 & 0.0 & 0.5 & 0.8 \\
\hline \multirow[t]{2}{*}{ aleatória } & 64 & - & - & 2 & - & - & 1 & - & - \\
\hline & $99.9 \%$ & $12.8 \%$ & $12.8 \%$ & $100.0 \%$ & $14.1 \%$ & $14.1 \%$ & $100.0 \%$ & $16.5 \%$ & $16.5 \%$ \\
\hline \multirow[t]{2}{*}{ alto-vizi } & 2 & - & - & 1 & - & - & 1 & 1658 & 3165 \\
\hline & $99.8 \%$ & $13.9 \%$ & $13.9 \%$ & $100.0 \%$ & $21.6 \%$ & $20.2 \%$ & $100.0 \%$ & $97.7 \%$ & $96.4 \%$ \\
\hline \multirow[t]{2}{*}{ alto-mens } & 2 & - & - & 1 & - & - & 1 & 1549 & 2940 \\
\hline & $100.0 \%$ & $13.8 \%$ & $13.8 \%$ & $100.0 \%$ & $21.2 \%$ & $19.8 \%$ & $100.0 \%$ & $97.6 \%$ & $96.5 \%$ \\
\hline \multirow[t]{2}{*}{ alto-reci } & 11 & - & - & 1 & - & - & 1 & 2438 & 4102 \\
\hline & $99.7 \%$ & $13.4 \%$ & $13.4 \%$ & $100.0 \%$ & $17.7 \%$ & $17.7 \%$ & $100.0 \%$ & $97.7 \%$ & $96.5 \%$ \\
\hline \multirow[t]{2}{*}{ alto-aglo } & 9 & - & - & 1 & - & - & 1 & 4527 & - \\
\hline & $99.9 \%$ & $12.9 \%$ & $12.9 \%$ & $100.0 \%$ & $14.7 \%$ & $14.7 \%$ & $100.0 \%$ & $97.7 \%$ & $18.0 \%$ \\
\hline \multirow[t]{2}{*}{ anti-aglo } & 513 & - & - & 2 & - & - & 1 & - & - \\
\hline & $99.8 \%$ & $12.5 \%$ & $12.5 \%$ & $100.0 \%$ & $12.8 \%$ & $12.8 \%$ & $100.0 \%$ & $13.2 \%$ & $13.2 \%$ \\
\hline \multirow[t]{2}{*}{ andarilho } & 27 & - & - & 2 & - & - & 1 & 3624 & - \\
\hline & $99.9 \%$ & $13.2 \%$ & $13.3 \%$ & $100.0 \%$ & $16.8 \%$ & $16.8 \%$ & $100.0 \%$ & $97.6 \%$ & $27.1 \%$ \\
\hline \multirow[t]{2}{*}{ anda-aglo } & 23 & - & - & 2 & - & - & 1 & 3391 & - \\
\hline & $99.9 \%$ & $13.1 \%$ & $13.2 \%$ & $100.0 \%$ & $16.2 \%$ & $16.2 \%$ & $100.0 \%$ & $97.6 \%$ & $26.9 \%$ \\
\hline
\end{tabular}


Tabela B.26

\begin{tabular}{|c|c|c|c|c|c|c|c|c|c|}
\hline \multicolumn{10}{|c|}{$\tau=8 \mid T=4$} \\
\hline$p$ & \multicolumn{3}{|c|}{0.2} & \multicolumn{3}{|c|}{0.5} & \multicolumn{3}{|c|}{0.8} \\
\hline$r$ & 0.0 & 0.5 & 0.8 & 0.0 & 0.5 & 0.8 & 0.0 & 0.5 & 0.8 \\
\hline \multirow[t]{2}{*}{ aleatória } & 67 & - & - & 3 & - & - & 1 & - & - \\
\hline & $99.9 \%$ & $12.8 \%$ & $12.8 \%$ & $100.0 \%$ & $14.1 \%$ & $14.1 \%$ & $100.0 \%$ & $16.4 \%$ & $16.4 \%$ \\
\hline \multirow[t]{2}{*}{ alto-vizi } & 5 & - & - & 1 & - & - & 1 & 1773 & 3252 \\
\hline & $99.5 \%$ & $13.8 \%$ & $13.8 \%$ & $100.0 \%$ & $21.4 \%$ & $20.1 \%$ & $100.0 \%$ & $97.6 \%$ & $96.4 \%$ \\
\hline \multirow[t]{2}{*}{ alto-mens } & 6 & - & - & 1 & - & - & 1 & 1659 & 3096 \\
\hline & $99.9 \%$ & $13.8 \%$ & $13.7 \%$ & $100.0 \%$ & $20.9 \%$ & $19.6 \%$ & $100.0 \%$ & $97.7 \%$ & $96.4 \%$ \\
\hline \multirow[t]{2}{*}{ alto-reci } & 8 & 一 & 一 & 1 & 一 & 一 & 1 & 2516 & 4177 \\
\hline & $99.9 \%$ & $13.3 \%$ & $13.3 \%$ & $100.0 \%$ & $17.5 \%$ & $17.5 \%$ & $100.0 \%$ & $97.6 \%$ & $96.4 \%$ \\
\hline \multirow[t]{2}{*}{ alto-aglo } & 10 & - & - & 1 & - & - & 1 & 4609 & - \\
\hline & $99.3 \%$ & $12.9 \%$ & $12.9 \%$ & $100.0 \%$ & $14.7 \%$ & $14.7 \%$ & $100.0 \%$ & $97.7 \%$ & $18.0 \%$ \\
\hline \multirow[t]{2}{*}{ anti-aglo } & 514 & 一 & - & 1 & - & - & 1 & - & - \\
\hline & $99.8 \%$ & $12.5 \%$ & $12.5 \%$ & $100.0 \%$ & $12.7 \%$ & $12.7 \%$ & $100.0 \%$ & $13.1 \%$ & $13.1 \%$ \\
\hline \multirow[t]{2}{*}{ andarilho } & 24 & - & - & 1 & - & - & 1 & 3696 & - \\
\hline & $99.9 \%$ & $13.2 \%$ & $13.2 \%$ & $100.0 \%$ & $16.7 \%$ & $16.6 \%$ & $100.0 \%$ & $97.7 \%$ & $25.4 \%$ \\
\hline \multirow[t]{2}{*}{ anda-aglo } & 17 & - & - & 1 & - & - & 1 & 3376 & - \\
\hline & $99.9 \%$ & $13.1 \%$ & $13.1 \%$ & $100.0 \%$ & $16.2 \%$ & $16.2 \%$ & $100.0 \%$ & $97.6 \%$ & $26.2 \%$ \\
\hline
\end{tabular}

Tabela B.27

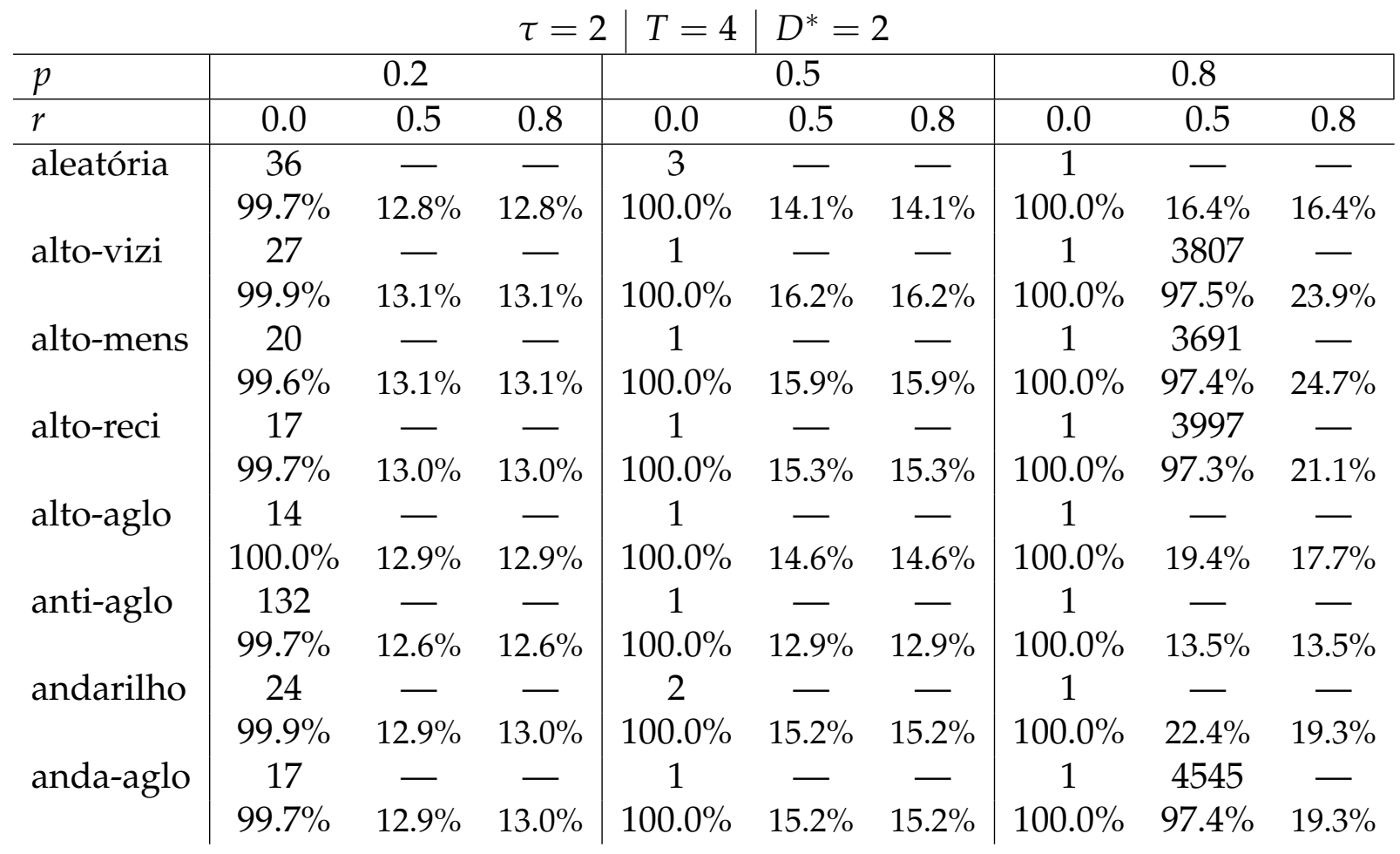


Tabela B.28

\begin{tabular}{|c|c|c|c|c|c|c|c|c|c|}
\hline \multicolumn{10}{|c|}{$\tau=1 \mid T=4$} \\
\hline$p$ & \multicolumn{3}{|c|}{0.2} & \multicolumn{3}{|c|}{0.5} & \multicolumn{3}{|c|}{0.8} \\
\hline$r$ & 0.0 & 0.5 & 0.8 & 0.0 & 0.5 & 0.8 & 0.0 & 0.5 & 0.8 \\
\hline \multirow[t]{2}{*}{ aleatória } & 20 & - & - & 1 & - & - & 1 & - & - \\
\hline & $99.4 \%$ & $12.7 \%$ & $12.7 \%$ & $100.0 \%$ & $13.8 \%$ & $13.9 \%$ & $100.0 \%$ & $15.9 \%$ & $15.9 \%$ \\
\hline \multirow[t]{2}{*}{ alto-vizi } & 73 & - & - & 2 & - & - & 2 & - & - \\
\hline & $99.7 \%$ & $12.7 \%$ & $12.7 \%$ & $100.0 \%$ & $13.7 \%$ & $13.7 \%$ & $100.0 \%$ & $15.5 \%$ & $15.6 \%$ \\
\hline \multirow[t]{2}{*}{ alto-mens } & 46 & - & - & 2 & - & - & 1 & - & - \\
\hline & $98.8 \%$ & $12.7 \%$ & $12.7 \%$ & $100.0 \%$ & $13.6 \%$ & $13.6 \%$ & $100.0 \%$ & $15.3 \%$ & $15.3 \%$ \\
\hline \multirow[t]{2}{*}{ alto-reci } & 16 & - & - & 1 & - & - & 1 & - & - \\
\hline & $99.6 \%$ & $12.7 \%$ & $12.7 \%$ & $100.0 \%$ & $13.6 \%$ & $13.6 \%$ & $100.0 \%$ & $15.3 \%$ & $15.3 \%$ \\
\hline \multirow[t]{2}{*}{ alto-aglo } & 19 & - & - & 1 & 一 & - & 1 & - & - \\
\hline & $99.6 \%$ & $12.7 \%$ & $12.7 \%$ & $100.0 \%$ & $13.7 \%$ & $13.7 \%$ & $100.0 \%$ & $15.5 \%$ & $15.5 \%$ \\
\hline \multirow[t]{2}{*}{ anti-aglo } & 16 & 一 & - & 1 & - & - & 1 & - & - \\
\hline & $99.5 \%$ & $12.7 \%$ & $12.7 \%$ & $100.0 \%$ & $13.6 \%$ & $13.6 \%$ & $100.0 \%$ & $15.1 \%$ & $15.1 \%$ \\
\hline \multirow[t]{2}{*}{ andarilho } & 27 & - & - & 2 & - & - & 1 & - & - \\
\hline & $99.4 \%$ & $12.7 \%$ & $12.7 \%$ & $100.0 \%$ & $13.8 \%$ & $13.8 \%$ & $100.0 \%$ & $15.8 \%$ & $15.8 \%$ \\
\hline \multirow[t]{2}{*}{ anda-aglo } & 34 & - & - & 2 & - & - & 1 & - & - \\
\hline & $99.6 \%$ & $12.7 \%$ & $12.7 \%$ & $100.0 \%$ & $13.7 \%$ & $13.7 \%$ & $100.0 \%$ & $15.6 \%$ & $15.6 \%$ \\
\hline
\end{tabular}

Tabela B.29

\begin{tabular}{|c|c|c|c|c|c|c|c|c|c|}
\hline \multicolumn{10}{|c|}{$\tau=-2 \mid T=4$} \\
\hline$p$ & \multicolumn{3}{|c|}{0.2} & \multicolumn{3}{|c|}{0.5} & \multicolumn{3}{|c|}{0.8} \\
\hline$r$ & 0.0 & 0.5 & 0.8 & 0.0 & 0.5 & 0.8 & 0.0 & 0.5 & 0.8 \\
\hline \multirow[t]{2}{*}{ aleatória } & 2092 & - & - & 3 & - & - & 2 & - & - \\
\hline & $97.4 \%$ & $12.6 \%$ & $12.6 \%$ & $99.9 \%$ & $13.1 \%$ & $13.1 \%$ & $100.0 \%$ & $14.0 \%$ & $14.0 \%$ \\
\hline \multirow[t]{2}{*}{ alto-vizi } & 2765 & - & - & 15 & - & - & 4 & - & - \\
\hline & $97.4 \%$ & $12.6 \%$ & $12.6 \%$ & $99.9 \%$ & $12.9 \%$ & $12.9 \%$ & $100.0 \%$ & $13.6 \%$ & $13.6 \%$ \\
\hline \multirow[t]{2}{*}{ alto-mens } & 2814 & - & - & 10 & 一 & - & 2 & 一 & - \\
\hline & $97.2 \%$ & $12.6 \%$ & $12.6 \%$ & $99.6 \%$ & $12.9 \%$ & $12.9 \%$ & $100.0 \%$ & $13.5 \%$ & $13.5 \%$ \\
\hline \multirow[t]{2}{*}{ alto-reci } & 2944 & - & - & 3 & - & - & 1 & - & - \\
\hline & $97.4 \%$ & $12.6 \%$ & $12.6 \%$ & $99.6 \%$ & $12.9 \%$ & $12.9 \%$ & $100.0 \%$ & $13.5 \%$ & $13.5 \%$ \\
\hline \multirow[t]{2}{*}{ alto-aglo } & 2403 & 一 & 一 & 1 & 一 & 一 & 1 & 一 & 一 \\
\hline & $97.2 \%$ & $12.6 \%$ & $12.6 \%$ & $99.4 \%$ & $13.0 \%$ & $13.0 \%$ & $100.0 \%$ & $13.7 \%$ & $13.7 \%$ \\
\hline \multirow[t]{2}{*}{ anti-aglo } & 1767 & - & - & 1 & - & - & 1 & - & - \\
\hline & $97.2 \%$ & $12.6 \%$ & $12.6 \%$ & $99.9 \%$ & $13.2 \%$ & $13.2 \%$ & $100.0 \%$ & $14.1 \%$ & $14.1 \%$ \\
\hline \multirow[t]{2}{*}{ andarilho } & 2423 & - & - & 6 & - & - & 3 & - & - \\
\hline & $97.4 \%$ & $12.6 \%$ & $12.6 \%$ & $99.8 \%$ & $13.0 \%$ & $13.0 \%$ & $100.0 \%$ & $13.7 \%$ & $13.8 \%$ \\
\hline \multirow[t]{2}{*}{ anda-aglo } & 2575 & - & - & 7 & - & - & 3 & - & - \\
\hline & $97.5 \%$ & $12.6 \%$ & $12.6 \%$ & $99.9 \%$ & $13.0 \%$ & $13.0 \%$ & $100.0 \%$ & $13.7 \%$ & $13.7 \%$ \\
\hline
\end{tabular}




\section{Tabela B.30}

\begin{tabular}{|c|c|c|c|c|c|c|c|c|c|}
\hline \multicolumn{10}{|c|}{$\tau=-8 \mid T=4$} \\
\hline$p$ & \multicolumn{3}{|c|}{0.2} & \multicolumn{3}{|c|}{0.5} & \multicolumn{3}{|c|}{0.8} \\
\hline$r$ & 0.0 & 0.5 & 0.8 & 0.0 & 0.5 & 0.8 & 0.0 & 0.5 & 0.8 \\
\hline \multirow[t]{2}{*}{ aleatória } & - & - & - & - & - & - & - & - & - \\
\hline & $13.2 \%$ & $12.5 \%$ & $12.5 \%$ & $16.4 \%$ & $12.5 \%$ & $12.5 \%$ & $21.9 \%$ & $12.6 \%$ & $12.6 \%$ \\
\hline \multirow[t]{2}{*}{ alto-vizi } & - & - & - & - & - & - & - & - & - \\
\hline & $12.5 \%$ & $12.5 \%$ & $12.5 \%$ & $12.5 \%$ & $12.5 \%$ & $12.5 \%$ & $12.5 \%$ & $12.5 \%$ & $12.5 \%$ \\
\hline \multirow[t]{2}{*}{ alto-mens } & - & - & - & - & - & 一 & - & 一 & 一 \\
\hline & $12.5 \%$ & $12.5 \%$ & $12.5 \%$ & $12.5 \%$ & $12.5 \%$ & $12.5 \%$ & $12.5 \%$ & $12.5 \%$ & $12.5 \%$ \\
\hline \multirow[t]{2}{*}{ alto-reci } & - & - & 一 & - & 一 & - & 一 & 一 & - \\
\hline & $12.5 \%$ & $12.5 \%$ & $12.5 \%$ & $12.5 \%$ & $12.5 \%$ & $12.5 \%$ & $12.7 \%$ & $12.5 \%$ & $12.5 \%$ \\
\hline \multirow[t]{2}{*}{ alto-aglo } & - & - & - & - & - & - & - & - & - \\
\hline & $12.9 \%$ & $12.5 \%$ & $12.5 \%$ & $14.0 \%$ & $12.5 \%$ & $12.5 \%$ & $16.3 \%$ & $12.5 \%$ & $12.5 \%$ \\
\hline \multirow[t]{2}{*}{ anti-aglo } & - & - & - & - & - & - & - & 一 & - \\
\hline & $14.1 \%$ & $12.5 \%$ & $12.5 \%$ & $21.8 \%$ & $12.6 \%$ & $12.6 \%$ & $35.6 \%$ & $12.7 \%$ & $12.7 \%$ \\
\hline \multirow[t]{2}{*}{ andarilho } & - & - & - & - & - & - & - & - & - \\
\hline & $12.6 \%$ & $12.5 \%$ & $12.5 \%$ & $13.3 \%$ & $12.5 \%$ & $12.5 \%$ & $14.5 \%$ & $12.5 \%$ & $12.5 \%$ \\
\hline \multirow[t]{2}{*}{ anda-aglo } & - & - & - & - & - & - & - & - & - \\
\hline & $12.5 \%$ & $12.5 \%$ & $12.5 \%$ & $12.9 \%$ & $12.5 \%$ & $12.5 \%$ & $13.5 \%$ & $12.5 \%$ & $12.5 \%$ \\
\hline
\end{tabular}

\section{Tabela B.31}

\begin{tabular}{|c|c|c|c|c|c|c|c|c|c|}
\hline \multicolumn{10}{|c|}{$\tau=64 \mid T=$} \\
\hline$p$ & \multicolumn{3}{|c|}{0.2} & \multicolumn{3}{|c|}{0.5} & \multicolumn{3}{|c|}{0.8} \\
\hline$r$ & 0.0 & 0.5 & 0.8 & 0.0 & 0.5 & 0.8 & 0.0 & 0.5 & 0.8 \\
\hline \multirow[t]{2}{*}{ aleatória } & - & - & - & 615 & - & - & 61 & - & - \\
\hline & $33.8 \%$ & $12.5 \%$ & $12.5 \%$ & $99.9 \%$ & $12.6 \%$ & $12.6 \%$ & $100.0 \%$ & $12.9 \%$ & $12.9 \%$ \\
\hline \multirow[t]{2}{*}{ alto-vizi } & 2043 & - & - & 33 & - & - & 2 & - & - \\
\hline & $98.0 \%$ & $12.5 \%$ & $12.5 \%$ & $99.4 \%$ & $13.2 \%$ & $13.2 \%$ & $100.0 \%$ & $15.5 \%$ & $15.4 \%$ \\
\hline \multirow[t]{2}{*}{ alto-mens } & 2095 & - & - & 24 & - & - & 1 & - & - \\
\hline & $98.2 \%$ & $12.5 \%$ & $12.5 \%$ & $99.9 \%$ & $13.1 \%$ & $13.2 \%$ & $99.8 \%$ & $15.4 \%$ & $15.2 \%$ \\
\hline \multirow[t]{2}{*}{ alto-reci } & 3287 & - & 一 & 127 & - & - & 8 & - & - \\
\hline & $98.2 \%$ & $12.5 \%$ & $12.5 \%$ & $99.5 \%$ & $12.9 \%$ & $12.9 \%$ & $100.0 \%$ & $14.2 \%$ & $14.2 \%$ \\
\hline \multirow[t]{2}{*}{ alto-aglo } & - & 一 & - & 119 & - & 一 & 9 & 一 & - \\
\hline & $86.3 \%$ & $12.5 \%$ & $12.5 \%$ & $99.8 \%$ & $12.6 \%$ & $12.6 \%$ & $100.0 \%$ & $13.0 \%$ & $13.0 \%$ \\
\hline \multirow[t]{2}{*}{ anti-aglo } & - & - & - & 3850 & - & - & 447 & - & - \\
\hline & $13.8 \%$ & $12.5 \%$ & $12.5 \%$ & $99.6 \%$ & $12.5 \%$ & $12.5 \%$ & $99.8 \%$ & $12.5 \%$ & $12.5 \%$ \\
\hline \multirow[t]{2}{*}{ andarilho } & 4002 & - & - & 224 & - & - & 22 & - & - \\
\hline & $98.7 \%$ & $12.5 \%$ & $12.5 \%$ & $99.9 \%$ & $12.8 \%$ & $12.8 \%$ & $100.0 \%$ & $13.8 \%$ & $13.8 \%$ \\
\hline \multirow[t]{2}{*}{ anda-aglo } & 3965 & - & - & 192 & - & - & 17 & - & - \\
\hline & $98.1 \%$ & $12.5 \%$ & $12.5 \%$ & $99.8 \%$ & $12.8 \%$ & $12.8 \%$ & $100.0 \%$ & $13.6 \%$ & $13.6 \%$ \\
\hline
\end{tabular}




\section{Tabela B.32}

\begin{tabular}{|c|c|c|c|c|c|c|c|c|c|}
\hline \multicolumn{4}{|r|}{$\tau=$} & \multicolumn{6}{|c|}{$D^{*}=3$} \\
\hline$p$ & \multicolumn{3}{|c|}{0.2} & \multicolumn{3}{|c|}{0.5} & \multicolumn{3}{|c|}{0.8} \\
\hline$r$ & 0.0 & 0.5 & 0.8 & 0.0 & 0.5 & 0.8 & 0.0 & 0.5 & 0.8 \\
\hline \multirow[t]{2}{*}{ aleatória } & - & - & - & 643 & - & - & 65 & - & - \\
\hline & $33.8 \%$ & $12.5 \%$ & $12.5 \%$ & $99.9 \%$ & $12.6 \%$ & $12.6 \%$ & $99.9 \%$ & $12.9 \%$ & $12.9 \%$ \\
\hline \multirow[t]{2}{*}{ alto-vizi } & 2146 & - & - & 56 & - & - & 6 & - & - \\
\hline & $98.1 \%$ & $12.5 \%$ & $12.5 \%$ & $99.7 \%$ & $13.2 \%$ & $13.2 \%$ & $100.0 \%$ & $15.4 \%$ & $15.4 \%$ \\
\hline \multirow[t]{2}{*}{ alto-mens } & 2245 & - & - & 29 & - & - & 2 & - & - \\
\hline & $98.4 \%$ & $12.5 \%$ & $12.5 \%$ & $99.7 \%$ & $13.1 \%$ & $13.1 \%$ & $100.0 \%$ & $15.2 \%$ & $15.1 \%$ \\
\hline \multirow[t]{2}{*}{ alto-reci } & 3331 & - & - & 126 & - & - & 7 & - & - \\
\hline & $98.1 \%$ & $12.5 \%$ & $12.5 \%$ & $99.3 \%$ & $12.9 \%$ & $12.9 \%$ & $100.0 \%$ & $14.2 \%$ & $14.2 \%$ \\
\hline \multirow[t]{2}{*}{ alto-aglo } & - & - & - & 146 & - & - & 8 & - & - \\
\hline & $86.3 \%$ & $12.5 \%$ & $12.5 \%$ & $99.9 \%$ & $12.7 \%$ & $12.7 \%$ & $100.0 \%$ & $13.1 \%$ & $13.1 \%$ \\
\hline \multirow[t]{2}{*}{ anti-aglo } & - & - & - & 3877 & - & - & 436 & - & - \\
\hline & $13.9 \%$ & $12.5 \%$ & $12.5 \%$ & $99.8 \%$ & $12.5 \%$ & $12.5 \%$ & $99.9 \%$ & $12.5 \%$ & $12.5 \%$ \\
\hline \multirow[t]{2}{*}{ andarilho } & 3974 & - & - & 220 & - & - & 17 & - & - \\
\hline & $98.4 \%$ & $12.5 \%$ & $12.5 \%$ & $99.8 \%$ & $12.8 \%$ & $12.8 \%$ & $99.9 \%$ & $13.8 \%$ & $13.8 \%$ \\
\hline \multirow[t]{2}{*}{ anda-aglo } & 4000 & - & - & 200 & - & - & 18 & - & - \\
\hline & $98.3 \%$ & $12.5 \%$ & $12.5 \%$ & $99.9 \%$ & $12.8 \%$ & $12.8 \%$ & $100.0 \%$ & $13.6 \%$ & $13.6 \%$ \\
\hline
\end{tabular}

\section{Tabela B.33}

\begin{tabular}{|c|c|c|c|c|c|c|c|c|c|}
\hline \multicolumn{4}{|c|}{$\tau=2$} & \multicolumn{6}{|c|}{$D^{*}=3$} \\
\hline$p$ & \multicolumn{3}{|c|}{0.2} & \multicolumn{3}{|c|}{0.5} & \multicolumn{3}{|c|}{0.8} \\
\hline$r$ & 0.0 & 0.5 & 0.8 & 0.0 & 0.5 & 0.8 & 0.0 & 0.5 & 0.8 \\
\hline \multirow[t]{2}{*}{ aleatória } & - & - & - & 519 & - & - & 34 & - & - \\
\hline & $34.3 \%$ & $12.5 \%$ & $12.5 \%$ & $99.7 \%$ & $12.6 \%$ & $12.6 \%$ & $100.0 \%$ & $12.9 \%$ & $12.9 \%$ \\
\hline \multirow[t]{2}{*}{ alto-vizi } & 4247 & - & - & 295 & - & - & 32 & - & - \\
\hline & $98.0 \%$ & $12.5 \%$ & $12.5 \%$ & $99.8 \%$ & $12.8 \%$ & $12.7 \%$ & $100.0 \%$ & $13.6 \%$ & $13.6 \%$ \\
\hline \multirow[t]{2}{*}{ alto-mens } & 4391 & - & - & 164 & - & - & 13 & - & - \\
\hline & $98.3 \%$ & $12.5 \%$ & $12.5 \%$ & $99.7 \%$ & $12.7 \%$ & $12.7 \%$ & $99.8 \%$ & $13.5 \%$ & $13.5 \%$ \\
\hline \multirow[t]{2}{*}{ alto-reci } & - & - & - & 198 & - & - & 9 & - & - \\
\hline & $97.5 \%$ & $12.5 \%$ & $12.5 \%$ & $99.9 \%$ & $12.6 \%$ & $12.6 \%$ & $99.9 \%$ & $13.2 \%$ & $13.2 \%$ \\
\hline \multirow[t]{2}{*}{ alto-aglo } & - & - & - & 163 & - & - & 8 & - & - \\
\hline & $72.0 \%$ & $12.5 \%$ & $12.5 \%$ & $99.9 \%$ & $12.6 \%$ & $12.6 \%$ & $100.0 \%$ & $13.0 \%$ & $13.0 \%$ \\
\hline \multirow[t]{2}{*}{ anti-aglo } & - & - & - & 2198 & - & - & 72 & - & - \\
\hline & $15.3 \%$ & $12.5 \%$ & $12.5 \%$ & $99.8 \%$ & $12.5 \%$ & $12.5 \%$ & $99.9 \%$ & $12.6 \%$ & $12.6 \%$ \\
\hline \multirow[t]{2}{*}{ andarilho } & - & - & - & 314 & - & - & 17 & - & - \\
\hline & $94.6 \%$ & $12.5 \%$ & $12.5 \%$ & $99.9 \%$ & $12.7 \%$ & $12.7 \%$ & $100.0 \%$ & $13.2 \%$ & $13.2 \%$ \\
\hline \multirow[t]{2}{*}{ anda-aglo } & - & - & - & 240 & - & - & 16 & - & - \\
\hline & $96.4 \%$ & $12.5 \%$ & $12.5 \%$ & $99.9 \%$ & $12.7 \%$ & $12.7 \%$ & $99.9 \%$ & $13.2 \%$ & $13.2 \%$ \\
\hline
\end{tabular}




\section{Tabela B.34}

\begin{tabular}{l|ccc|c|cc|ccc}
\multicolumn{1}{c}{$\tau=1$} & $T=4$ & $D^{*}=3$ \\
\hline$p$ & & 0.2 & & \multicolumn{3}{c|}{0.5} & & \multicolumn{3}{c}{0.8} & \\
\hline$r$ & 0.0 & 0.5 & 0.8 & 0.0 & 0.5 & 0.8 & 0.0 & 0.5 & 0.8 \\
\hline aleatória & - & - & - & 344 & - & - & 4 & - & - \\
& $30.2 \%$ & $12.5 \%$ & $12.5 \%$ & $99.4 \%$ & $12.6 \%$ & $12.6 \%$ & $100.0 \%$ & $12.8 \%$ & $12.8 \%$ \\
alto-vizi & - & - & - & 723 & - & - & 27 & - & - \\
& $27.6 \%$ & $12.5 \%$ & $12.5 \%$ & $99.1 \%$ & $12.5 \%$ & $12.5 \%$ & $99.9 \%$ & $12.7 \%$ & $12.7 \%$ \\
alto-mens & - & - & - & 659 & - & - & 4 & - & - \\
& $25.4 \%$ & $12.5 \%$ & $12.5 \%$ & $99.5 \%$ & $12.5 \%$ & $12.5 \%$ & $99.9 \%$ & $12.7 \%$ & $12.7 \%$ \\
alto-reci & - & - & - & 480 & - & - & 6 & - & - \\
& $25.3 \%$ & $12.5 \%$ & $12.5 \%$ & $99.2 \%$ & $12.5 \%$ & $12.5 \%$ & $100.0 \%$ & $12.7 \%$ & $12.7 \%$ \\
alto-aglo & - & - & - & 379 & - & - & 5 & - & - \\
& $27.3 \%$ & $12.5 \%$ & $12.5 \%$ & $98.9 \%$ & $12.5 \%$ & $12.5 \%$ & $99.9 \%$ & $12.7 \%$ & $12.7 \%$ \\
anti-aglo & - & - & - & 273 & - & - & 2 & - & - \\
& $23.3 \%$ & $12.5 \%$ & $12.5 \%$ & $98.6 \%$ & $12.6 \%$ & $12.6 \%$ & $100.0 \%$ & $12.8 \%$ & $12.8 \%$ \\
andarilho & - & - & - & 444 & - & - & 8 & - & - \\
& $31.5 \%$ & $12.5 \%$ & $12.5 \%$ & $99.3 \%$ & $12.6 \%$ & $12.6 \%$ & $100.0 \%$ & $12.7 \%$ & $12.7 \%$ \\
anda-aglo & - & - & - & 475 & - & - & 7 & - & - \\
& $29.4 \%$ & $12.5 \%$ & $12.5 \%$ & $99.4 \%$ & $12.5 \%$ & $12.6 \%$ & $99.9 \%$ & $12.7 \%$ & $12.7 \%$
\end{tabular}

\section{Tabela B.35}

\begin{tabular}{|c|c|c|c|c|c|c|c|c|c|}
\hline \multicolumn{10}{|c|}{$\tau=-2 \mid T=4$} \\
\hline$p$ & \multicolumn{3}{|c|}{0.2} & \multicolumn{3}{|c|}{0.5} & \multicolumn{3}{|c|}{0.8} \\
\hline$r$ & 0.0 & 0.5 & 0.8 & 0.0 & 0.5 & 0.8 & 0.0 & 0.5 & 0.8 \\
\hline \multirow[t]{2}{*}{ aleatória } & - & - & - & - & - & - & - & - & - \\
\hline & $13.2 \%$ & $12.5 \%$ & $12.5 \%$ & $20.4 \%$ & $12.5 \%$ & $12.5 \%$ & $44.8 \%$ & $12.5 \%$ & $12.5 \%$ \\
\hline \multirow[t]{2}{*}{ alto-vizi } & - & - & - & - & - & - & - & - & - \\
\hline & $12.5 \%$ & $12.5 \%$ & $12.5 \%$ & $12.5 \%$ & $12.5 \%$ & $12.5 \%$ & $12.5 \%$ & $12.5 \%$ & $12.5 \%$ \\
\hline \multirow[t]{2}{*}{ alto-mens } & - & 一 & 一 & - & 一 & 一 & 一 & 一 & 一 \\
\hline & $12.5 \%$ & $12.5 \%$ & $12.5 \%$ & $12.5 \%$ & $12.5 \%$ & $12.5 \%$ & $12.5 \%$ & $12.5 \%$ & $12.5 \%$ \\
\hline \multirow[t]{2}{*}{ alto-reci } & - & - & - & - & - & - & - & - & - \\
\hline & $12.5 \%$ & $12.5 \%$ & $12.5 \%$ & $12.5 \%$ & $12.5 \%$ & $12.5 \%$ & $12.8 \%$ & $12.5 \%$ & $12.5 \%$ \\
\hline \multirow[t]{2}{*}{ alto-aglo } & - & 一 & 一 & - & 一 & 一 & - & - & - \\
\hline & $12.8 \%$ & $12.5 \%$ & $12.5 \%$ & $15.6 \%$ & $12.5 \%$ & $12.5 \%$ & $23.6 \%$ & $12.5 \%$ & $12.5 \%$ \\
\hline \multirow[t]{2}{*}{ anti-aglo } & - & - & - & - & - & - & - & - & - \\
\hline & $14.7 \%$ & $12.5 \%$ & $12.5 \%$ & $35.5 \%$ & $12.5 \%$ & $12.5 \%$ & $74.2 \%$ & $12.5 \%$ & $12.5 \%$ \\
\hline \multirow[t]{2}{*}{ andarilho } & - & - & - & - & - & - & - & - & - \\
\hline & $12.6 \%$ & $12.5 \%$ & $12.5 \%$ & $13.9 \%$ & $12.5 \%$ & $12.5 \%$ & $18.6 \%$ & $12.5 \%$ & $12.5 \%$ \\
\hline \multirow[t]{2}{*}{ anda-aglo } & - & - & - & - & - & - & - & - & - \\
\hline & $12.5 \%$ & $12.5 \%$ & $12.5 \%$ & $13.2 \%$ & $12.5 \%$ & $12.5 \%$ & $15.3 \%$ & $12.5 \%$ & $12.5 \%$ \\
\hline
\end{tabular}


Tabela B.36

\begin{tabular}{|c|c|c|c|c|c|c|c|c|c|}
\hline \multicolumn{10}{|c|}{$\tau=-8 \mid T=4$} \\
\hline$p$ & \multicolumn{3}{|c|}{0.2} & \multicolumn{3}{|c|}{0.5} & \multicolumn{3}{|c|}{0.8} \\
\hline$r$ & 0.0 & 0.5 & 0.8 & 0.0 & 0.5 & 0.8 & 0.0 & 0.5 & 0.8 \\
\hline \multirow[t]{2}{*}{ aleatória } & - & - & - & - & - & - & - & - & - \\
\hline & $12.5 \%$ & $12.5 \%$ & $12.5 \%$ & $12.5 \%$ & $12.5 \%$ & $12.5 \%$ & $12.5 \%$ & $12.5 \%$ & $12.5 \%$ \\
\hline \multirow[t]{2}{*}{ alto-vizi } & - & - & - & - & - & - & - & - & 一 \\
\hline & $12.5 \%$ & $12.5 \%$ & $12.5 \%$ & $12.5 \%$ & $12.5 \%$ & $12.5 \%$ & $12.5 \%$ & $12.5 \%$ & $12.5 \%$ \\
\hline \multirow[t]{2}{*}{ alto-mens } & - & - & - & - & - & - & - & 一 & - \\
\hline & $12.5 \%$ & $12.5 \%$ & $12.5 \%$ & $12.5 \%$ & $12.5 \%$ & $12.5 \%$ & $12.5 \%$ & $12.5 \%$ & $12.5 \%$ \\
\hline \multirow[t]{2}{*}{ alto-reci } & - & - & - & - & - & - & - & 一 & 一 \\
\hline & $12.5 \%$ & $12.5 \%$ & $12.5 \%$ & $12.5 \%$ & $12.5 \%$ & $12.5 \%$ & $12.5 \%$ & $12.5 \%$ & $12.5 \%$ \\
\hline \multirow[t]{2}{*}{ alto-aglo } & - & - & - & - & - & - & - & - & - \\
\hline & $12.5 \%$ & $12.5 \%$ & $12.5 \%$ & $12.5 \%$ & $12.5 \%$ & $12.5 \%$ & $12.5 \%$ & $12.5 \%$ & $12.5 \%$ \\
\hline \multirow[t]{2}{*}{ anti-aglo } & - & - & - & - & - & - & - & 一 & - \\
\hline & $12.5 \%$ & $12.5 \%$ & $12.5 \%$ & $12.5 \%$ & $12.5 \%$ & $12.5 \%$ & $12.5 \%$ & $12.5 \%$ & $12.5 \%$ \\
\hline \multirow[t]{2}{*}{ andarilho } & - & - & - & - & - & 一 & 一 & 一 & - \\
\hline & $12.5 \%$ & $12.5 \%$ & $12.5 \%$ & $12.5 \%$ & $12.5 \%$ & $12.5 \%$ & $12.5 \%$ & $12.5 \%$ & $12.5 \%$ \\
\hline \multirow[t]{2}{*}{ anda-aglo } & 一 & - & 一 & - & - & 一 & 一 & - & 一 \\
\hline & $12.5 \%$ & $12.5 \%$ & $12.5 \%$ & $12.5 \%$ & $12.5 \%$ & $12.5 \%$ & $12.5 \%$ & $12.5 \%$ & $12.5 \%$ \\
\hline
\end{tabular}




\section{Apêndice C}

\section{Atividades de extensão universitária}

Abrindo mão da terceira pessoa, acrescento este apêndice de memórias por considerar frutífero mencionar as atividades de extensão que iniciei e realizei durante o curso da minha pós-graduação.

Meus estudos iniciaram-se por necessidade do trabalho de extensão na Cidade do Conhecimento da USP com o professor Gilson Schwartz, realizando projetos de comunicação com monitores de telecentros, professores de ensino médio e comunidades empobrecidas, onde lidávamos com o problema da difusão de informações em redes que me motivou a procurar uma pós-graduação na área.

Depois, durante os estudos, com o colega Leonardo Trabuco construí e editei diversos números da Revista Ciências Moleculares, com artigos de conscientização científica de autoria dos alunos do curso homônimo da USP.

Iniciei no Instituto de Física, com o colega Everton Alvarenga, um grupo de estudos interdepartamental de pós-graduandos que, apesar de durar apenas um semestre, contou com a participação e apresentações de alunos do DFGE, DFMA e FAP — uma ocorrência um tanto incomum. Aproveito para felicitar o colega Masayuki que vem organizando os seminários de alunos do DFGE com sucesso mais longevo do que consegui com aquele grupo.

Como monitor da disciplina Informação e Comunicação na Sociedade do Conhecimento, do IME USP, pude conhecer melhor o professor Imre Simon, cuja influência tornou-se indissociável das minhas recentes escolhas acadêmicas e profissionais, além de dar aulas para um grupo muito bacana de computeiros, advogados, jornalistas e músicos sobre as novas formas de produção social na sociedade interconectada.

Mais recentemente, venho amparando um movimento político baseado no voluntariado apartidário, o Movimento Nossa São Paulo, em questões de organização e difusão de informações, assim como participado como voluntário da Wikimedia Brasil, o capítulo brasileiro da fundação que mantém a Wikipédia - o maior projeto de compartilhamento de conhecimento da história da humanidade. 


\section{Referências Bibliográficas}

[Asch, 1956] Asch, S. E. (1956). Studies of independence and conformity: a minority of one against a unanimous majority. Psychological Monographs, 70(416).

[Bailey, 1975] Bailey, N. T. J. (1975). The Mathematical Theory of Infectious Diseases and Its Applications. Hafner Press, New York.

[Batada et al., 2007] Batada, N. N., Hurst, L. D., and Tyers, M. (2007). Still stratus not altocumulus: Further evidence against the date/party hub distinction. PLoS Biology, 5:1202.

[Bertin et al., 2007] Bertin, N., Roth, F. P., and Vidal, M. (2007). Confirmation of organized modularity in the yeast interactome. PLoS Biology, 5:1202.

[Bianconi and Capocci, 2003] Bianconi, G. and Capocci, A. (2003). Number of loops of size $\mathrm{h}$ in growing scale-free networks. Physical Review Letters, 90:078701, arXiv:cond-mat/0212028v2.

[Bianconi and Marsili, 2005] Bianconi, G. and Marsili, M. (2005). Loops of any size and hamilton cycles in random scale-free networks. Journal of Statistical Mechanics: Theory and Experiment, 2005(06):P06005, arXiv:cond-mat/0502552v2.

[Boccaletti et al., 2006] Boccaletti, S., Latora, V., Moreno, Y., Chavez, M., and Hwanga, D.-U. (2006). Complex networks: Structure and dynamics. Physics Reports, 424:175-308. Disponível em http: //complex.unizar.es/papers/phys_rep_ 2006.pdf.

[Borgatti, 2005] Borgatti, S. P. (2005). Centrality and network flow. Social Networks, 27:55-71.

[Caldarelli et al., 2004] Caldarelli, G., Pastor-Satorras, R., and Vespignani, A. (2004). Structure of cycles and local ordering in complex networks. European Physical Journal B, 38:183-186, arXiv:cond-mat/0212026v2.

[Costa and da Rocha, 2006] Costa, L. d. F. and da Rocha, L. E. C. (2006). A generalized approach to complex networks. European Physical Journal B, 50:237-242, arXiv:cond-mat/0408076v2.

[Costa and Silva, 2006] Costa, L. d. F. and Silva, F. N. (2006). Hierarchical characterization of complex networks. Journal of Statistical Physics, 125:845-876, arXiv:condmat/0412761v4. 
[Deane et al., 2002] Deane, C. M., Xenarios, I., and Eisenberg, D. (2002). Protein interactions: two methods for assessment of the reliability of high throughput observations. Mol Cell Proteomics, 1:349-356.

[Diestel, 1997] Diestel, R. (2005 (2000,1997)). Graph Theory. Springer-Verlag, Heidelberg, New York. Também disponível em http://www.math.uni-hamburg.de/ home/diestel/books/graph. theory/.

[Dodds et al., 2003] Dodds, P. S., Muhamad, R., and Watts, D. J. (2003). An experimental study of search in global social networks. Science, 301:827 - 829.

[Dodds and Watts, 2004] Dodds, P. S. and Watts, D. J. (2004). Universal behavior in a generalized model of contagion. Physical Review Letters, 92:218701.

[Dodds and Watts, 2005] Dodds, P. S. and Watts, D. J. (2005). A generalized model of social and biological contagion. Journal of Theoretical Biology, 232:587-604.

[Durkheim, 1895] Durkheim, E. (1895). Les Règles de la méthode sociologique. As Regras do método sociológico.

[Feofiloff et al., 2004] Feofiloff, P., Kohayakawa, Y., and Wakabayashi, Y. (2009 (2004)). Uma Introdução Sucinta à Teoria dos Grafos. Disponível em http://www. ime.usp.br/ pf/teoriadosgrafos/.

[Fronczak et al., 2002] Fronczak, A., Holyst, J. A., Jedynak, M., and Sienkiewicz, J. (2002). Higher order clustering coefficients in barabási-albert networks. Physica A, 316:688.

[Gibson, 2005] Gibson, D. R. (2005). Concurrency and commitment: Network scheduling and its consequences for diffusion. Journal of Mathematical Sociology, 29:295.

[Golder et al., 2006] Golder, S. A., Wilkinson, D., and Huberman., B. A. (2007 (2006)). Rhythms of social interaction: Messaging within a massive online network. 3rd International Conference on Communities and Technologies (CT2007), arXiv:cs/0611137v1. http://www.hpl .hp.com/research/idl/papers/facebook/.

[Granovetter, 1973] Granovetter, M. (1973). The strength of weak ties. American Journal of Sociology, 78(6):1360-1380.

[Granovetter, 1978] Granovetter, M. (1978). Threshold models of collective behavior. American Journal of Sociology, 83(6):1420-1443.

[Granovetter and Soong, 1988] Granovetter, M. and Soong, R. (1988). Threshold models of diversity: Chinese restaurants, residential segregation, and the spiral of silence. Sociological Methodology, 18:69-104.

[Jin et al., 2001] Jin, E. M., Girvan, M., and Newman, M. E. J. (2001). Structure of growing social networks. Physical Review E, 64:046132.

[Katz and Lazarsfeld, 1955] Katz, E. and Lazarsfeld, P. F. (1955). Personal Influence. 
[Kempe et al., 2003] Kempe, D., Kleinberg, J., and Tardos, E. (2003). Maximizing the spread of influence through a social network. Proceedings of the 9th ACM SIGKDD International Conference on Knowledge Discovery and Data Mining, pages 137-146.

[Kempe et al., 2005] Kempe, D., Kleinberg, J., and Tardos, E. (2005). Influential nodes in a diffusion model for social networks. Proceedings of the 32nd International Colloquium on Automata, Languages and Programming (ICALP), pages 1127-1138.

[Lazarsfeld et al., 1944] Lazarsfeld, P. F., Berelson, B., and Gaudet, H. (1944). The People's Choice.

[Lind et al., 2005] Lind, P. G., González, M. C., and Herrmann, H. J. (2005). Cycles and clustering in bipartite networks. Physical Review E, 72:056127.

[Malekinejad et al., 2008] Malekinejad, M., Johnston, L. G., Kendall, C., Kerr, L. R. F. S., Rifkin, M. R., and Rutherford, G. W. (2008). Using respondent-driven sampling methodology for hiv biological and behavioral surveillance in international settings: A systematic review. AIDS and Behavior, 12:105-130.

[Milo et al., 2002] Milo, R., Shen-Orr, S., Itzkovitz, S., Kashtan, N., Chklovskii, D., and Alon, U. (2002). Network motifs: Simple building blocks of complex networks. Science, 298:824.

[Newman, 2002] Newman, M. E. J. (2002). Assortative mixing in networks. Physical Review Letters, 89:208701.

[Newman, 2003a] Newman, M. E. J. (2003a). Mixing patterns in networks. Physical Review E, 67:026126.

[Newman, 2003b] Newman, M. E. J. (2003b). The structure and function of complex networks. SIAM Review, 45:167, arXiv:cond-mat/0303516v1.

[Newman and Park, 2003] Newman, M. E. J. and Park, J. (2003). Why social networks are different from other types of networks. Physical Review E, 68:036122.

[Newman et al., 2001] Newman, M. E. J., Strogatz, S. H., and Watts, D. J. (2001). Random graphs with arbitrary degree distributions and their applications. Physical Review E, 64:026118.

[Noh and Rieger, 2004] Noh, J. D. and Rieger, H. (2004). Random walks on complex networks. Physical Review Letters, 92:118701.

[Page et al., 1999] Page, L., Brin, S., Motwani, R., and Winograd, T. (1999). The pagerank citation ranking: Bringing order to the web. Technical Report 1999-66, Stanford InfoLab. Previous number = SIDL-WP-1999-0120.

[Peixoto, 2006] Peixoto, T. P. (2009 (2006)). graph-tool - a general graph manipulation python module. http://projects.forked.de/graph-tool/.

[Peixoto and Drossel, 2009] Peixoto, T. P. and Drossel, B. (2009). Boolean networks with reliable dynamics. arXiv:0905.0925v1. 
[Ravasz and Barabási, 2003] Ravasz, E. and Barabási, A.-L. (2003). Hierarchical organization in complex networks. Physical Review E, 67:026112.

[Ravasz et al., 2002] Ravasz, E., Somera, A. L., Mongru, D. A., Oltvai, Z. N., and Barabási, A.-L. (2002). Hierarchical organization of modularity in metabolic networks. Science, 297:1551.

[Rogers, 1962] Rogers, E. M. (1962). Diffusion of Innovations.

[Ryan and Gross, 1943] Ryan, R. and Gross, N. (1943). The diffusion of hybrid seed corn in two iowa communities. Rural Sociology, 8(1):15-24.

[Salwinski et al., 2004] Salwinski, L., Miller, C. S., Smith, A. J., Pettit, F. K., Bowie, J. U., and Eisenberg, D. (2004). The database of interacting proteins: 2004 update. Nucleic Acids Research, 32, Database issue:D449-D451.

[Serrano and Boguñá, 2006a] Serrano, M. Á. and Boguñá, M. (2006a). Clustering in complex networks. i. general formalism. Physical Review E, 74(5):056114, arXiv:cond-mat/0608336v1.

[Serrano and Boguñá, 2006b] Serrano, M. Á. and Boguñá, M. (2006b). Clustering in complex networks. ii. percolation properties. Physical Review E, 74(5):056115, arXiv:cond-mat/0608337v2.

[Soffer and Vázquez, 2005] Soffer, S. N. and Vázquez, A. (2005). Network clustering coefficient without degree-correlation biases. Physical Review E, 71:057101.

[Travers and Milgram., 1969] Travers, J. and Milgram., S. (1969). An experimental study of the small world problem. Sociometry, 32(4):425-443.

[Valente, 2005] Valente, T. W. (2005). Network models and methods for studying the diffusion of innovations. In Carrington, P. J., Scott, J., and Wasserman, S., editors, Models and Methods in Social Network Analysis. Cambridge University Press, New York.

[Vázquez et al., 2003] Vázquez, A., Maritan, A., and Vespignani, A. (2003). Modeling of protein interaction networks. ComPlexUs, 1:38.

[Watts and Dodds, 2007] Watts, D. J. and Dodds, P. S. (2007). Influentials, networks, and public opinion formation. Journal of Consumer Research, 34:441-458.

[Watts and Strogatz, 1998] Watts, D. J. and Strogatz, S. H. (1998). Collective dynamics of small-world networks. Nature, 393:440. 